Determination of the Water Content of Snow by Dielectric Measurements

Paul R. Camp and David R. LaBrecque July 1992

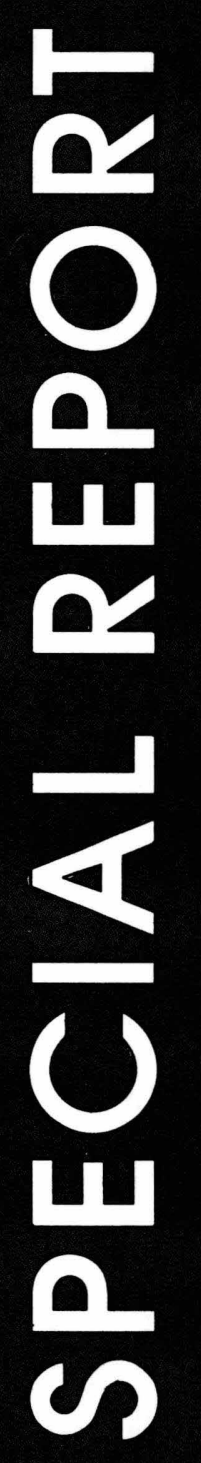




\begin{abstract}
The dielectric properties of wet and dry natural snow were studied in the frequency range of $50 \mathrm{~Hz}$ to $100 \mathrm{kHz}$ to determine whether measurements made in this frequency range might prove useful in evaluating the water content of snow. Dielectric heating at $20 \mathrm{kHz}$ proved a very useful means of modifying the water content from 0 to $30 \%$ by weight. Six different natural snows were used in these experiments. Meltwater was analyzed for conductivity, $\mathrm{pH}$, and impurity content. In addition to developing information on the dielectric properties of wet and dry snow, we measured the changes produced in dry snow by altering its density over the range of 0.11 to $0.66 \mathrm{~g} / \mathrm{cm}^{3}$. Details of the experimental technique and the data obtained are fully reported. Our results do not lead to optimism about the usefulness of measurements in this frequency range alone for the determination of water content.
\end{abstract}

For conversion of $\mathrm{SI}$ metric units to U.S./British customary units of measurement consult ASTM Standard E380, Metric Practice Guide, published by the American Society for Testing and Materials, 1916 Race St., Philadelphia, Pa. 19103.

This report is printed on paper that contains a minimum of $50 \%$ recycled material. 


\section{Special Report 92-18}

U.S. Army Corps of Engineers

Cold Regions Research \&

Engineering Laboratory

\section{Determination of the Water Content of Snow by Dielectric Measurements}

Paul R. Camp and David R. LaBrecque

July 1992 


\section{PREFACE}

This report was prepared by Paul R. Camp, Professor, of the Department of Physics, University of Maine at Orono, and David R. LaBrecque of Micro Physics, Old Town, Maine. Funding for this project was provided by DA Project 4A762784AT42, Design, Construction and Operations Technology for Cold Regions, Task FS, Work Unit 032, Mesoscale Prediction in Denied Areas.

The authors thank Kurt Knuth and Gary Koh of CRREL for technically reviewing the manuscript of this report. They also express their appreciation to Ronald Atkins of CRREL for many hours of technical discussion during the progress of this work as well as for review of the manuscript.

The contents of this report are not to be used for advertising or promotional purposes. Citation of brand names does not constitute an official endorsement or approval of the use of such commercial products. 


\section{CONTENTS}

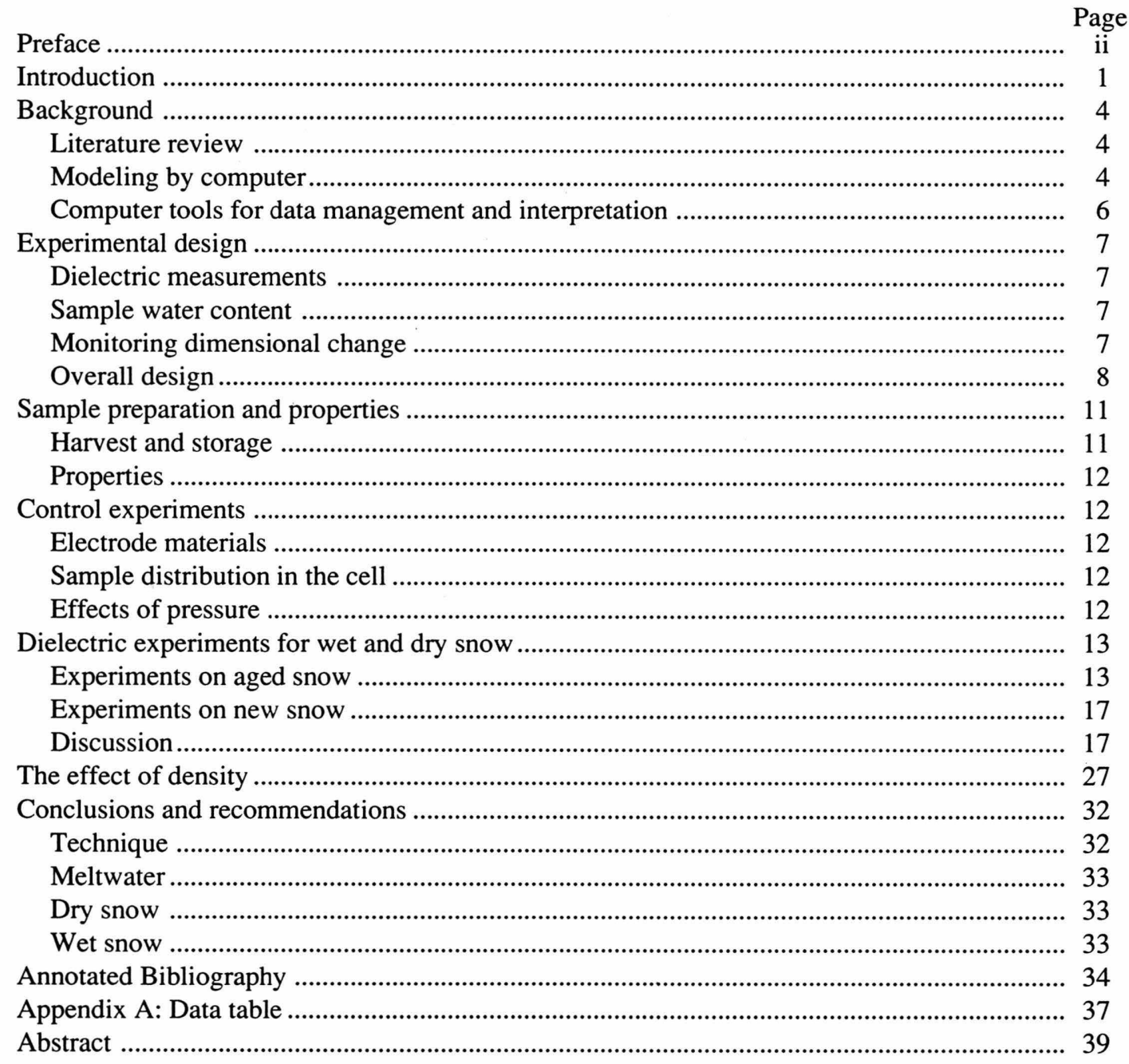

\section{ILLUSTRATIONS}

Figure

1. Approximate dielectric constants of ice and water as a function of frequency at $0^{\circ} \mathrm{C} \ldots \ldots . \quad 2$

2. Approximate electrical conductivities of ice and water as a function of frequency ........... 2

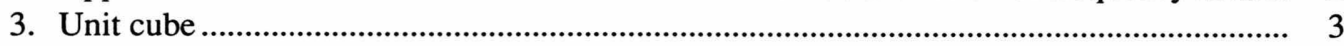

4. Example of matching a model to experimental results using data available from dielectric spectrum of portland cement paste cured for one day ............................................. 4

5. Example of matching a model to experimental results using data available from dielectric spectrum of portland cement paste cured for 35 days ............................................... 5

6. Equivalent parallel capacitance and conductance as functions of frequency for the net-

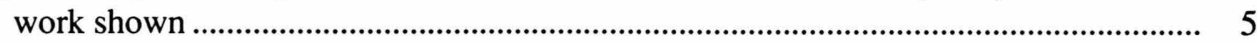

7. Properties of the network shown ................................................................................... 6

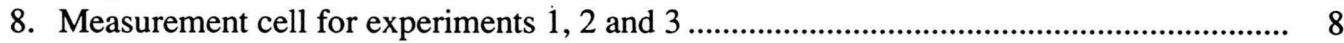


Figure

9. Measurement cell for experiments $10-16$

10. Circuit arrangement for measuring dielectric properties of wet snow .............................. 10

11. Photomicrographs of snow samples I through V ............................................................ 11

12. Temperature, power level, and sample thickness as a function of time during a typical experiment

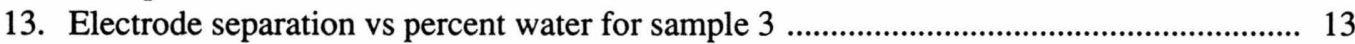

14. Dielectric spectra for sample 1 for indicated water contents ............................................... 14

15. Dielectric spectra for sample 2 for indicated water contents ............................................ 15

16. Dielectric spectra for sample 3 for indicated water contents ................................................. 16

17. Dielectric spectra for sample 13 for indicated water contents .............................................. 18

18. Dielectric spectra for sample 16 for indicated water contents .............................................. 19

19. Dielectric spectra for sample 10 for indicated water contents .............................................. 20

20. Dielectric spectra for sample 16 for indicated water contents ........................................... 21

21. Dielectric spectra for sample 12 for indicated water contents .......................................... 22

22. Dielectric spectra for sample 14 for indicated water contents ........................................... 23

23. Dielectric spectra for sample 15 for indicated water contents ........................................... 24

24. $\log _{10}$ low-frequency conductivity and $\log _{10}$ low-frequency dielectric constant for various snows vs $\mathrm{pH}$ of the melt water...

25. Concentrations of sodium and chloride ions vs conductivity of the meltwater for various snows

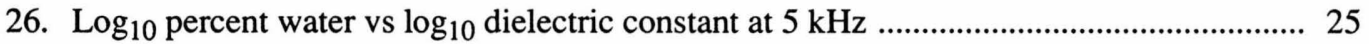

27. Micrometer cell used for variable density experiments ..................................................... 28

28. Conductivity and dielectric constant as functions of frequency for sample 5 ..................... 29

29. Conductivity and dielectric constant as functions of frequency for sample 6 .................... 29

30. Conductivity, and dielectric constant, as functions of frequency for sample 7 .................. 29

31. Conductivity, and dielectric constant as functions of frequency for sample $8 \ldots \ldots \ldots \ldots \ldots \ldots . . . . . .30$

32. Conductivity and dielectric constant as functions of frequency for sample 9 ................... 30

33. Conductivity and dielectric constant at $50 \mathrm{~Hz}$ vs density for the samples indicated

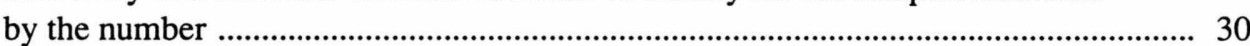

34. Conductivity, $\sigma$, and dielectric constant, $K$, at $500 \mathrm{~Hz}$ vs density for the samples indicated

35. Conductivity, $\sigma$, and dielectric constant, $K$, at $5 \mathrm{~Hz}$ vs density for the samples indicated by the number

36. Conductivity, $\sigma$, and dielectric constant, $K$, at $50 \mathrm{kHz}$ vs density for the samples indicated by the number

37. Conductivity, $\sigma$, at $50 \mathrm{kHz}$ minus that at $50 \mathrm{~Hz}$ vs density for dry snow

38. Dielectric constant at $50 \mathrm{kHz}$ minus that at $50 \mathrm{~Hz}$ vs density for dry snow ..................... 32

39. $\log _{10} K$ vs $\log _{10}$ density for dry snow samples .......................................................... 32

40. $\log _{10} K$ vs $\log _{10}$ density for samples $10-16$ having water contents between 1 and $3 \% \ldots . .32$

\section{TABLES}

Table

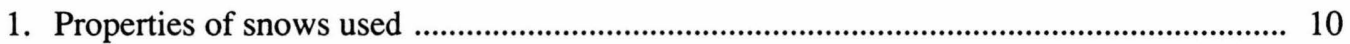

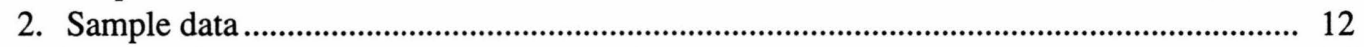

3. Polynomial fit to data for samples 10-16 ......................................................................... 26

4. Cole plot parameters for the various samples ………………………………................... 27

5. Cole plot parameters for the various samples ……...................................................... 28 


\title{
Determination of the Water Content of Snow by Dielectric Measurements
}

\author{
PAUL R. CAMP AND DAVID R. LABRECQUE
}

\section{INTRODUCTION}

Knowledge of the free water content of snowfields is important in snow mechanics, hydrology, avalanche control and in satellite imagery interpretation. Various techniques for determining the water content of snow have been employed, but these measurements must be made by teams in the field. Direct methods reviewed by Boyne and Fisk (1990) include melting and freezing calorimetry, alcohol calorimetry and ionic dilution. Electrical methods have focused on measurements of the dielectric properties at frequencies at which the dielectric constant of water is high and that of ice is low, generally above $1 \mathrm{MHz}$. These methods, reviewed by Denoth et al. (1984), also involve field studies because they require an independent measurement of density. Clearly, it would be highly desirable to be able to make free water determinations by remote sensing or by automatic instruments that can be interrogated remotely without the need for field measurements.

A wide spectrum of frequencies has been explored for electrical methods of determining the free water content of snow, the most popular being the UHF or microwave ranges. It is here that water has a high dielectric constant (about 88 at $0^{\circ} \mathrm{C}$ ) and ice a low dielectric constant (about 4), thus providing good contrast to reveal the presence of water. Typically these measurements focus on the behavior at one frequency only. In this study, we have chosen to see what might be learned from measuring the dielectric response over the lowfrequency range in which ice has a Debye dispersion. Our thought was that by knowing the dispersion properties of ice, measurements at several frequencies over the dispersion region might provide simultaneous equations the solution of which would yield the water content without an independent measurement of density. The argument is given in more detail below.
Figure 1 shows the approximate dielectric constant for ice at $0^{\circ} \mathrm{C}$ as a function of frequency (solid line). The dielectric constant of water is also shown (dashed line). It would appear that one might easily determine the water content of the snow by combining a very low frequency measurement of effective dielectric constant (in which the contributions of the water and the ice are nearly equal) and a high-frequency measurement in which they are very different. However, a variety of things distort the low-frequency end of the ice spectrum, as is shown by the dotted line. These include impurities and electrode polarization effects. As frequency increases, the importance of these anomalies decreases but we get into the dispersion part of the curve where the calculations become more difficult.

Figure 2 shows the approximate dispersion with frequency of the conductivity of pure ice (solid line) and of pure water calculated from the relaxation (dashed line). Again one might hope to be able to infer the relative amounts of water and ice in a sample by measurements at two frequencies, one well below the ice dispersion and one above. However, as is shown in Figure 2, the low-frequency end of the dispersion flattens out due to the DC conductivity of ice and to the presence of other low-frequency dispersions. Moreover, both the DC conductivity of ice and the strength of the dispersion are sensitive to impurities in the ice. More important still, the DC conductivity of water is dominated by ions. The thermal dissociation of water alone gives pure water a resistivity at room temperature of $5 \times 10^{5} \mathrm{ohm}-\mathrm{m}$. Dissolved $\mathrm{CO}_{2}$ from the atmosphere can decrease this to $2 \times 10^{4} \mathrm{ohm}-\mathrm{m}$. The respective conductivities are also shown in Figure 2 as dashed lines. Since additional impurity will raise the conductivity even further, this baseline is very strongly dependent on impurities. We conclude that the measurement of dielectric constant is more promising than that of dielectric loss. 


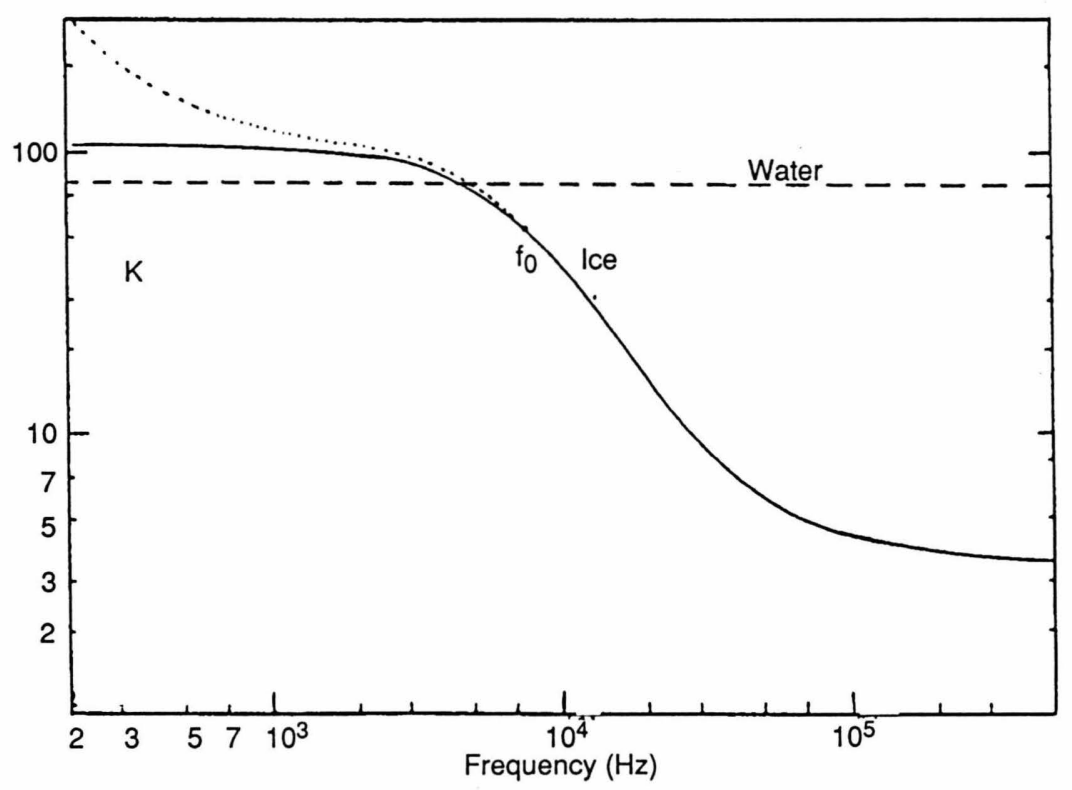

Figure 1. Approximate dielectric constants of ice and water as a function of frequency at $0^{\circ} \mathrm{C}$ (extrapolated from Camp et al. 1967).

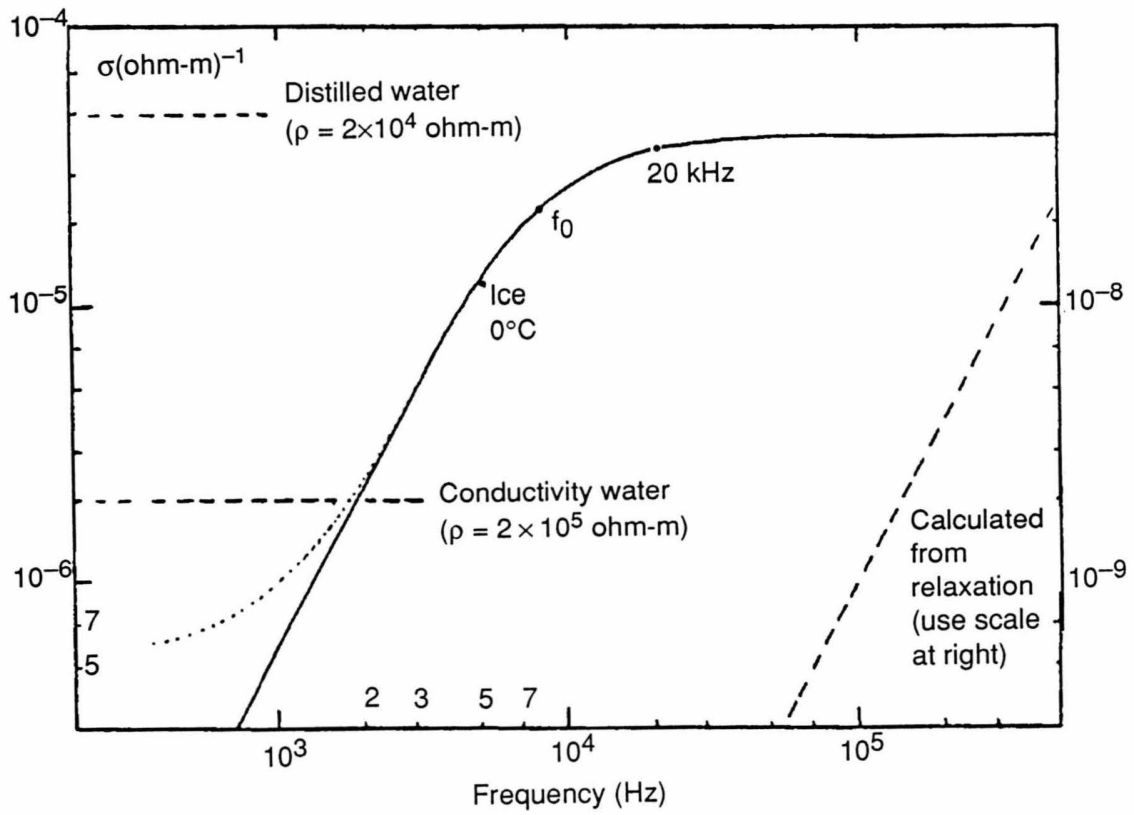

Figure 2. Approximate electrical conductivities of ice and water as a function of frequency. Dashed line to the right shows the conductivity of pure water calculated from its relaxation spectrum (use scale at the right for these values) (data from Camp et al. 1967). 


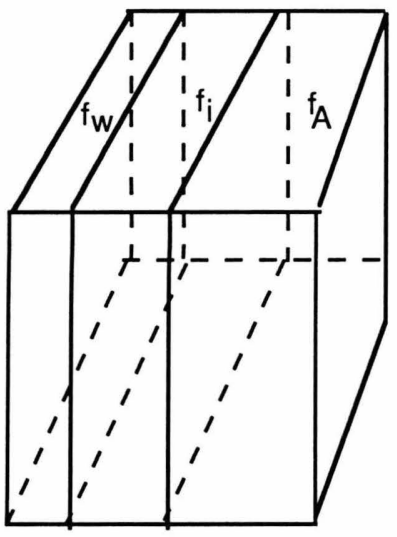

Figure 3. Unit cube.
Although the low-frequency measurements may be distorted by electrode and other phenomena as mentioned, it now appears possible to use measurements in the dispersion region in a fairly simple way. The advent of inexpensive, handheld, programmable computers makes possible the rapid interpretation of this more complicated data. It can be automated in the

field, almost in real time.

As shown in Figures 1 and 2, the dielectric properties of ice change rapidly in the dispersion range, while those of water are essentially constant. Thus we should be able to separate the effects of water and ice by measurements at different frequencies. We pick an overly simplified case for illustration.

Let us suppose that the various components of a sample, ice, water and air, could be modeled as acting in parallel as shown in Figure 3, a unit cube. If electrodes are applied at the top and the bottom, the contributions to the measured capacitance of each material would be in parallel. Let $f_{\mathrm{A}}, f_{\mathrm{w}}$, and $f_{\mathrm{i}}$, be the volume fractions of each material and $C_{\mathrm{A}}, C_{\mathrm{w}}$ and $C_{\mathrm{i}}$ the partial capacitances due to air, water and ice. respectively. Using $\varepsilon_{0}$ as the permittivity of free space (air) and $k_{\mathrm{w}}$ and $k_{\mathrm{i}}$ as the dielectric constants of water and ice, we have $C$ measured $\left(C_{\mathrm{m}}\right)$ given by

$$
C_{\mathrm{m}}=C_{\mathrm{A}}+C_{\mathrm{w}}+C_{\mathrm{i}}=\varepsilon_{0}\left(f_{\mathrm{A}}+k_{\mathrm{w}} f_{\mathrm{w}}+k_{\mathrm{j}} f_{\mathrm{i}}\right) .
$$

Also

$$
f_{\mathrm{A}+} f_{\mathrm{W}}+f_{\mathrm{A}}=1 \text { (unit cube). }
$$

Since $k_{\mathrm{i}}$ (high frequency) is very different from $k_{\mathrm{i}}$ (low frequency), if we measure $C$ at both high and low frequencies, we have three different independent equations and three unknowns. Therefore, we should be able to solve for $f_{\mathrm{A}}, f_{\mathrm{w}}$ and $f_{\mathrm{i}}$, without an independent measurement of density. Unfortunately the situation is more complicated for two basic reasons. The first is electrical and has already been touched on. The second is geometrical.

The electrical problem with capacitance measurement is that the low frequency capacitance is complicated by electrode and impurity effects and the possibility of very low-frequency dispersions for ice, which have been reported in the literature (Camp et al. 1967, Von
Hippel 1972). Perhaps this can be overcome by making measurements at several different frequencies throughout the Debye dispersion range and using these to effectively project the true low-frequency value.

To illustrate the geometrical problems, we refer again to Figure 3. If instead of placing electrodes on the top and bottom of the cube, we place them on the lefthand and right-hand sides, we have an entirely different geometry. The air, water and ice are now in series instead of in parallel. Our measurements would give entirely different values, as

$$
C_{\text {meas }}=\frac{1}{1 / C_{\mathrm{A}}+1 / C_{\mathrm{w}}+1 / C_{\mathrm{i}}}
$$

instead of $C_{\mathrm{A}}+C_{\mathrm{w}}+C_{\mathrm{i}}$ in the parallel case.

As a specific illustration, let us suppose $f_{\mathrm{A}}=0.8, f_{\mathrm{i}}=$ 0.15 and $f_{\mathrm{W}}=0.05$. For the parallel case (eq 1$)$, using $k_{\mathrm{i}}$ $($ low $)=100, k_{\mathrm{w}}=88$, and $k_{\mathrm{i}}($ high $)=3.5$,

$$
\begin{aligned}
& C_{\text {meas }}(\text { low freq })=20.2 \varepsilon_{0} \\
& C_{\text {meas }}(\text { high freq })=5.73 \varepsilon_{0} .
\end{aligned}
$$

In the series case, we would have,

$$
\begin{aligned}
& C_{\text {meas }}(\text { series })=\varepsilon_{0} \frac{1}{f_{\mathrm{A}}+f_{\mathrm{i}} / k_{\mathrm{i}}+f_{\mathrm{w}} / k_{\mathrm{w}}} \\
& C_{\text {meas }}(\text { low freq })=1.247 \varepsilon_{0} \\
& C_{\text {meas }}(\text { high freq })=1.186 \varepsilon_{0} .
\end{aligned}
$$

These approximate the two extreme cases for the possible grain structure of snow, parallel columns and series plates. Thus, from the measurements themselves, one might be able to infer something about the grain structure. However, the situation is even more complicated than this. Temperate snow is a complex structure of grains of ice of various shapes in series and parallel combinations with water that has electrical conductivity as well as dielectric constant. (This is also a problem with microwave measurements.) Thus in the end, the measurements must be calibrated against samples having known properties. But these complicating factors have their positive side as well. If we measure at a number of points over the range of the Debye dispersion, we might be able to develop a set of profiles each of which is uniquely characteristic of a specific water content, density and snow structure. The studies reported here were undertaken to explore this possibility.

In this specific effort, we have been so far unsuccessful. However, in the process, we have developed what we believe is a significant tool for studies of wet snow, 
some useful insights into the process involved, and a body of specific information concerning the dielectric properties of snow, both wet and dry, in this frequency region. In order to make this information generally available and useful we give in this report a rather detailed account of our experiments and their results. We have found no such extensive information in the literature and hope that this work will provide a useful basis for theoretical or further experimental studies.

\section{BACKGROUND}

\section{Literature review}

A computer search was conducted covering the following databases and years: "Information Service for Physics and Engineering (INSPEC)," 1969-1989; and "Engineering Index," 1970-1989. This was supplemented by a manual search of the CRREL abstracts for the years available to us, 1961-75. We are indebted to Ronald Atkins who has provided us with further titles from the CRREL abstracts. All references that we have found useful to this line of study are included in the Annotated Bibliography.

\section{Modeling by computer}

Because any electrical analog we might make involves the series-parallel interconnection of resistors and capacitors, an interactive computer program has been developed (using Microsoft Quick-Basic, version 4) that allows us to model resistance to capacitance circuits of almost any complexity. If we have a model in mind, we can try it out and plot its capacitance and conductance spectrum. We can also go to the other extreme and find out how tinkering with a circuit will change its characteristics. Figures 4 and 5 are examples of the first process. We happened to have available dielectric spectra for portland cement samples and a model that had been proposed to describe two different states of curing. By adjusting parameters, we were able to fit the data for cement cured only one day (Fig. 4) and cement cured 35 days (Fig. 5). Figures 6 and 7a are examples of the second process. We asked whether it was possible to create from resistors and capacitors alone a network that would have a dispersion curve in which the capacitance would drop (and the conductance would rise) over a wide frequency range, not as frequency squared, but as frequency to a lower power (as happens in snow). These figures show that it can be done. Figure 6 shows that by

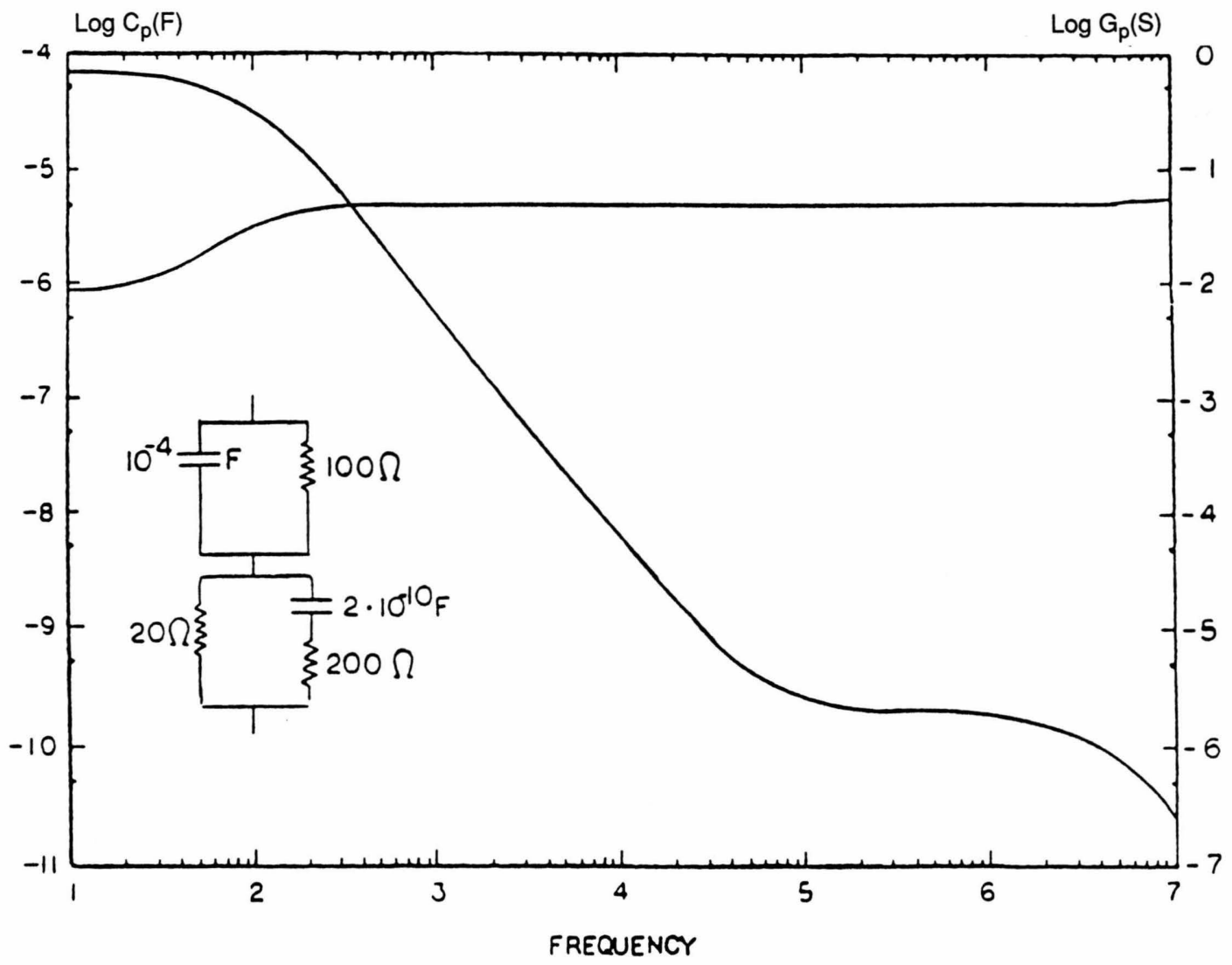

Figure 4. Example of matching a model to experimental results using data available from dielectric spectra of portland cement paste cured for one day. 


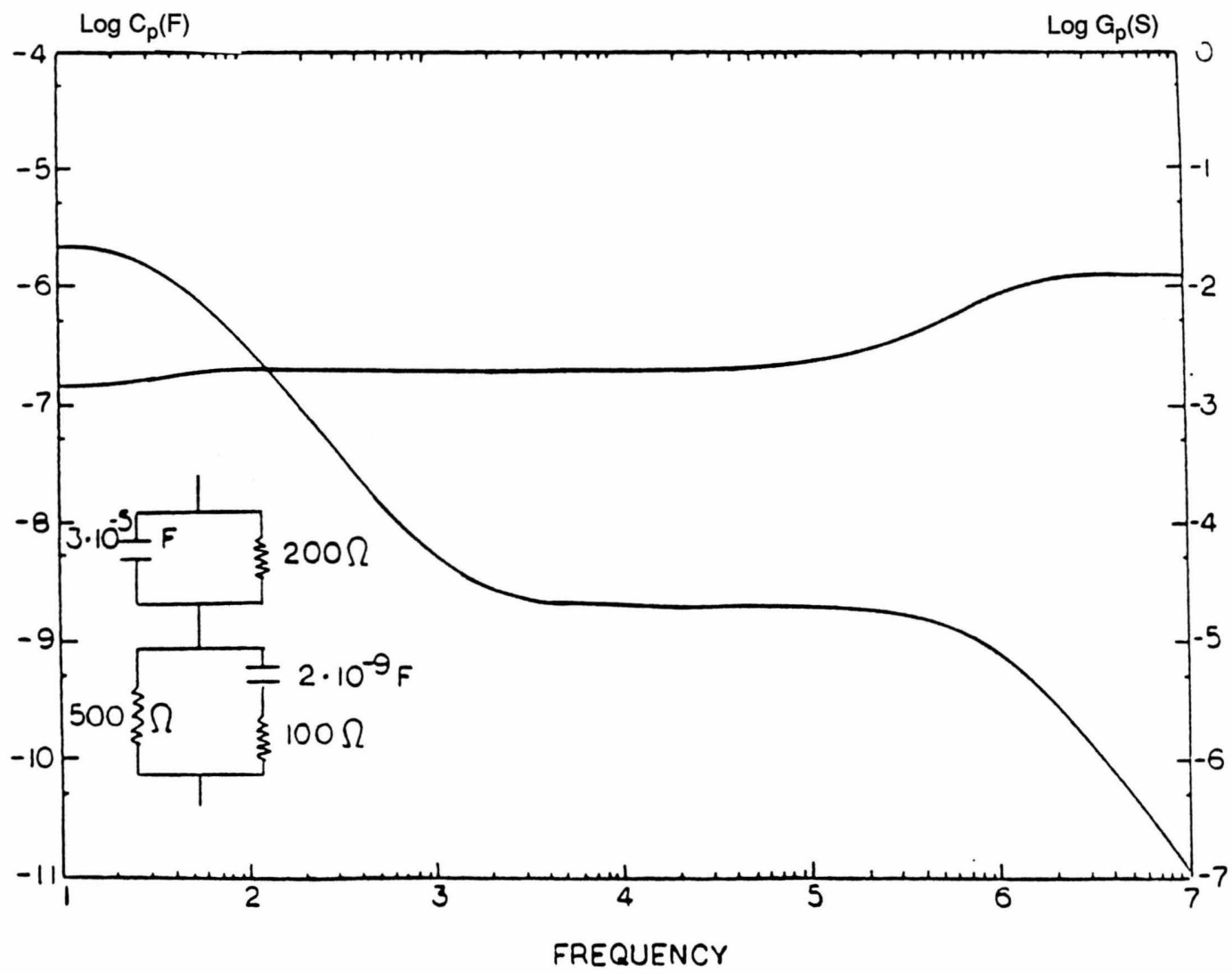

Figure 5. Example of matching a model to experimental results using data available from dielectric spectra of portland cement paste cured for 35 days.

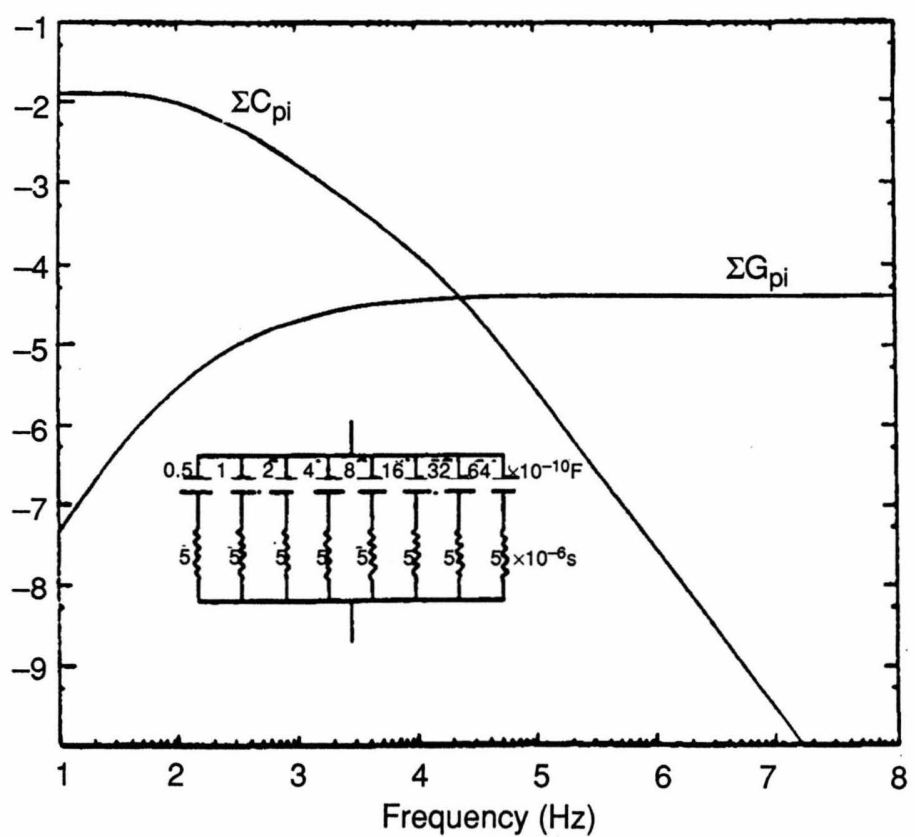

Figure 6. Equivalent parallel capacitance and conductance as functions of frequency for the network shown. 


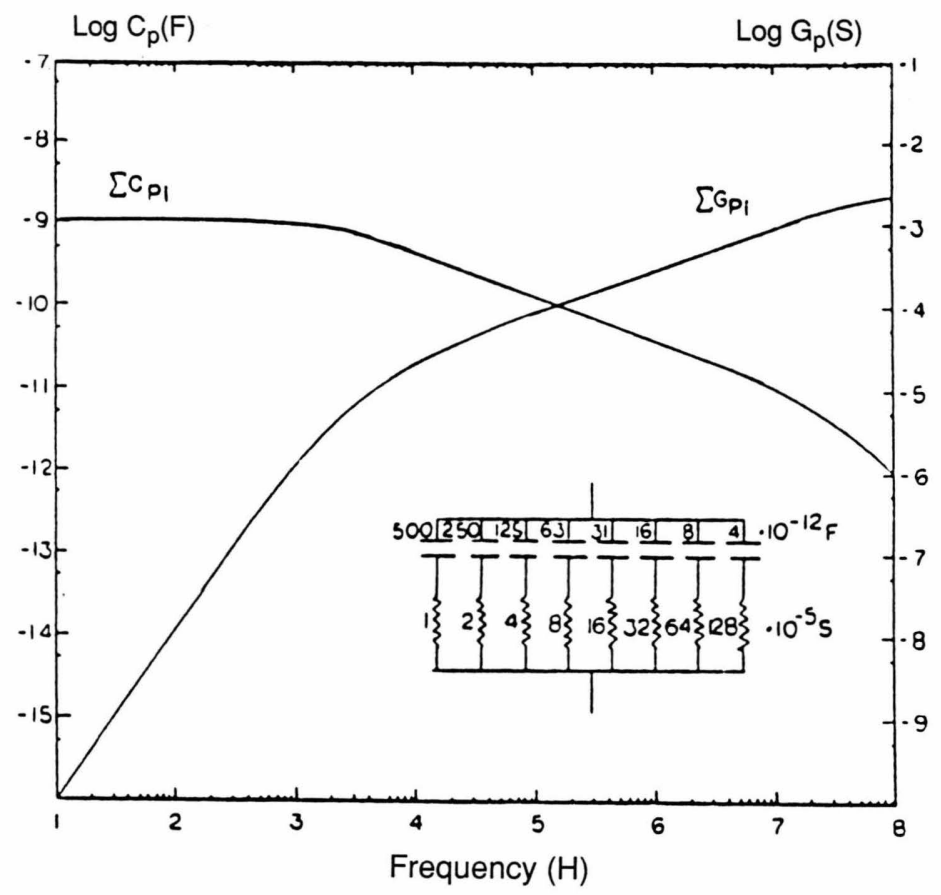

a. Equivalent parallel capacitance and conductance as functions of frequency for the network shown.

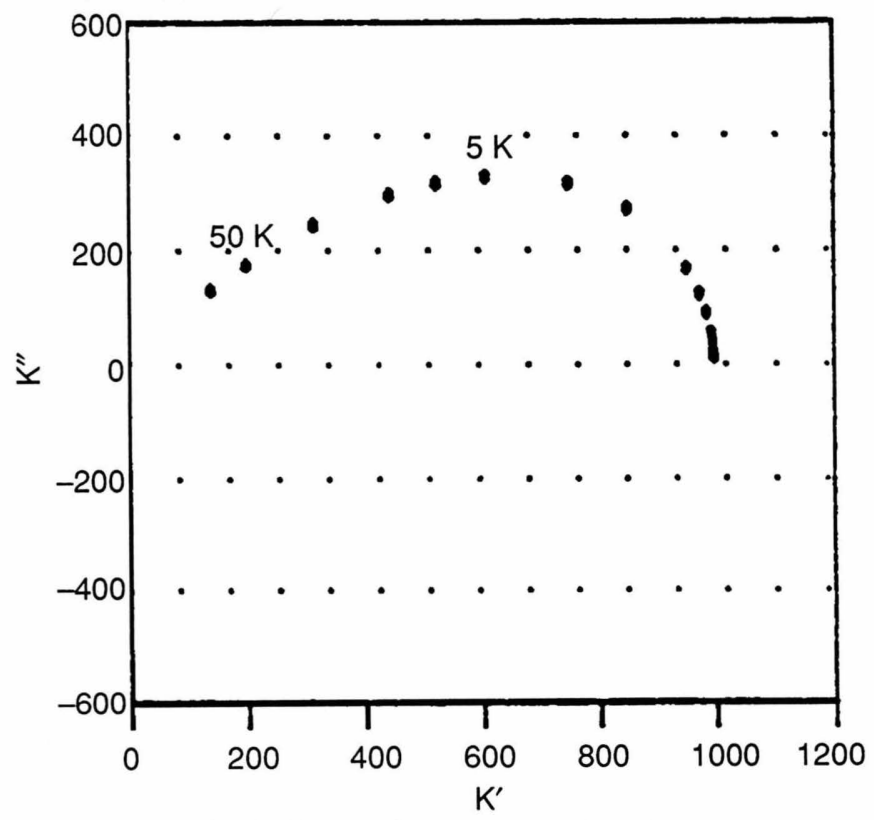

b. Cole plot for the network of $7 a$.

Figure 7. Properties of the network shown.

doubling $C$ per section and keeping $G$ constant, the total capacitance can be made to fall as the first power of the frequency from about $200 \mathrm{~Hz}$ to $20 \mathrm{kHz}$. Figure $7 \mathrm{a}$ shows that if $C$ is halved and $G$ is doubled for each succeeding section the total $C$ falls and the total $G$ rises as the square root of frequency over about three decades. Figure $7 \mathrm{~b}$ shows how the Cole semicircle is dis- torted for this distribution of Debye relaxations. Both of these features show up in our data for snow.

\section{Computer tools for data management and interpretation}

Each snow experiment involved the collection, processing and organization of a large variety of data. 
These data included time, sample temperature, plate separation, snow parameters, power measurement and dielectric properties as a function of frequency. The data entry, processing and organization was simplified by the use of a computer spreadsheet (Quattro by Borland) on a standard IBM AT microcomputer. The spreadsheet was used for the calculation of snow water content. During the dielectric heating of the snow, the power was calculated from the current, voltage and phase measurements. Numerical integration of power during the heating process determined the heat input and thus the water content. The spreadsheet was also used in calculating the conductivity and dielectric constants, and the data for the logarithmic graphs and the Cole plots.

To further analyze the data, an interactive, curvefitting program was written in Microsoft Quick-Basic, version 4.This program finds the parameters giving the best fit for a set of data to any type of polynomial specified by the user.

\section{EXPERIMENTAL DESIGN}

\section{Dielectric measurements}

Measurements were made of equivalent parallel capacitance $C \mathrm{p}$ and equivalent parallel conductance $G_{\mathrm{p}}$ using a General Radio 1615A bridge in the threeterminal mode. The sample holders are shown in Figures 8 and 9. The signal source was a General Radio 1210-C oscillator and the detector was the General Radio 1232-A tuned amplifier and null detector. The sample cells were placed inside an electrically shielded oven, which was itself inside a commercial chest type freezer. The oven temperature was controlled by a Cole-Palmer model 2158 Versatherm controller using a thermistor sensor. Sample and oven temperatures were monitored by Yellow Springs Instrument linearized thermistors with digital readout on Keithley model 160 voltmeters. All probes were calibrated against a Hewlett-Packard 2802-A platinum resistance thermometer and zeroed in a common ice bath.

\section{Sample water content}

An obvious way to prepare.snow of known water content is simply to add to dry snow at $0^{\circ} \mathrm{C}$ known amounts of water also at $0^{\circ} \mathrm{C}$. However, there are problems with this method. One of these is obtaining uniform mixing. Another is that if either the snow or the water is too cold, some of the water will freeze. If the water is slightly too warm, some of the ice will melt. Most importantly each time the water content is changed, we must work with a new and possibly fundamentally different sample that inevitably will be mixed and packed differently. What we would like to do is to vary the water content of a particular sample which remains undisturbed in the test cell. To this end, we have developed a method of electrically melting the sample itself.

In doing this, two things are important: the heat generated must be uniformly deposited in the sample and it must be measurable with sufficient precision. Direct current heating, perhaps the simplest approach, is unsatisfactory because once a liquid path has been created, ionic conduction will cause most of the heat to be deposited along that path, which will become larger and larger. To ensure that the energy is uniformly deposited in the ice itself, we use the heating due to dielectric loss in the ice. Thus we choose a frequency of the order of, or higher than, the Debye dispersion frequency for ice $\left(f_{D}\right)$. If we used microwave heating, we would again find water absorbing much of the energy. Moreover, microwave heating would be hard to monitor.

We have chosen $20 \mathrm{kHz}$ as our working frequency. The power is monitored by measuring the voltage applied to the sample, the current through it and the phase angle between them. A Singer model LT PS-ll oscillator and power amplifier supplies up to $1600 \mathrm{~V}$ at $20 \mathrm{kHz}$ from a 780-ohm source. Thus arbitrary increments of heat can be added to a sample in situ and dielectric measurements can be made after each increment without disturbing the sample. The circuit arrangement is shown in Figure 10.

The most difficult aspect of this procedure is the measurement of the phase angle, which changes significantly with time. At the start, we monitored this using a dual trace oscilloscope. More recently, we have been provided by CRREL with a Wavetek model 750 phase meter. We now use both. In two cases, we checked our water content as calculated by power measurement against alcohol calorimetry. In one, the energy calculation gave a $20 \%$ water content and the alcohol calorimeter a value of $23 \%$. In the other the energy calculation gave $5 \%$ and the alcohol calorimetry $7.8 \%$. To check further on the alcohol calorimetric technique, we simply added $5 \%$ and $10 \%$ water to snow samples at $0^{\circ} \mathrm{C}$ and found that alcohol calorimetry gave us $7.4 \%$ and $14.5 \%$ readings respectively. This error was consistent with the higher readings given above and gives us greater confidence in our power measurement procedure than in our alcohol calorimetry.

We appreciate the comment of a reviewer who has called our attention to the fact that E. Brun (1989) had previously used dielectric heating at $20 \mathrm{kHz}$ to change the water content of snow by melting. In that paper, Brun did not discuss his measurement of power.

\section{Monitoring dimensional change}

In preliminary experiments, we used a capacitance cell that had vertical plates $10 \mathrm{~cm}$ square separated by 2 


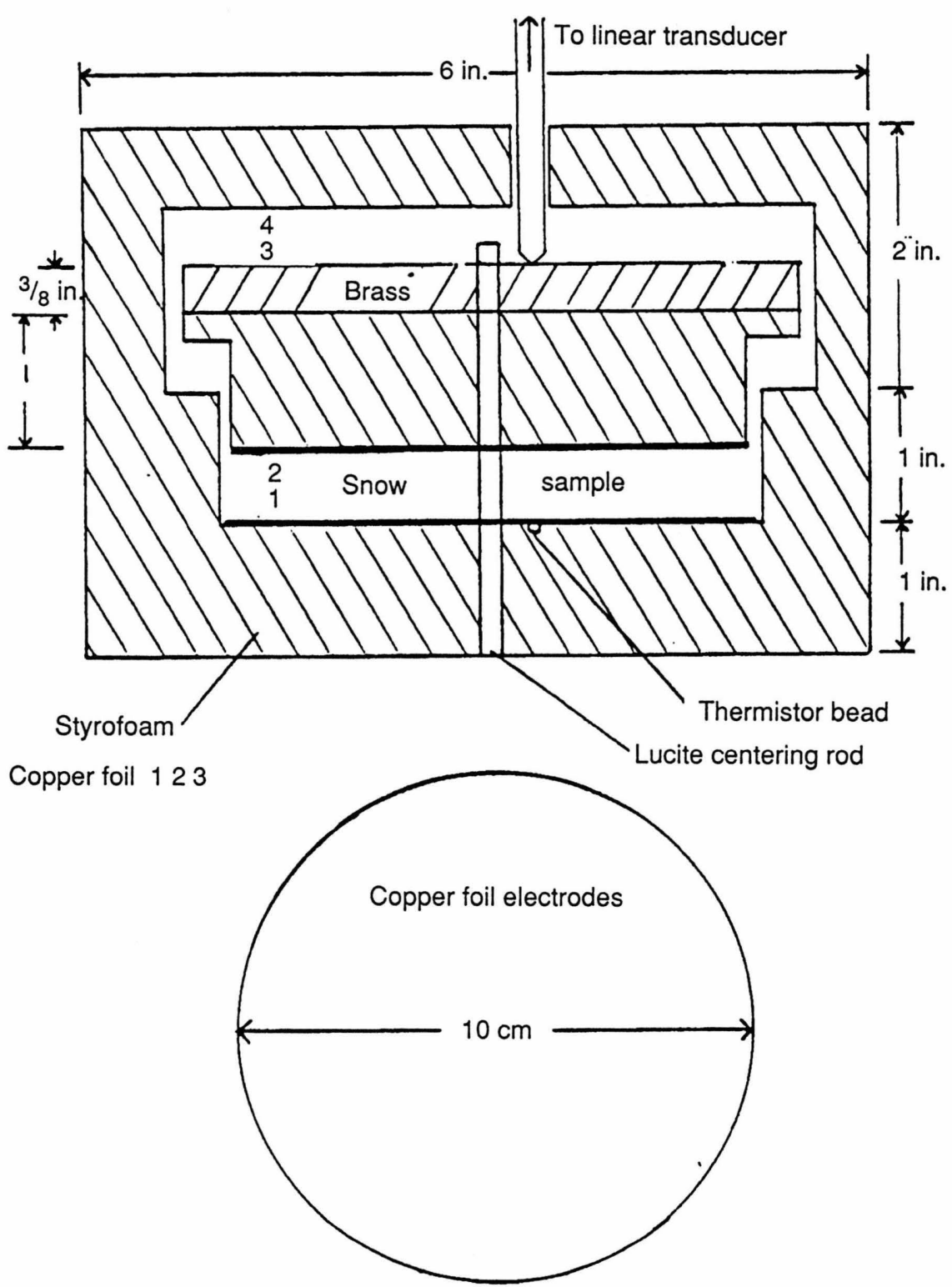

Figure 8. Measurement cell for experiments 1,2 and 3. The electrodes are thin copper foil.

$\mathrm{cm}$. A vertical structure was used so that if water drained away from the top of the sample, good electrical contact would be maintained over most of the sample and a good average measurement would still be made. However, we found that even a very small amount of moisture caused the sample to shrink away from the plates. This we attribute to capillarity at low water contents. At high water contents, there was also shrinkage due to the melting of ice. Thus we changed our basic design to a horizontal cell (Fig. 8) and included in it a device for monitoring the sample thickness by mechanically linking the top plate to a high resolution potentiometer on top of the sample cell. The resistance of the potentiometer was monitored on a chart recorder, which provided a continuous record of the position of the top plate. This also allowed us to correct for changes in sample thickness when calculating conductivity and dielectric constant.

\section{Overall design}

Except where noted, all the measurements reported here were made using one of two sample cells. The first is shown in Figure 8. The housing is made of buildinggrade dense Styrofoam having an R value of 6 for a 1in. thickness (thermal conductivity of $0.024 \mathrm{~W} / \mathrm{m} \mathrm{K}$ ). The electrodes are of thin copper foil to minimize the heat capacity. They are unguarded for fringing capacitance. The guard terminal of the bridge is connected 


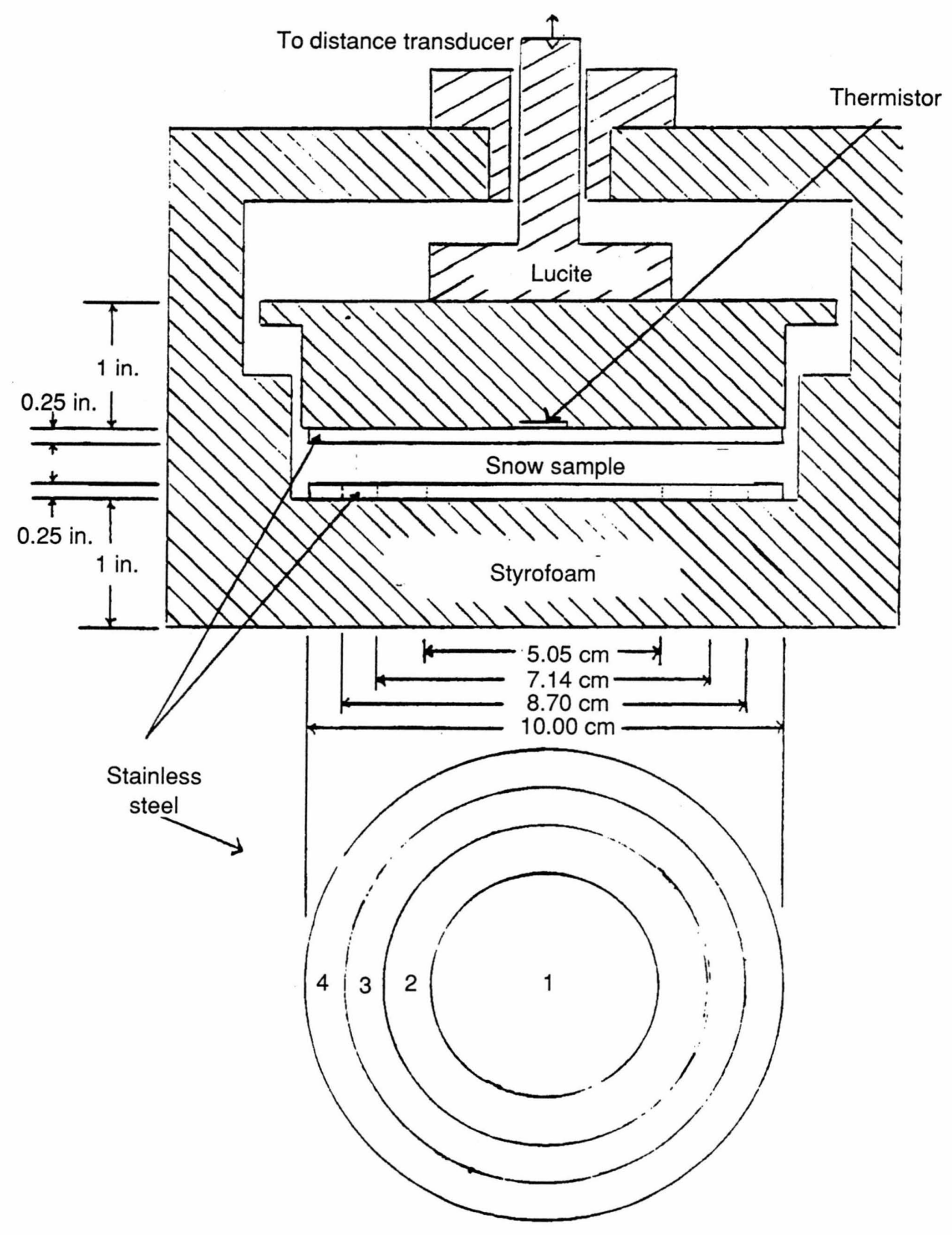

Figure 9. Measurement cell for experiments 10-16. In experiment 10, segments 2, 3 and 4 were guards and in experiments 11-16, segments 3 and 4 were guards and 1 and 2 connected together.

to the aluminum case of the oven. On top of the upper electrode and insulated from it both thermally and electrically is a brass disk that provides a constant gravitational loading of $1027 \mathrm{~N} / \mathrm{m}^{2}$ (about $0.15 \mathrm{lb} / \mathrm{in}^{2}$ ). This is done to ensure that all samples in these experiments have the same packing, thus eliminating one possible variable. A rod from this plate drives the precision potentiometer to provide displacement measurements as the sample thickness changes. A thermistor bead in contact with the bottom of the bottom plate monitors the temperature of the sample. Figure 9 shows the design of the second cell that we used. This was a guarded cell using $1 / 4$-in. stainless steel electrodes. The loading provided by this cell was $306 \mathrm{~N} / \mathrm{m}^{2}$. In all other respects it was very similar. (We show later that loading itself has a negligible effect on our measurements except as it changes density. The density of each sample was separately measured.) Each cell itself was placed inside a thick walled aluminum "oven," which was in turn inside the commercial freezer. The oven was wound with re- 


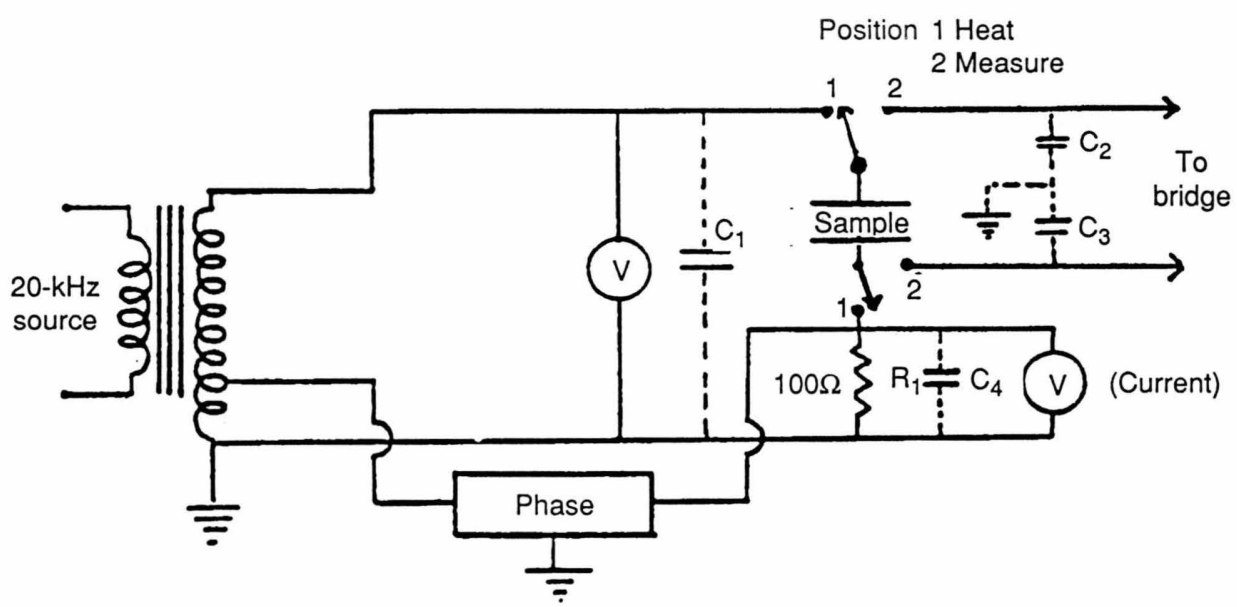

Figure 10. Circuit arrangement for measuring dielectric properties of wet snow.

sistance wire through which DC current was passed to maintain the desired temperature. This was controlled by a thermistor sensor and Cole-Palmer Model 2158 temperature controller. The oven temperature was independently monitored and was normally maintained at $-1( \pm 0.5){ }^{\circ} \mathrm{C}$.

Figure 10 is a diagram of the electrical connections to the test cell. Stray capacitances due to shielding of the leads, etc., are shown in dotted lines. Since the source is of low impedance, $C_{1}$ has negligible effect. Because of the bridge design, $C_{2}$ and $C_{3}$ can be neglected. Because $R_{1}$ is so small, it has a negligible effect on the measurement of $V$ and $C_{4}$ of this magnitude can be neglected.

The performance characteristics are as follows: $C_{\mathrm{r}}$ and $G_{\mathrm{r}}$ are ordinarily measured to 4 or more significant figures with an accuracy of $0.1 \%$ over most of the range. However, to translate this into dielectric constant and conductivity requires an accurate knowledge of sample dimensions, which are used in calculating the cell capacitance and the effects of fringing. The dominant uncertainty is in sample thickness. We estimate a combined uncertainty of $10 \%$ in absolute value and a resolution of better than $1 \%$. Density is measured by weighing the sample to better than $1 \%$ and measuring its thickness after the cell has been assembled. The absolute accuracy is estimated to be $10 \%$, the accuracy of changes about $0.1 \%$. We can resolve a change of thickness of $0.01 \mathrm{~mm}$ while thickness is accurate to $1 \mathrm{~mm}$. Temperatures are ordinarily measured with an accuracy of $0.2^{\circ} \mathrm{C}$ and a resolution of $0.01{ }^{\circ} \mathrm{C}$. Overall we believe our water content is accurate to 0.1 times the reading $\pm 0.5 \%$, and our values for conductivity and dielectric constant are accurate to $10 \%$ of the reading with a resolution of better than $1 \%$.

Table 1. Properties of snows used.

\begin{tabular}{|c|c|c|c|c|c|c|c|c|c|c|c|c|c|}
\hline \multirow[b]{2}{*}{ Snow } & \multicolumn{3}{|c|}{ Harvest data } & \multicolumn{2}{|c|}{ Melt } & \multicolumn{8}{|c|}{ Analysis $(\mu)(e q I)$} \\
\hline & Date & Temp & $\left(\mathrm{g} / \mathrm{cm}^{3}\right)$ & $p H$ & $\sigma^{\dagger}$ & $\mathrm{Ca}$ & $M g$ & $K$ & $\mathrm{Na}$ & $\mathrm{NH}_{4}$ & $\mathrm{Cl}$ & $\mathrm{NO}_{3}$ & $\mathrm{SO}_{4}$ \\
\hline IA & $\begin{array}{l}\text { March } 89 \\
\text { granular }\end{array}$ & & 0.42 & 4.5 & 169 & & & & & & & & \\
\hline IB & $\begin{array}{l}\text { March } 89 \\
\text { Granular }\end{array}$ & & 0.52 & 6.04 & 3.56 & 227 & 10.7 & 4.3 & 74.4 & 1.6 & 70 & 10.5 & 203 \\
\hline II & $\begin{array}{l}30 \text { Dec } 89 \\
\text { very fluffy }\end{array}$ & -8 & 0.38 & 4.27 & 2.80 & 11.5 & 3.3 & 4.3 & 52.6 & nd & 56 & 45.8 & 21 \\
\hline III & 30 Jan 90 & -2 & 0.41 & 5.36 & 0.305 & 5.0 & $\mathrm{nd}^{\mathrm{it}}$ & 1.5 & 1.7 & nd & 3 & 19 & 5 \\
\hline IV & $\begin{array}{l}5 \text { Feb } 90 \\
\text { light fluff }\end{array}$ & -15.5 & 0.32 & 5.0 & 0.534 & 7.0 & nd & 1.3 & 1.3 & nd & 4 & 8.2 & 6 \\
\hline V & $\begin{array}{l}25 \mathrm{Feb} 90 \\
\text { fine \& floc. }\end{array}$ & -8 & 0.27 & 4.82 & 0.865 & 19.0 & 1.6 & 4.3 & 7.4 & nd & 11 & 13.4 & 17 \\
\hline $\mathrm{VI}^{* *}$ & $\begin{array}{l}31 \text { Mar } 90 \\
\text { wet }\end{array}$ & 0 & & 5.64 & 0.17 & 0.1 & nd & 4.8 & nd & nd & 6 & 0.6 & 3 \\
\hline
\end{tabular}

\footnotetext{
* Density as measured on 14 April 1990.

$\dagger$ Units of conductivity are milli (ohm-meters) -1 or milli S/m.

** Snow VI not used in measurements reported here.

†† No data.
} 

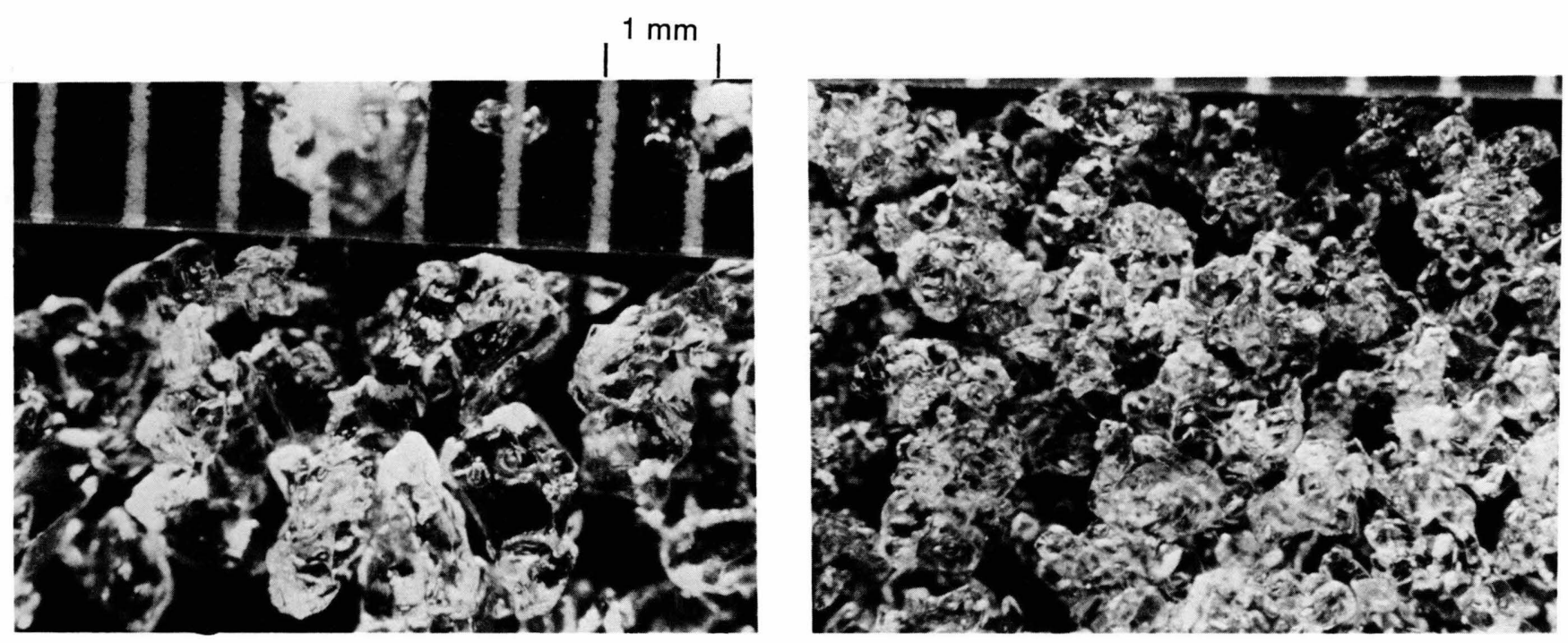

Sample I.

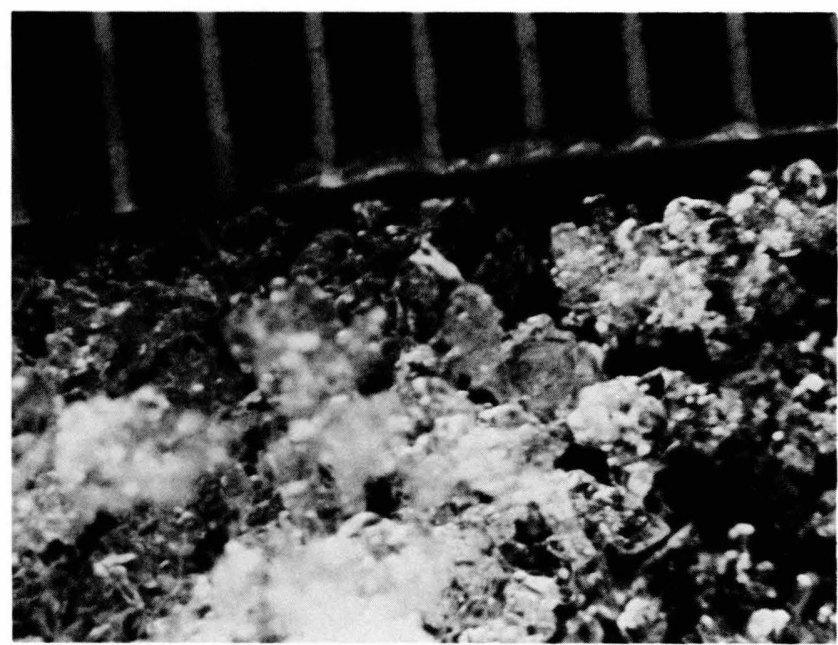

Sample II.

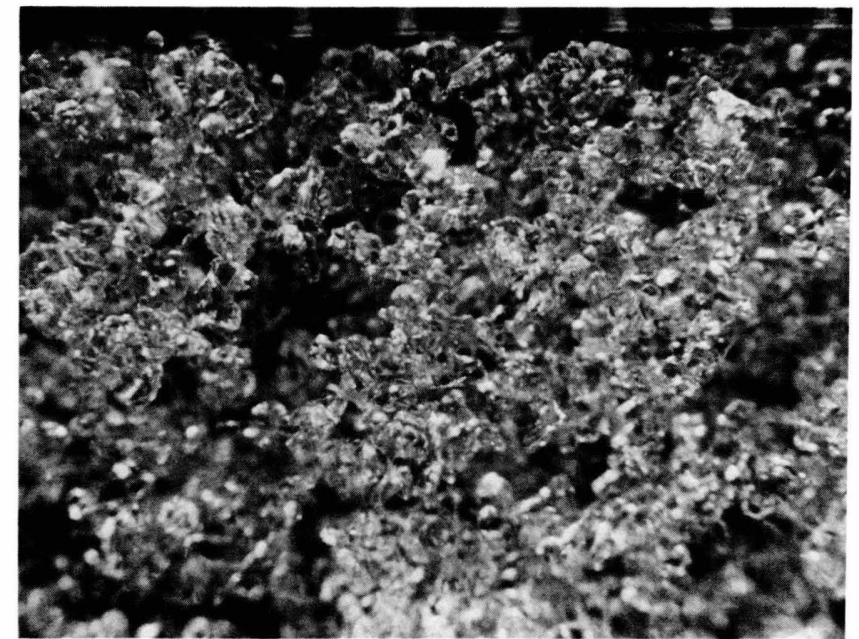

Sample III.

$1 \mathrm{~mm}$

Sample IV.

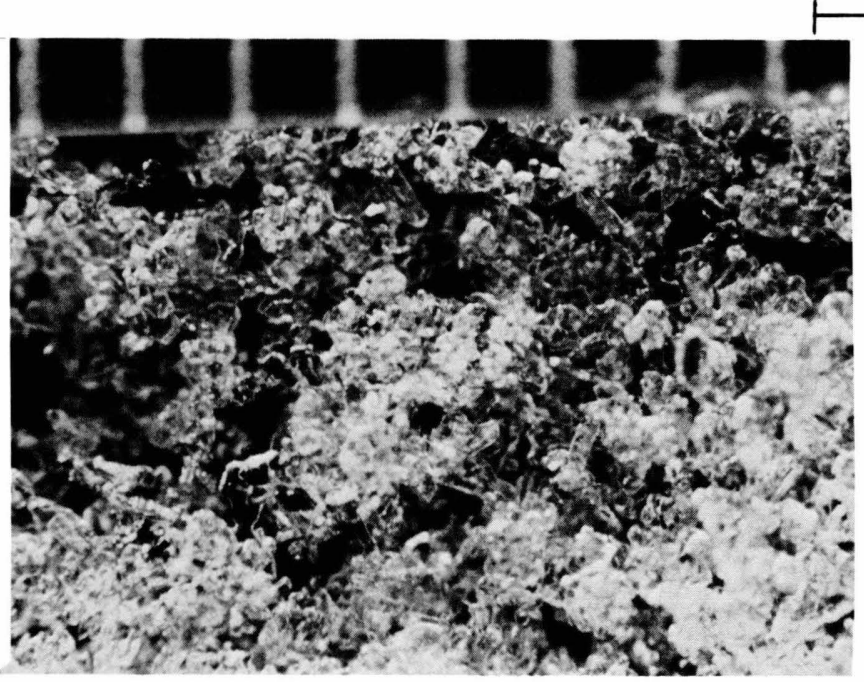

Sample V.

Figure 11. Photomicrographs of snow samples I through V.

\section{SAMPLE PREPARATION AND PROPERTIES}

\section{Harvest and storage}

Snow samples were collected locally and, except for snow I, soon after the storm had ended. At the time of collection, the snow temperature was measured and the structure noted. The snow was placed in Styrofoam boxes and stored in a freezer at $-12^{\circ} \mathrm{C}$ until it was used. The properties of the snows used are listed in Table 1. Microphotographs of snows I through V taken on 8 March 1990 are shown in Figure 11. Snow I (A and B) was harvested in March 1989. It had been on the ground for more than a week and already had undergone considerable metamorphosis when harvested. It was originally stored in polyethylene bags in the freezer and was first used in September 1989. The others were harvested in late 1989 and early 1990 as indicated in Table 1. 


\section{Properties}

One or more samples of each snow harvest were melted and the conductivity and $\mathrm{pH}$ of each determined. In addition an impurity analysis was made. The results are summarized in Table 1. Not surprisingly, there is a strong correlation between the $\mathrm{NaCl}$ concentration and the conductivity of the melt. It may also be of interest that the charge of the total anions minus the total cations is positive for the two lowest $\mathrm{pH}$ snows and negative for that having the highest value.

Since the same snow harvest was used for a number of experiments at different times and since properties such as density and grain size vary with time, each specific sample is identified by an (arabic) experiment number. Table 2 is an index to the samples.

Table 2. Sample data.

\begin{tabular}{|c|c|c|c|c|}
\hline Experiment & $\begin{array}{c}\text { Measurement } \\
\text { date }\end{array}$ & Snow & Code & Experiment \\
\hline 1 & 5 Sept 89 & IA & 8/89-A & $K \sigma \% W$ \\
\hline 2 & 11 Sept 89 & IA & 9/89-B & $K \sigma \% W$ \\
\hline \multirow[t]{3}{*}{3} & 15 Sept 89 & IA & 8/89-C & $K \sigma \% W$ \\
\hline & & & $1 / 90-\mathrm{A}$ & $\begin{array}{l}\text { Test run of } \\
\text { no interest }\end{array}$ \\
\hline & & & $1 / 90-\mathrm{B}$ & $\begin{array}{l}\text { Test run of } \\
\text { no interest }\end{array}$ \\
\hline 4 & 24 Jan 90 & II & $1 / 90-\mathrm{C}$ & Density \\
\hline \multirow[t]{2}{*}{5} & 31 Jan 90 & III & $1 / 90-\mathrm{D}$ & Density \\
\hline & & & \multicolumn{2}{|c|}{ Loose guard ring } \\
\hline 6 & 31 Jan 90 & III & $1 / 90-\mathrm{E}$ & Density \\
\hline 7 & 5 Feb 90 & IV & 2/90-A & Density \\
\hline 8 & 8 Feb 90 & II & 2/90-B & Density \\
\hline 9 & 12 Feb 90 & IB & $2 / 90-\mathrm{C}$ & Density \\
\hline 10 & $1 \mathrm{Mar} 90$ & $\mathrm{~V}$ & $3 / 90-A$ & $K \sigma \% W$ \\
\hline 11 & $6 \operatorname{Mar} 90$ & IV & 3/90-B & $K \sigma \% W$ \\
\hline 12 & $7 \operatorname{Mar} 90$ & II & $3 / 90-\mathrm{C}$ & $K \sigma \% W$ \\
\hline 13 & $8 \operatorname{Mar} 90$ & IB & 3/90-D & $K \sigma \% W$ \\
\hline 14 & $9 \operatorname{Mar} 90$ & III & $3 / 90-E$ & $K \sigma \% W$ \\
\hline 15 & 15 Mar 90 & II & $3 / 90-\mathrm{F}$ & $K \sigma \% W$ \\
\hline 16 & 20 Mar 90 & IB & $3 / 90-\mathrm{G}$ & $K \sigma \% W$ \\
\hline
\end{tabular}

\section{CONTROL EXPERIMENTS}

At various times during our experiments, questions arose about possible sources of error. Each time we tried to devise experiments to check these. Although they were conducted as the questions arose, they are grouped together in this section.

\section{Electrode materials}

A recurrent question in our early experiments was whether part of the dispersion we were seeing was an electrode effect characteristic of the electrode material. To explore this, we varied electrode materials. A problem with just using cells of various materials is that then we would always be comparing different samples. Thus we used a cell with a bottom plate of copper and changed the top plate without disturbing the sample. Top plates of aluminum, copper, stainless steel and a blocking electrode formed by insulating the top plate with a very thin layer of polyethylene were used. Measurements were made from $50 \mathrm{~Hz}$ to $50 \mathrm{kHz}$ with very similar results in each case. The maximum difference in $C_{\mathrm{p}}$, which was found at $50 \mathrm{~Hz}$, was only $12 \%$. That in $G_{\mathrm{p}}$ was only $8 \%$. We conclude that the electrode contribution was not a serious problem.

\section{Sample distribution in the cell}

Another concern was that our results might be significantly influenced by an undetected variation of the distribution of snow in the cell. Snow was typically placed in the cell as evenly as possible and then leveled with a blade. To test the distribution we built the cell of Figure 9 using stainless steel electrodes (this became our cell of choice for later experiments). The top electrode was one piece, $10 \mathrm{~cm}$ in diameter. The bottom plate comprised a central disk surrounded with three concentric rings with about one millimeter of insulation between them. The central disk and each ring had ar area of $20 \mathrm{~cm}^{2}$. By connecting all of the elements but one to the guard circuit, we were able to measure each region of the sample in turn without disturbance.

Several experiments with snow and one using wet sand suggested a possible small radial decrease in $C_{\mathrm{p}}$ and $G_{\mathrm{p}}$, with the largest variation at low frequencies. This induced us to use greater care in uniformly filling the cells.

We also considered the possibility of an azimuthal variation of snow distribution. To test for this possibility, we made a top plate that was segmented like a pie. We were able to sample one segment at a time and found no significant azimuthal variation. This test also verified the uniformity of the test samples themselves.

\section{Effects of pressure}

As explained earlier, a standard sample loading was used to eliminate possible variations due to pressure effects. However, the following experiment was done to explore the matter. A sample was measured with the standard load. Then incremental loads of $500 \mathrm{~g}$ were added and the sample remeasured with each addition.

Each time the samples became slightly more compacted and the values of $\mathrm{C}_{\mathrm{p}}$ and $G_{\mathrm{p}}$ increased by $2-3 \%$. But when all the extra loading was removed, the values remained almost unchanged. We conclude that the observed increases were due to increases in density, not pressure. Later experiments on the effect of density (VI B) confirm the large effect of density. 


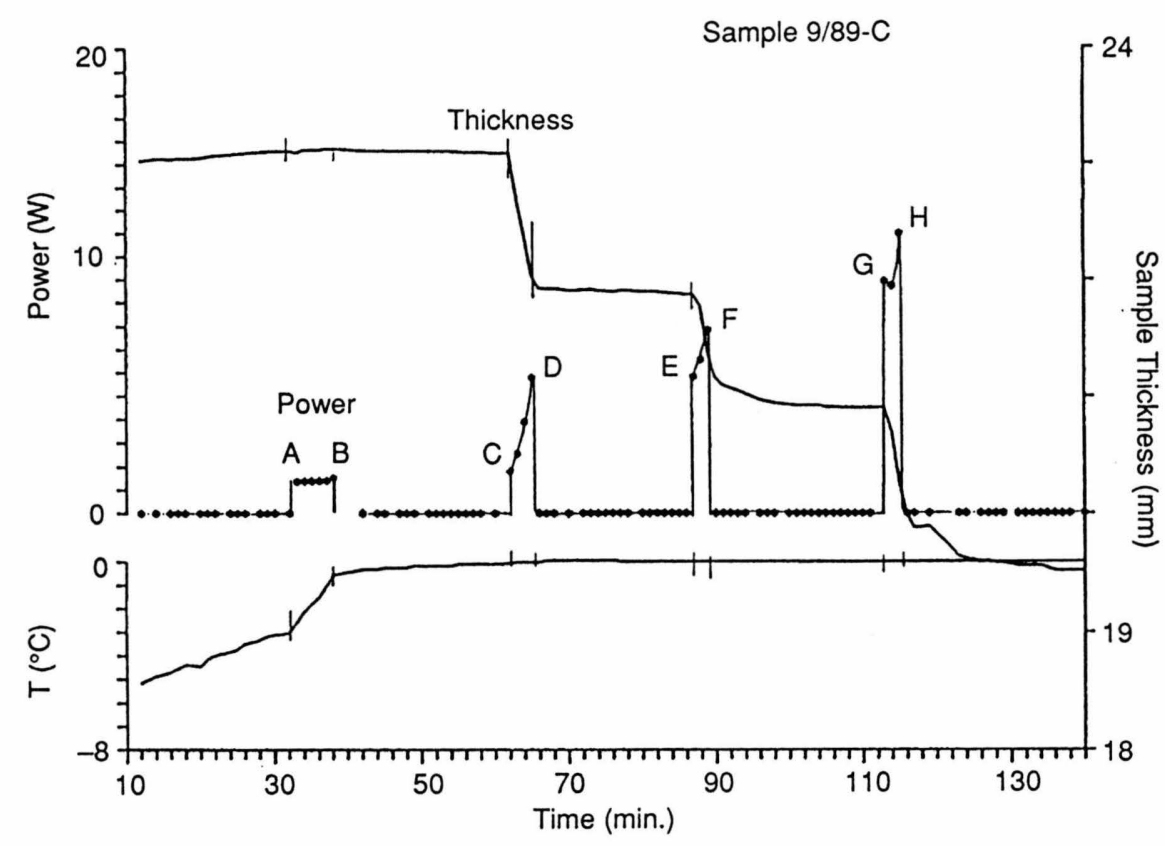

Figure 12. Temperature, power level, and sample thickness as a function of time during a typical experiment

\section{DIELECTRIC EXPERIMENTS FOR WET AND DRY SNOW}

\section{Experiments on aged snow}

Because it was late December 1989 before we were able to harvest fresh snow, many of our experiments had to use snow that had been harvested in the previous March (snow I). This snow had already been on the ground for a week or more before it was collected. Considerable metamorphosis had already taken place when it was first used. Its characteristics are listed in Table 1. Figure 11 is a microphotograph of its structure taken in March of 1990 when it was almost a year old. At the time of these measurements, a typical grain dimension was about $2 \mathrm{~mm}$. For these experiments, cell I (Fig. 8 ) was used.

Figure 12, a plot of temperature, power and sample thickness, illustrates how the experiments were conducted. The sample was placed in the cell at about $-6^{\circ} \mathrm{C}$, which was placed in the "oven" at $-0.5^{\circ} \mathrm{C}$. At this time, a measurement of $C_{\mathrm{p}}$ and $G_{\mathrm{p}}$ as a function of frequency (a frequency scan) was made.

Over the first 32 minutes, the sample warmed slowly to about $-3^{\circ} \mathrm{C}$ at which point (point A), the $20-\mathrm{kHz}$ power was turned on and left on until $\mathrm{B}$, heating the sample internally almost to zero. A second frequency scan was then made. At about 62 minutes (point $C$ ), the heating power was again turned on briefly until D. During this time ice was melted. Again a frequency scan was run, followed by another heat pulse, etc. Note the gradual rise in the sample thickness for about the first 30 minutes as if the sample were relaxing slightly after being loaded. Then the gradual packing at zero degrees, followed by a sharp decrease at $\mathrm{C}$ as ice melts followed by successive decreases at $\mathrm{E}$ and $\mathrm{G}$. These last two decreases do not stop abruptly with the cessation of power. Moreover, the rate of drop is not as great as the first, even though the power is larger. We suggest that capillary forces may play a significant role in the first and that the others are dominated by volume loss due to melting and rearrangement of the grains. The situation is illustrated in Figure 13 in which the electrode separation is shown to change as the water content is changed by heating.

Data for samples 1, 2 and 3 are shown in Figures 14 16 . These measurements were all made using cell I with

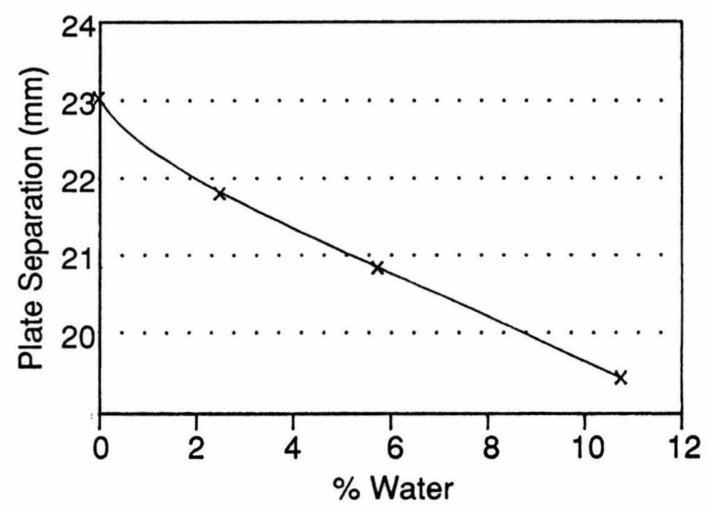

Figure 13.Electrode separation vs percent water for sample 3, which shows the sample shrinking as percent water increases. 

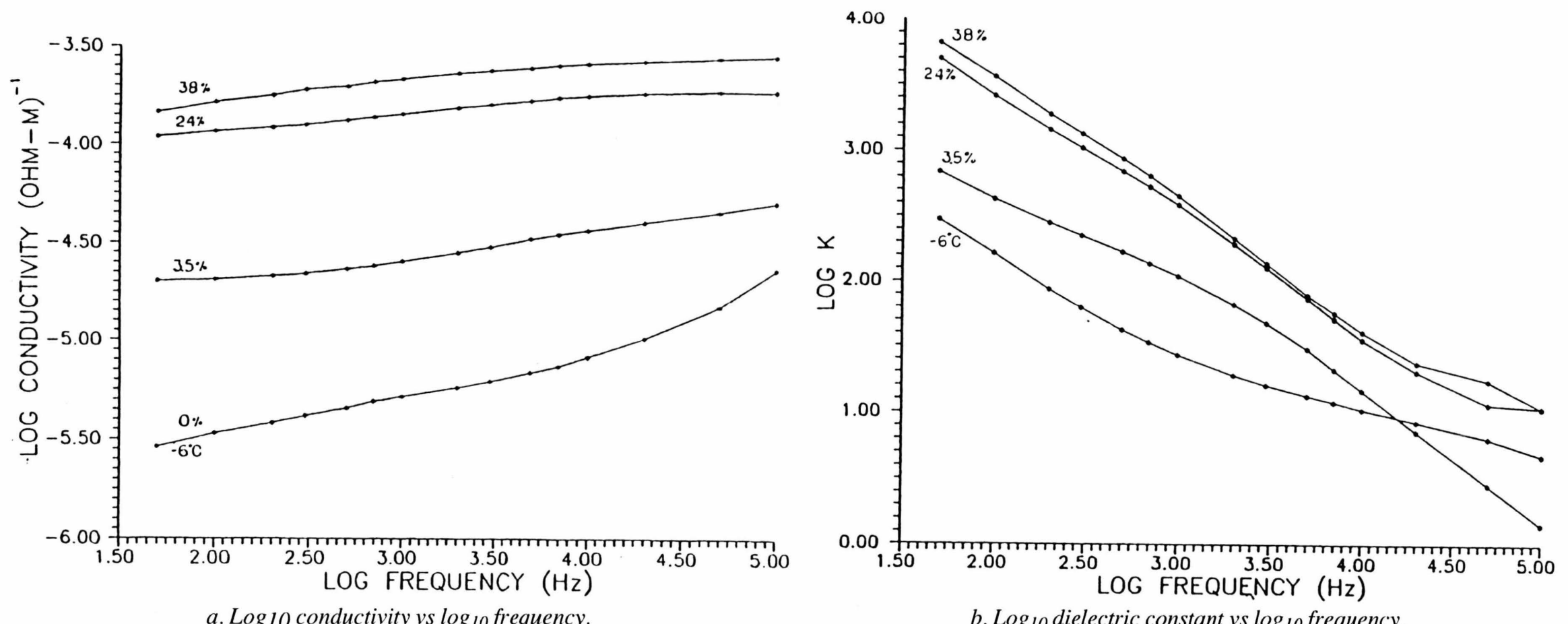

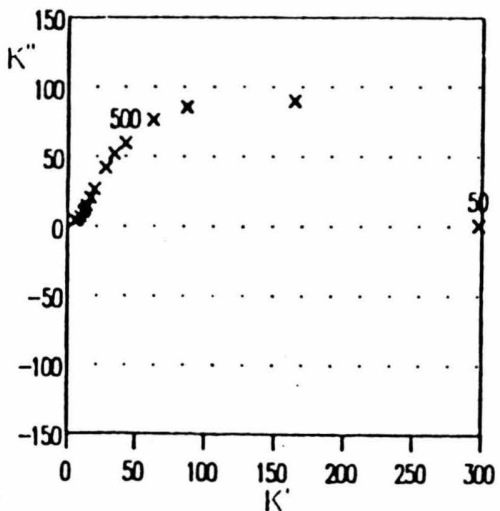

c. Cole plots, $-6^{\circ} \mathrm{C}$.

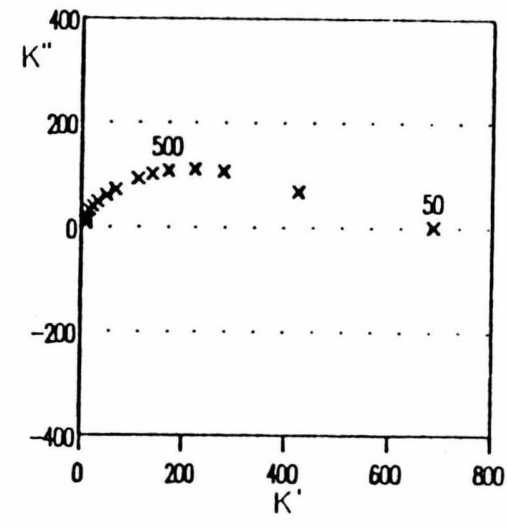

d. Cole plots, $35 \%$ water.

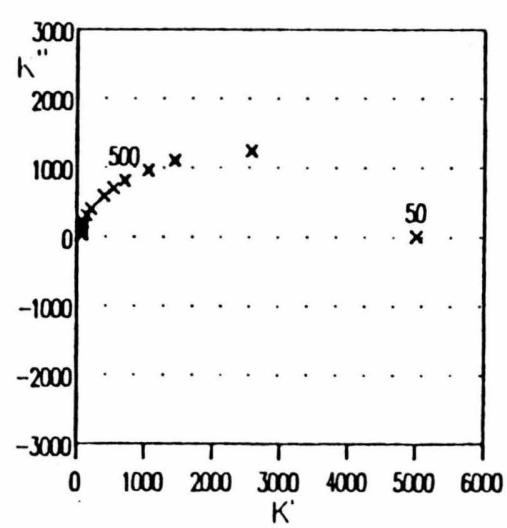

e. Cole plots, $24 \%$ water.

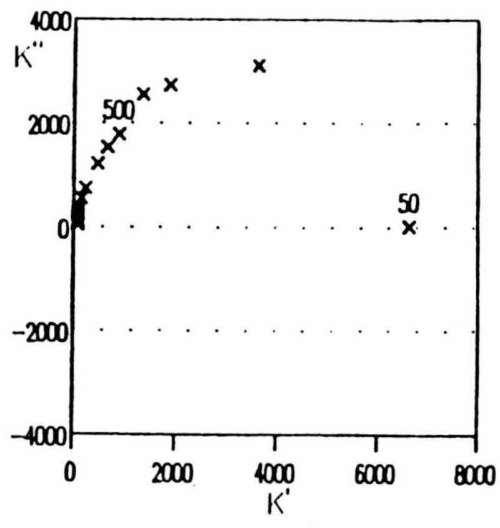

f. Cole plots, $38 \%$ water.

Figure 14. Dielectric spectra for sample 1 for indicated water contents (or temperatures). 


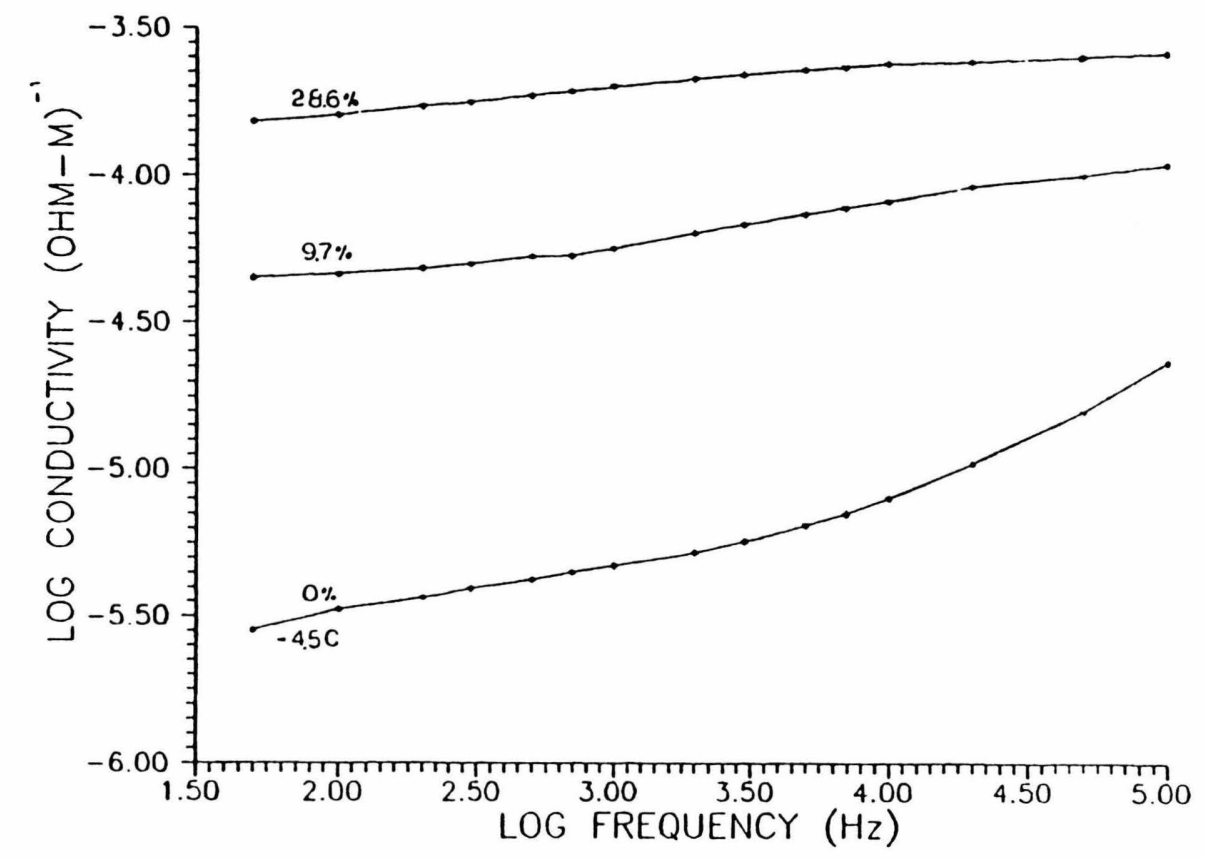

$\vec{u}$

a. $\log _{10}$ conductivity vs $\log _{10}$ frequency.

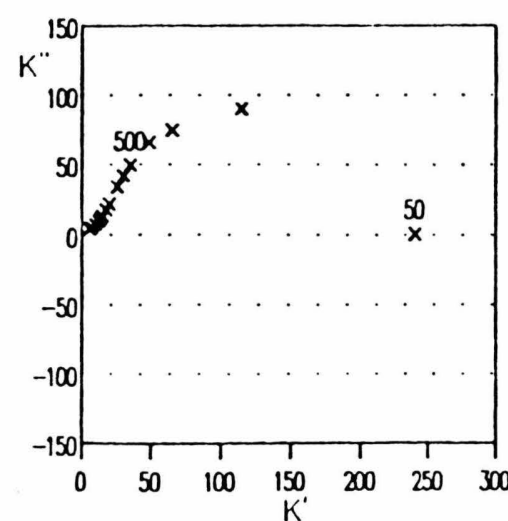

c. Cole plots, $-4.5^{\circ} \mathrm{C}$.

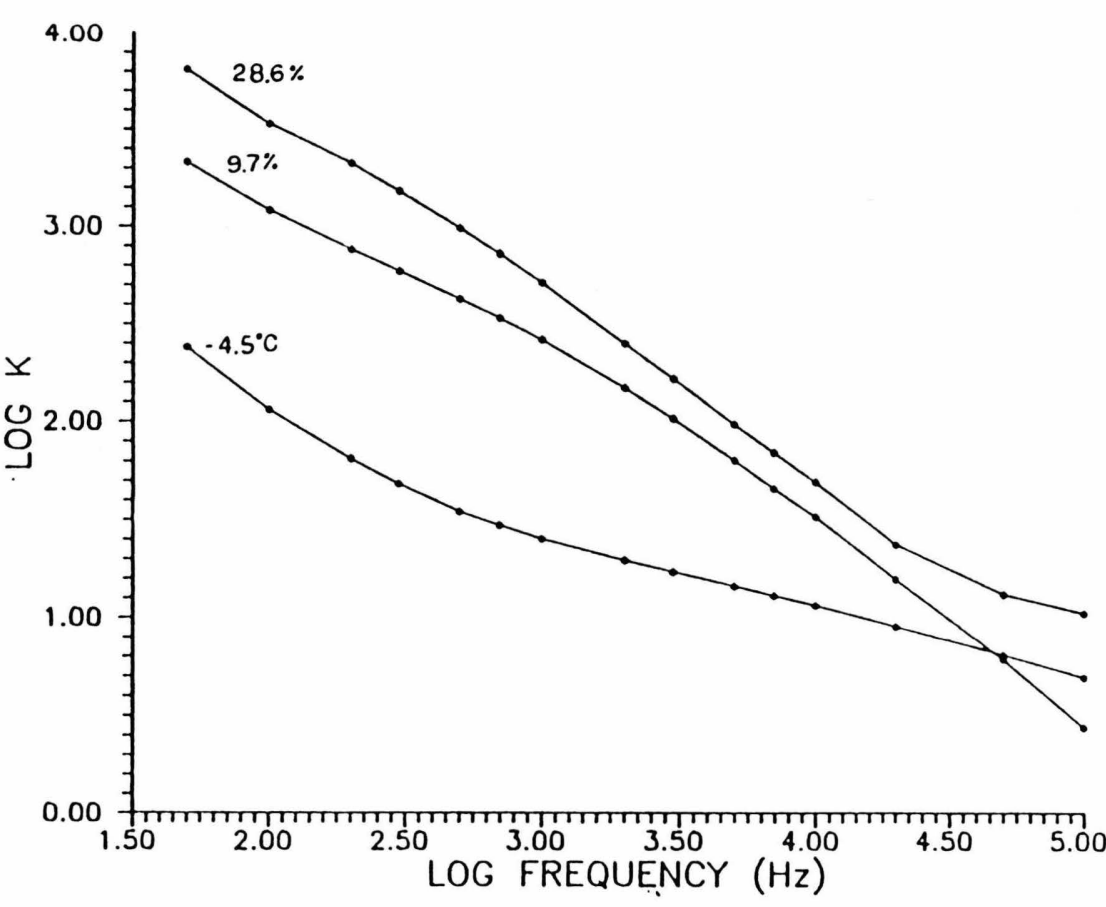

b. Log $_{10}$ dielectric constant vs $\log _{10}$ frequency.

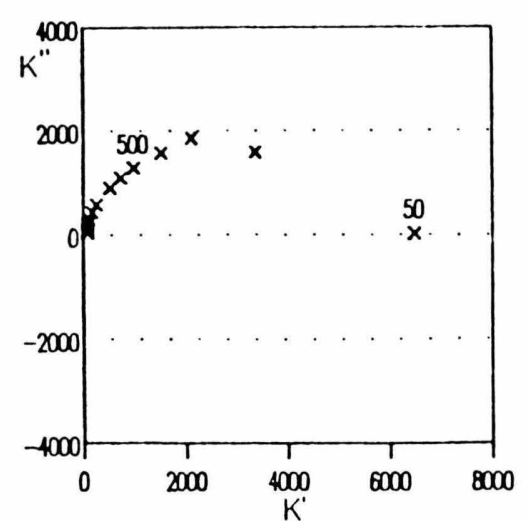

e. Cole plots, $28.6 \%$ water.

Figure 15. Dielectric spectra for sample 2 for indicated water contents (or temperatures). 


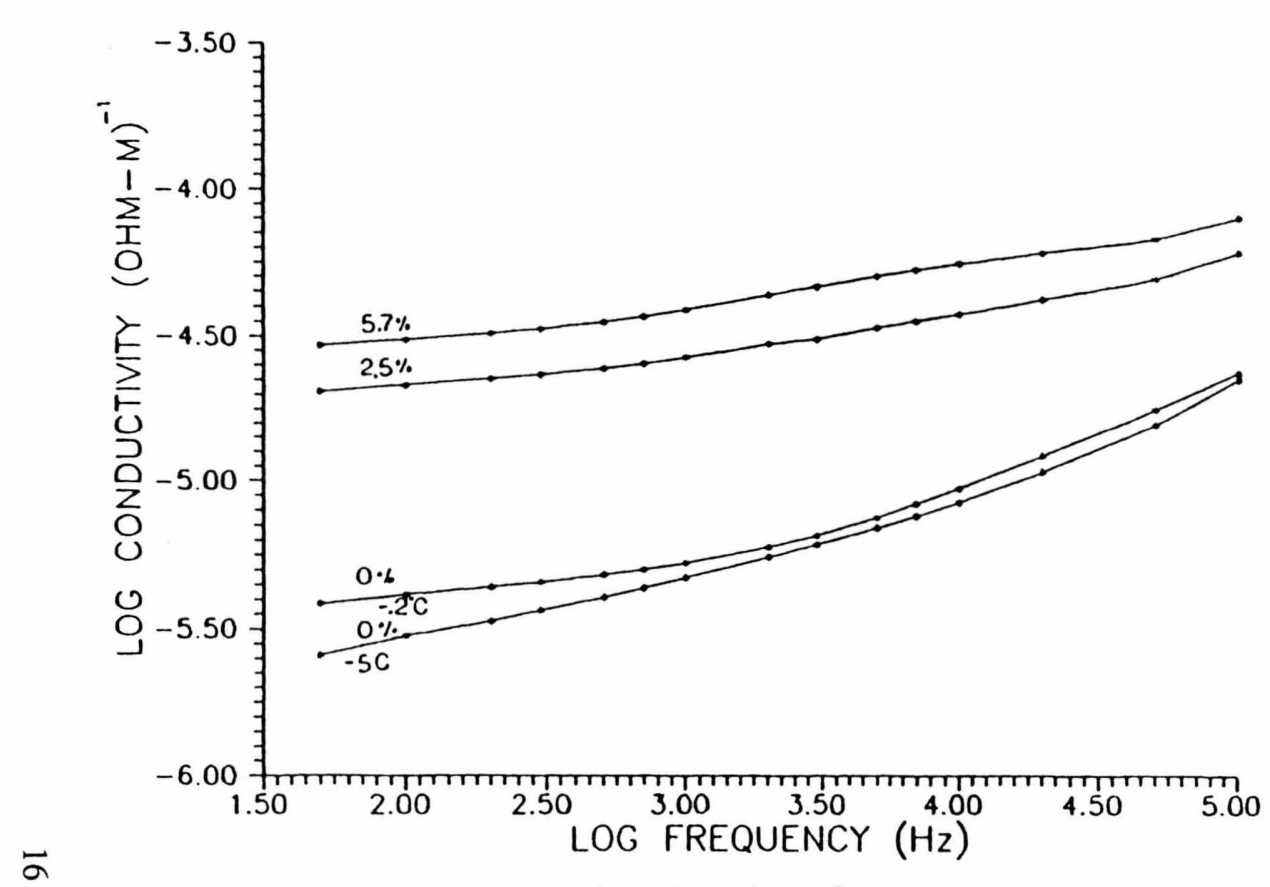

a. $\log _{10}$ conductivity vs $\log _{10}$ frequency.

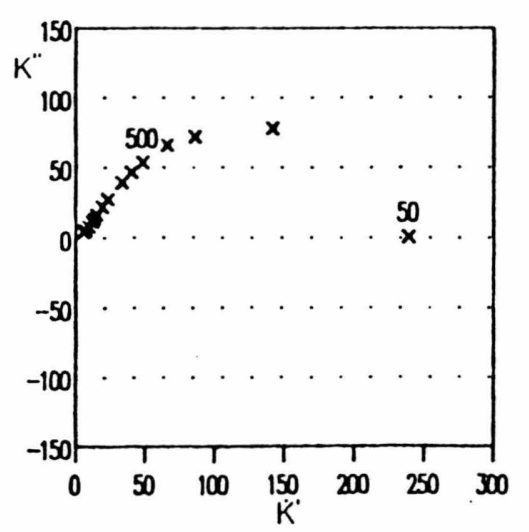

c. Cole plots, $-5^{\circ} \mathrm{C}$.

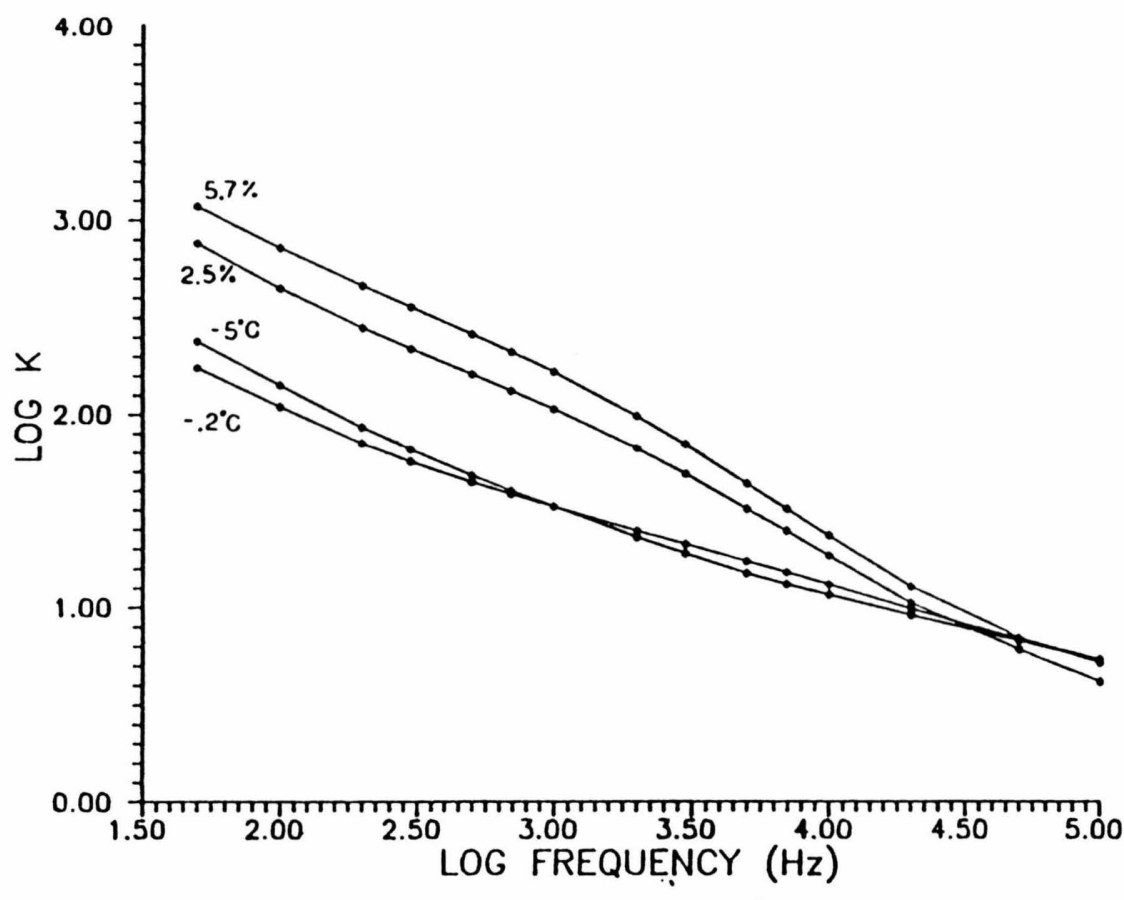

b. Log $_{10}$ dielectric constant vs $\log _{10}$ frequency.

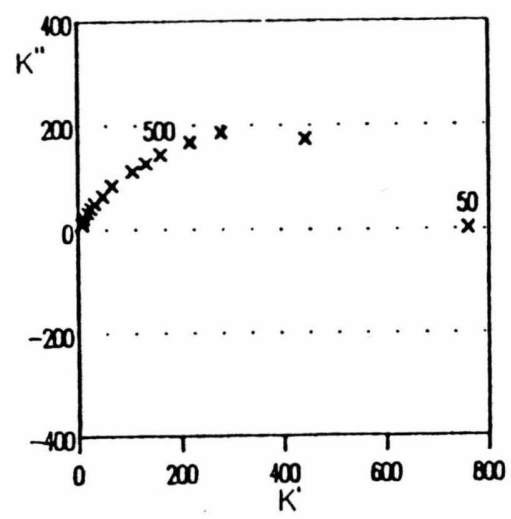

e. Cole plots, $2.5 \%$ water.

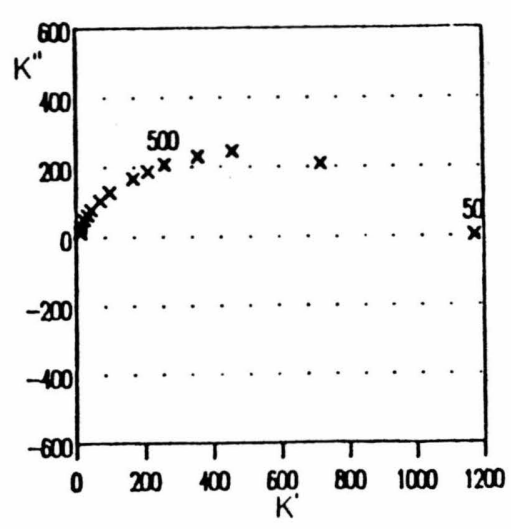

f. Cole plots, $5.7 \%$ water.

Figure 16. Dielectric spectra for sample 3 for indicated water contents (or temperatures). 
copper foil electrodes. The curves for the $\log _{10}$ conductivity vs $\log _{10}$ frequency change their curvature in going from dry snow to even slightly damp snow. Then the predominant change is a steady rise of the values with water content. The increase with frequency is slow and almost linear. The curves for the $\log _{10}$ of apparent dielectric constant $k$ also show a sudden change in going from dry snow to wet snow. Here again there is strong sample-to-sample similarity except for the highest frequency points of sample 1 . The $\log _{10}$ of $K$ falls roughly in proportion to the $\log _{10}$ of frequency. It was shown in the Modeling by Computer section that this type of dispersion in both the dielectric constant and conductivity is characteristic of a system having a number of Debye relaxations in parallel, each having a different relaxation time. This is also seen in the Cole plots (Fig. 14 $16 \mathrm{c}-\mathrm{f})$.

We have used above the term "apparent dielectric constant" because at low frequencies we frequently find values greatly exceeding that for pure ice or pure water. Thus the microscopic geometry of the sample must be very different from the geometry of our cell. There may be conducting paths that make the effective plate area much greater than the true plate area and the effective plate separation small. By the same argument, the term "effective conductivity" might be used. In the interest of brevity, we will drop the word "effective" in the remainder of this report.

The data for these three samples, all from snow IA, form a consistent set for 10 different water contents. For zero water content, they result in almost identical spectra, giving us confidence in the reproducibility of our experiments. When the water contents of different experiments are close, the spectra are very similar. This tends to confirm our estimates of the reliability of the water content $( \pm 1 \%)$. They were all taken within a space of 10 days. The data for samples 13 and 16 (Fig. 17 and 18 ) are for snow sample IB, which was harvested with sample IA but from a different region and has a different conductivity and $\mathrm{pH}$. These data were taken six months later than those for snow IA and with the cell of Figure 9. The figures are very different indeed, a fact that is discussed in the Discussion below..

\section{Experiments on new snow}

After the winter snowfall began, we were able to experiment with different snows. For all of these we used the stainless steel cell of Figure 9. The center plate and first ring were connected together as one electrode and the outer two electrodes connected to the guard. (In the case of sample 10, all three outer rings were connected to guard.) The procedure was essentially the same as that used in A. First, frequency runs were made on the sample when it was several degrees below zero, then the sample was heated to very close to zero using $20 \mathrm{kHz}$, as explained, and measured again. Thereafter, increments of heat were added to melt some snow, and frequency scans were run after each increment. Figures 17-23 show the data for these samples both as plots of the log conductivity and $\log _{10}$ dielectric constant vs $\log$ frequency and as Cole diagrams. These data, while covering the same general range of values, differ in detail from one another and from the earlier measurements.

\section{Discussion}

Our major experimental results are summarized in Figures 14-23. Numerical values are tabulated in Appendix A. For detailed information concerning the properties of any particular sample, see Tables 1 and 2 . The dominant source of absolute error in the measurement of conductivity and dielectric constant is the sample thickness. This is less than $10 \%$. However, the conductance and capacitance were measured to $0.1 \%$ or better. We believe that the major source of error in the water content was inaccuracy in the power measurement. This might cause an error between samples such that one sample measured at $8 \%$ might have the same water content as another measured at $10 \%$. But measurements on the same sample should be ordered so that the relative errors are considerably less.

The general features of the dielectric data for all samples show a rather large low-frequency conductivity rising monotonically with frequency. This is compatible with a conductivity made up of two parts, a frequencyindependent ionic conductivity (protons) to which is added a conductivity resulting from one or more dielectric dispersions. The dielectric constant data show these dispersions more clearly and indicate a range of dispersions. The Cole plots show a range of dispersions in the low-frequency range centered in the region of 100-200 $\mathrm{Hz}$ and often a range of dispersions in the kilohertz range. In general, both the conductivity and the dielectric constant rise with water content. On many samples, there is a change in curvature from concave up to concave down on the $\log _{10}$ conductivity and $\log _{10}$ dielectric constant vs frequency plots as the sample changes from dry to wet.

For dry snow, there appears to be a general tendency for the low-frequency conductivity to be proportional to the $\mathrm{H}^{+}$ion concentration and for the low-frequency dielectric constant to be proportional to the square root of the $\mathrm{H}^{+}$concentration. This is shown in Figure 24, in which are plotted the $50-\mathrm{Hz}$ values of log conductivity (circles) and log dielectric constant (crosses) as functions of $\mathrm{pH}$ (the negative $\log \mathrm{H}^{+}$ion concentration) of the meltwater of the various snows. Other ionic impurities seem to have little effect. This suggests that the lowfrequency conductivity is the result of proton hopping. 

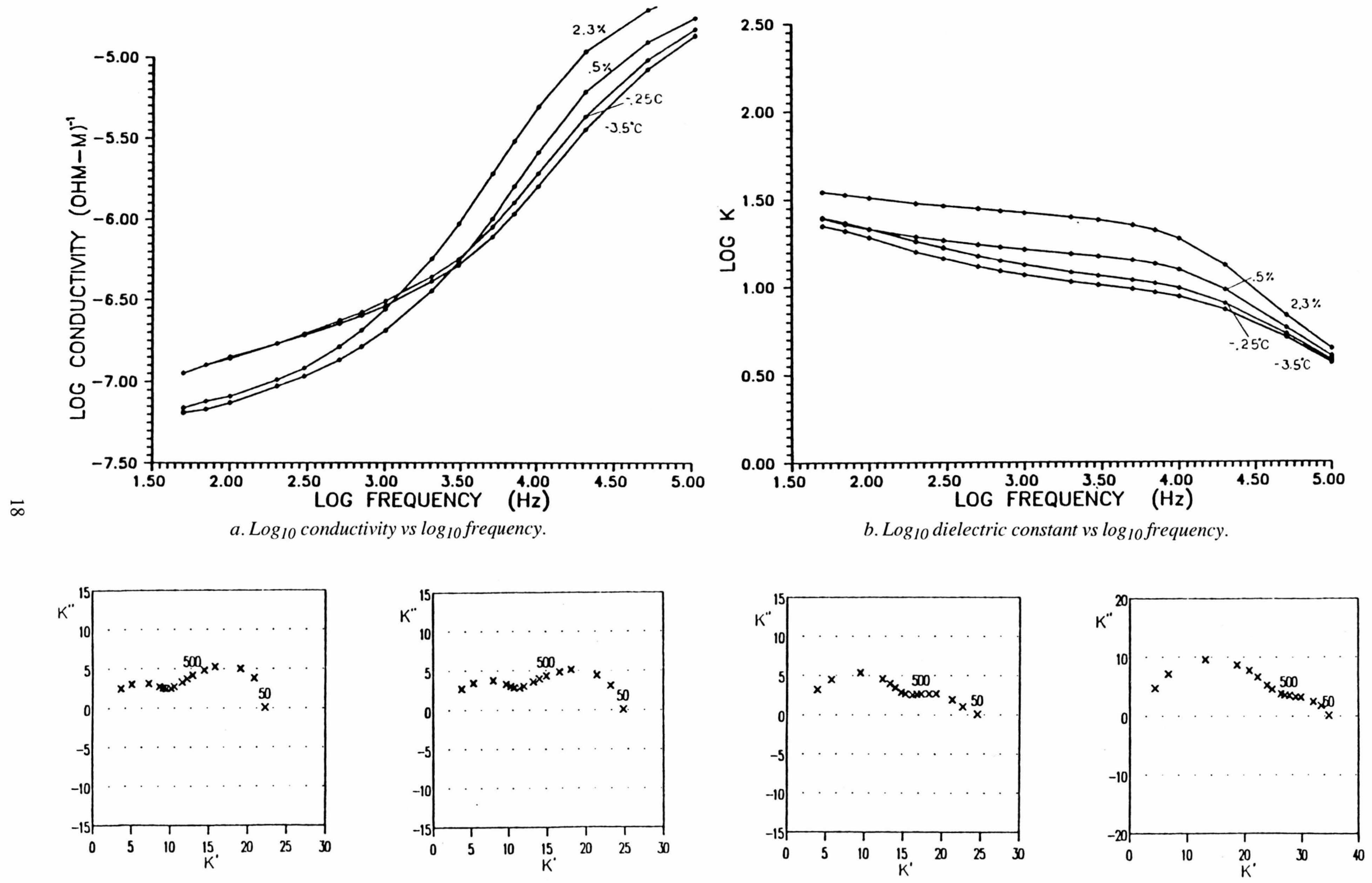

c. Cole plots, $-3.5^{\circ} \mathrm{C}$.

e. Cole plots, $0.5 \%$ water.

f. Cole plots, $2.3 \%$ water.

Figure 17. Dielectric spectra for sample 13 for indicated water contents (or temperatures). 


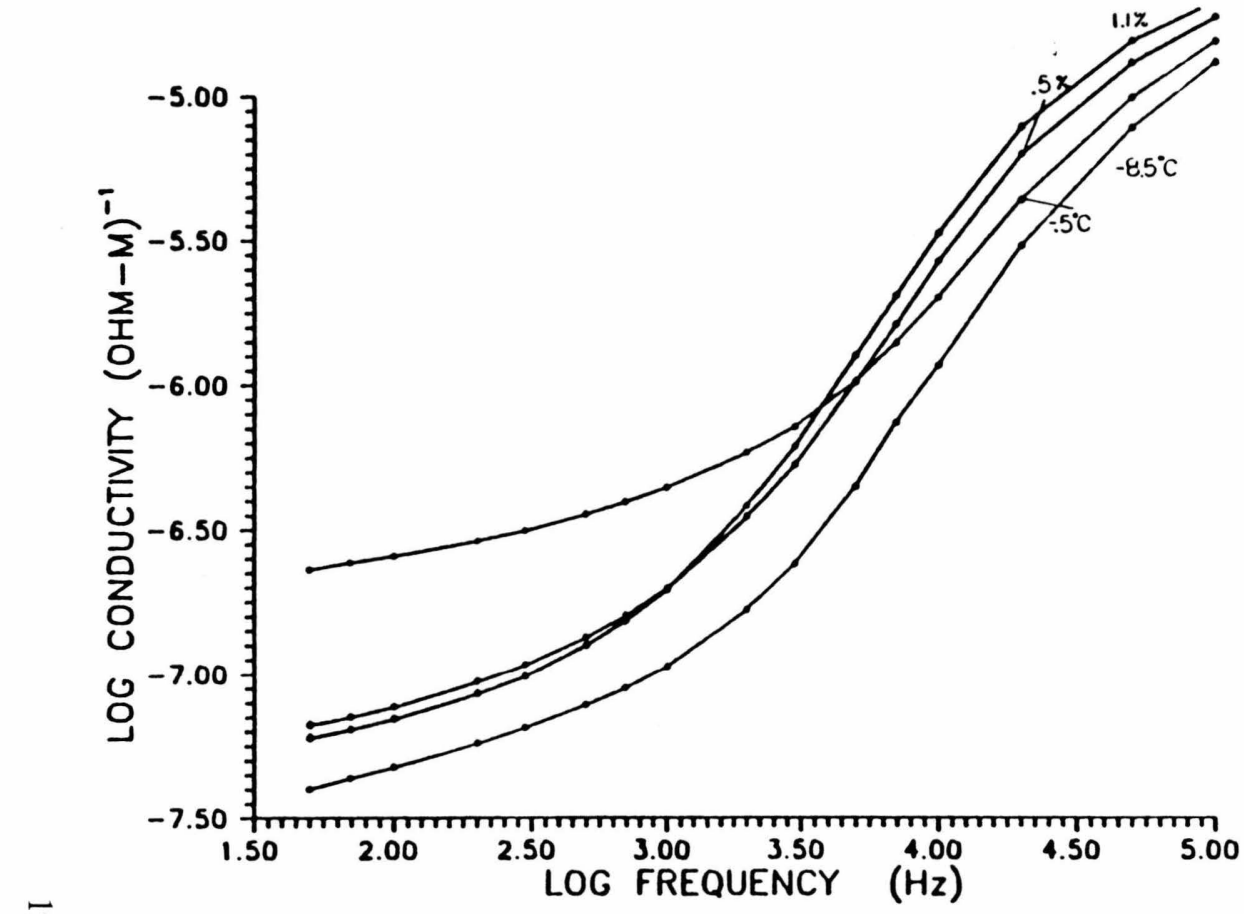

$\varpi$

a. $\log _{10}$ conductivity vs $\log _{10}$ frequency.

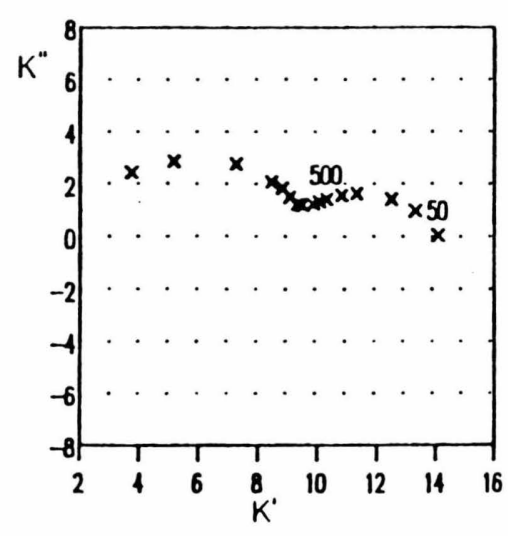

c. Cole plots, $-8.5^{\circ} \mathrm{C}$.

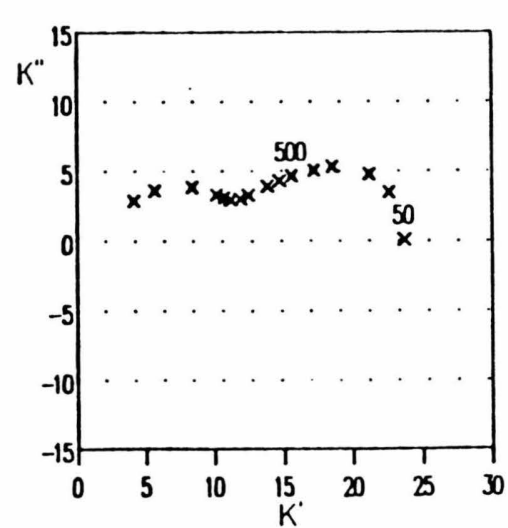

d. Cole plots, $-0.5^{\circ} \mathrm{C}$.

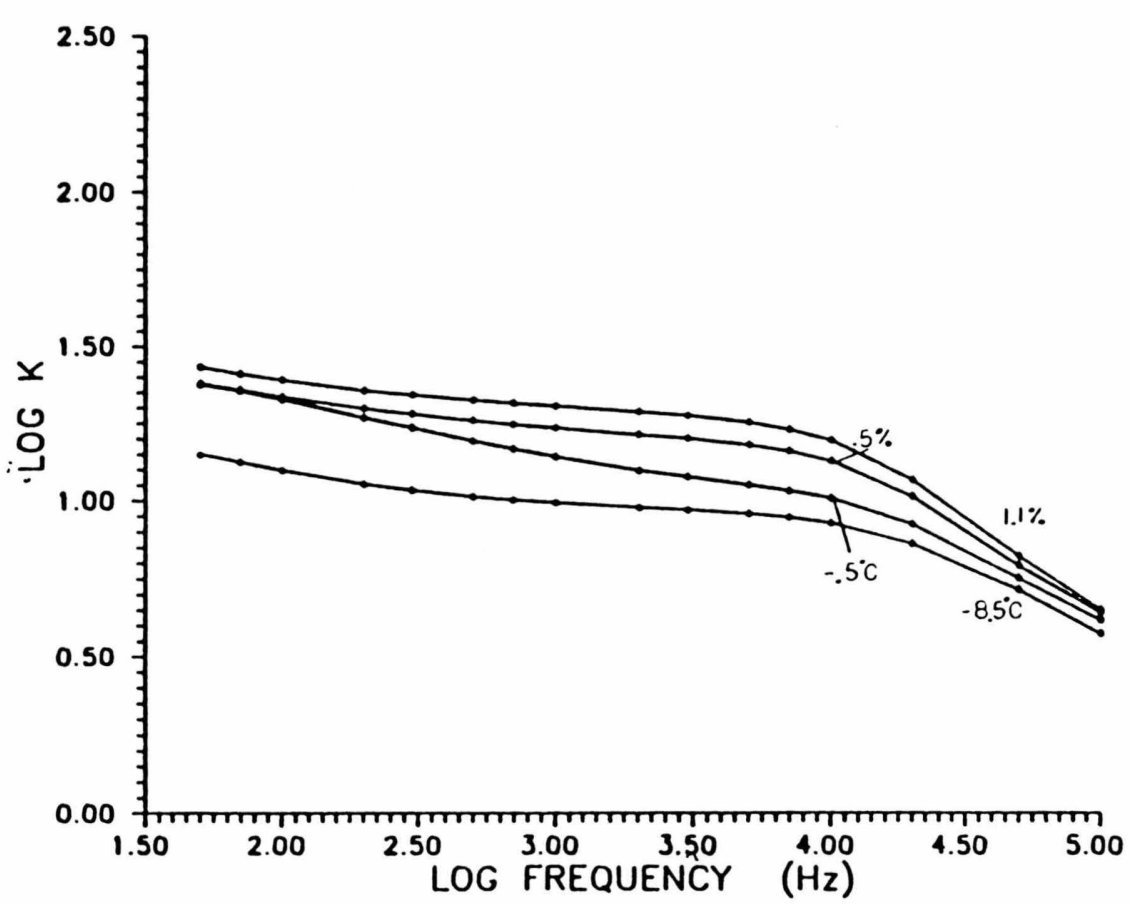

b. $\log _{10}$ dielectric constant vs $\log _{10}$ frequency.
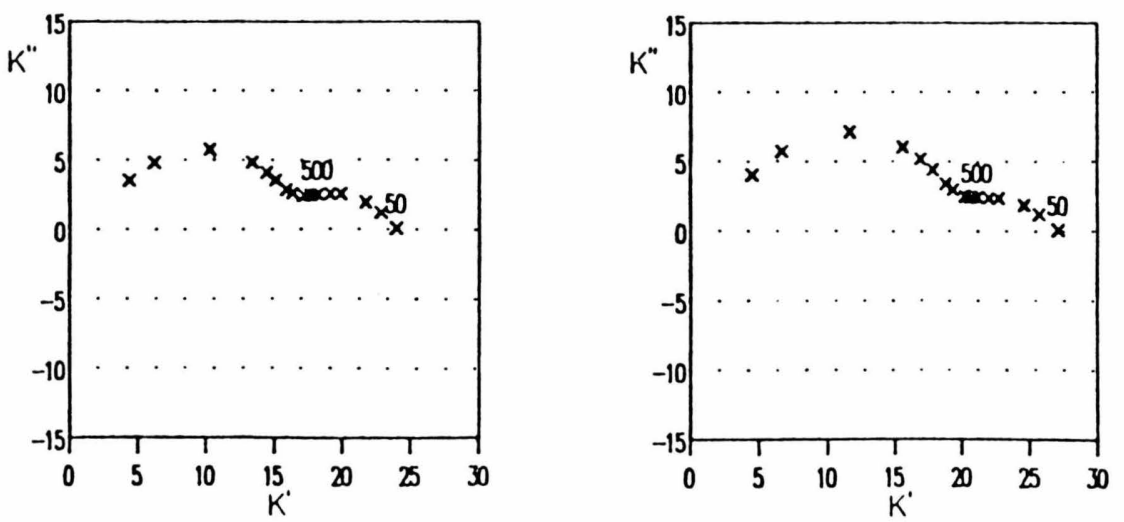

e. Cole plots, $0.5 \%$ water.

Figure 18. Dielectric spectra for sample 16 for indicated water contents (or temperatures). 


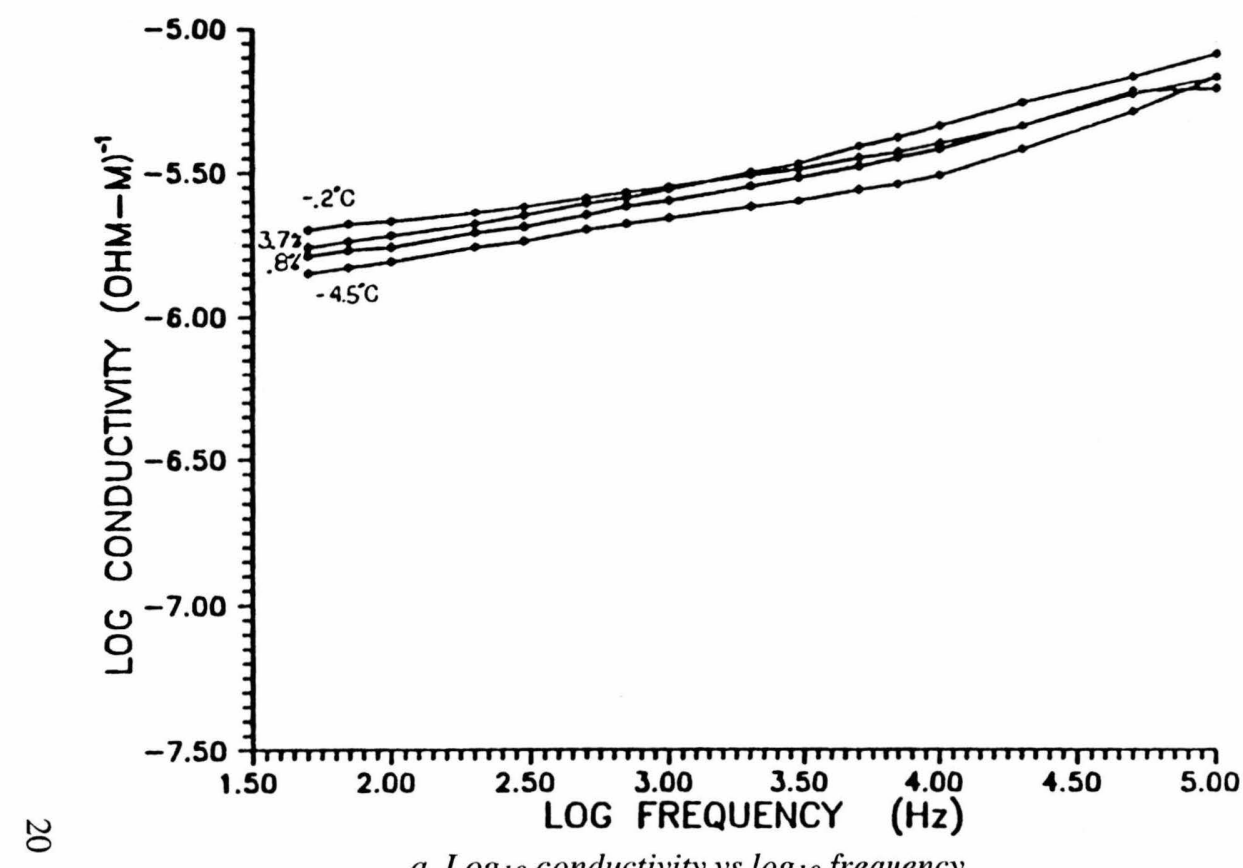

a. $\log _{10}$ conductivity vs $\log _{10}$ frequency.

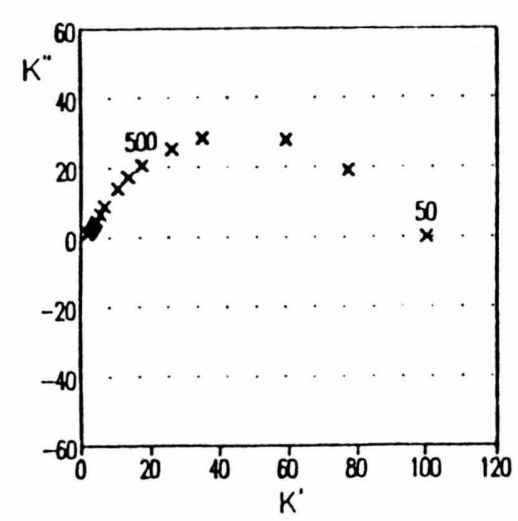

c. Cole plots, $-4.5^{\circ} \mathrm{C}$.

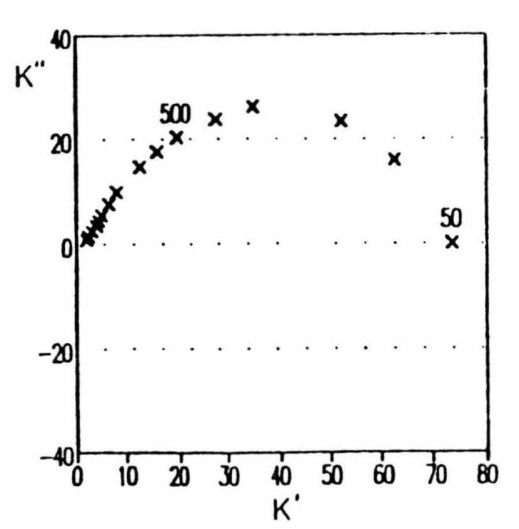

d. Cole plots, $-0.2^{\circ} \mathrm{C}$.
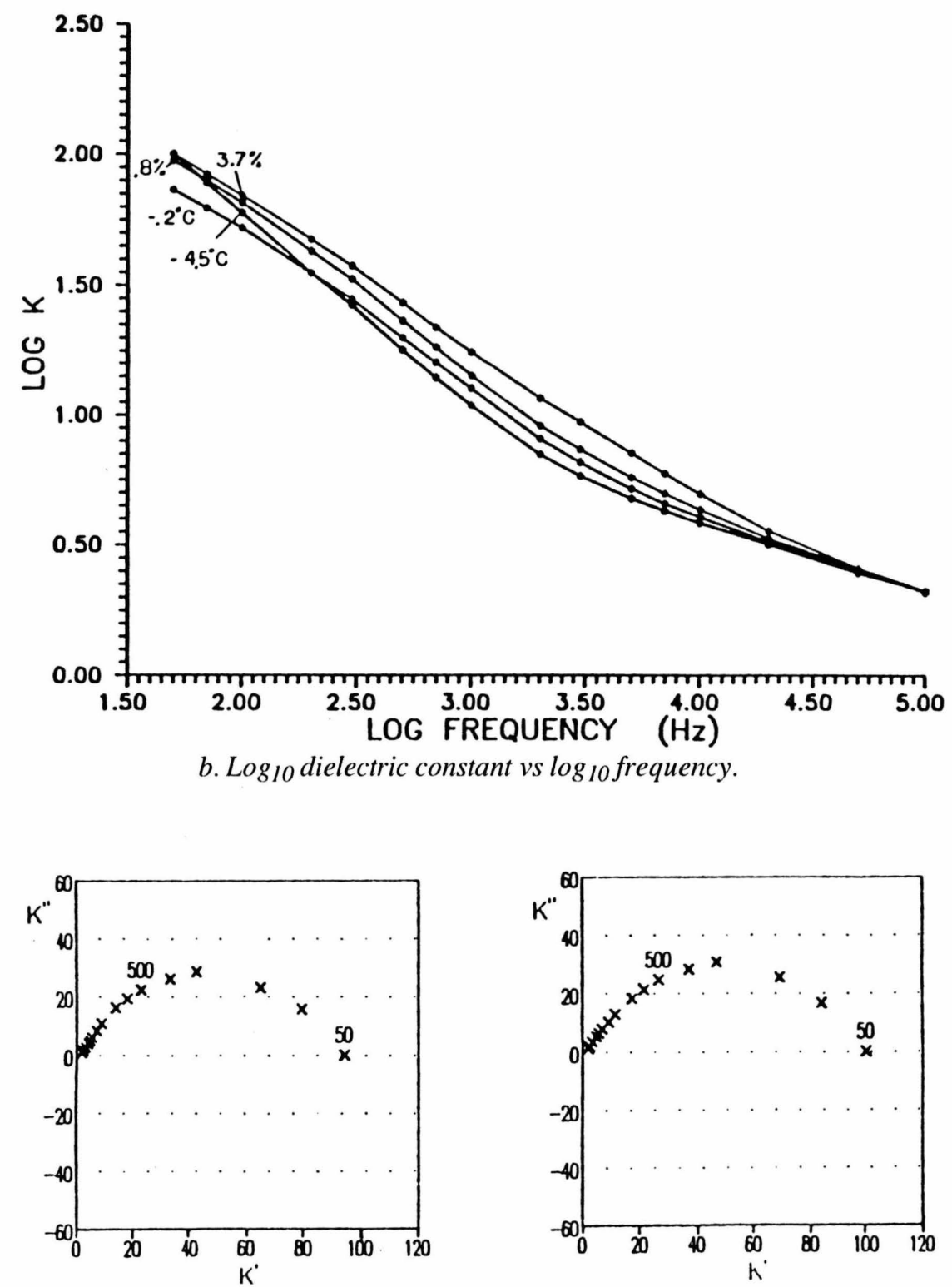

e. Cole plots, $0.8 \%$ water.

Figure 19. Dielectric spectra for sample 10 for indicated water contents (or temperatures). 


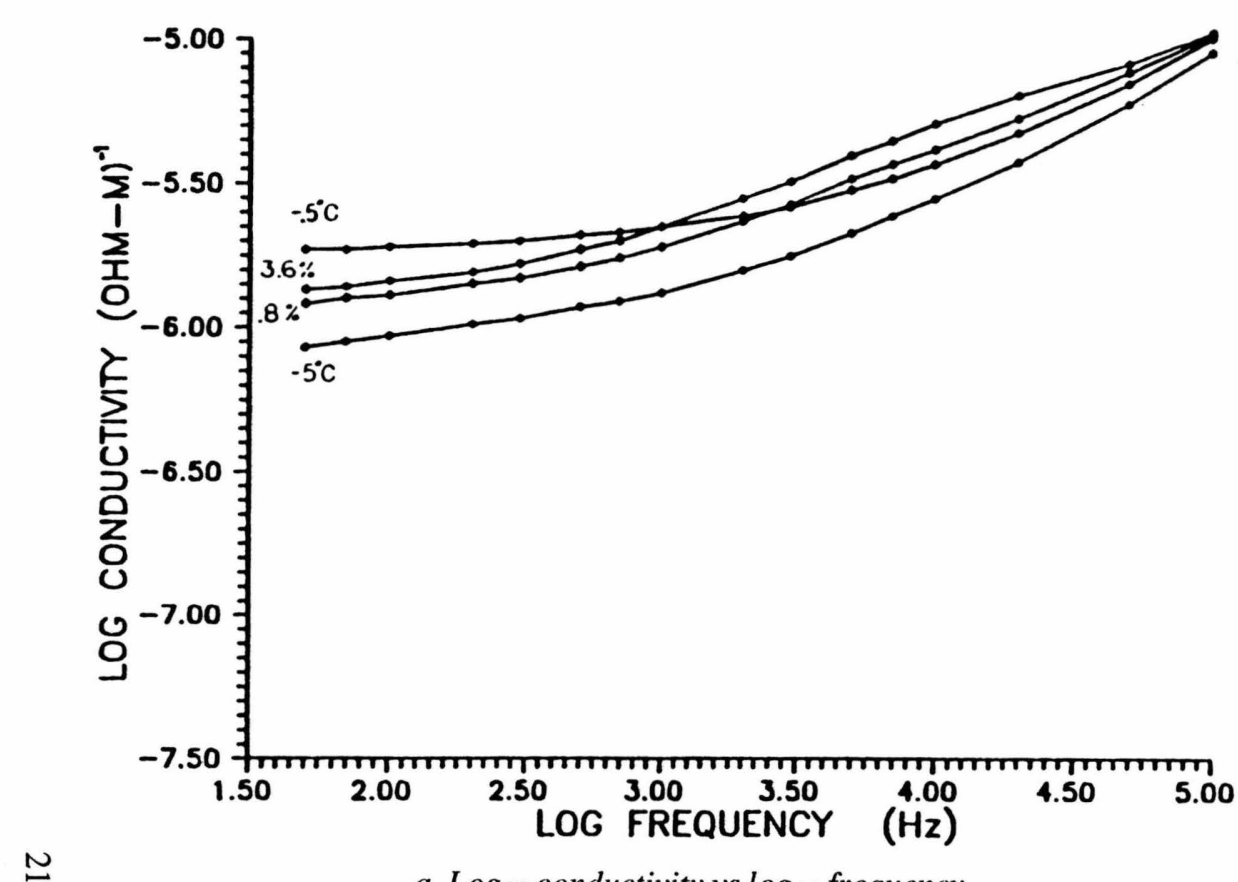

$\stackrel{N}{\simeq}$

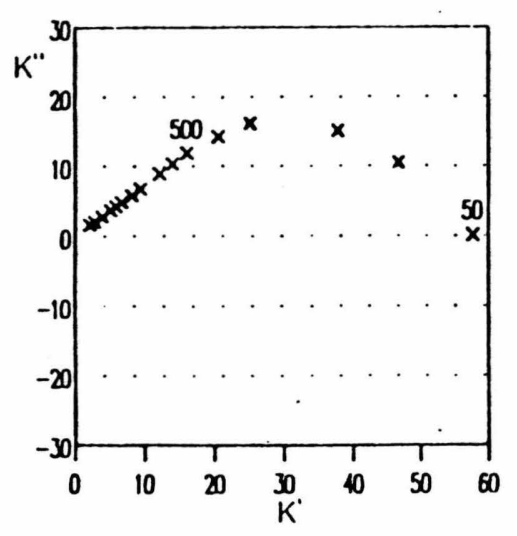

c. Cole plots, $-5^{\circ} \mathrm{C}$.

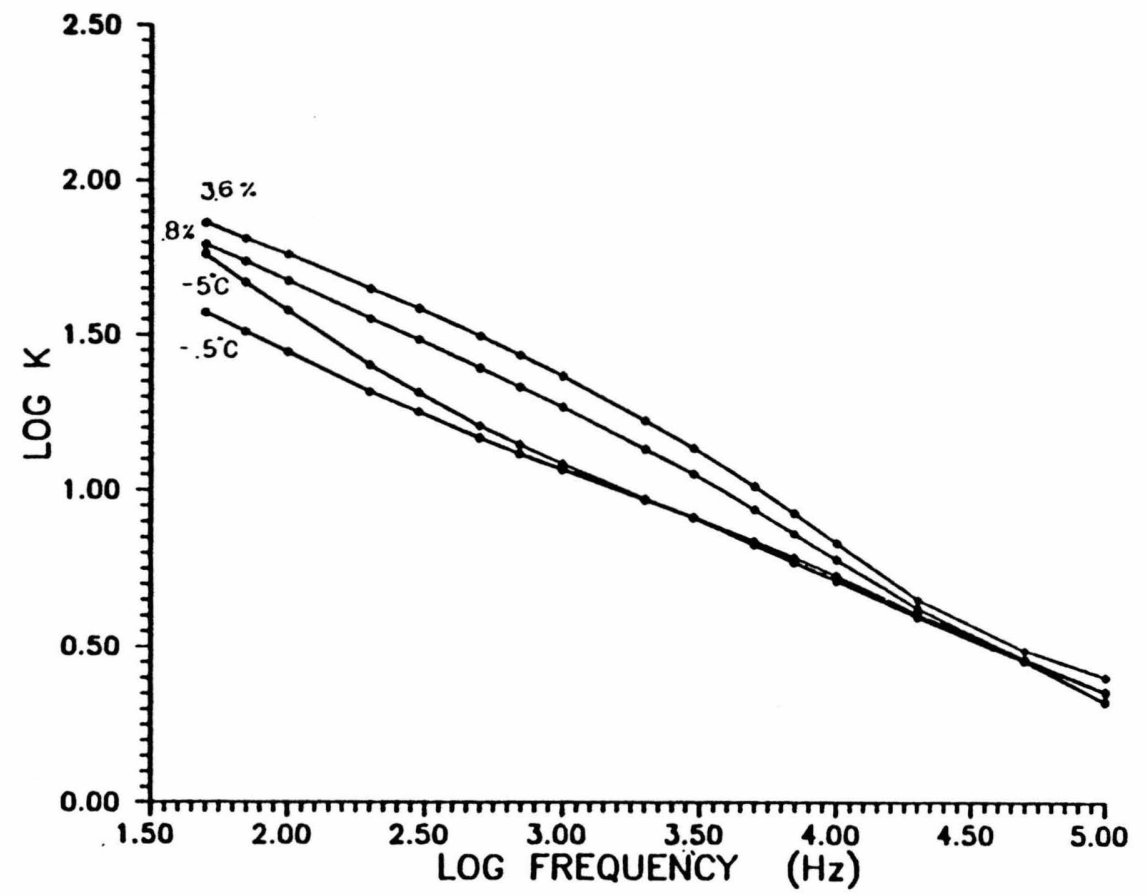

b. $\log _{10}$ dielectric constant vs $\log _{10}$ frequency.

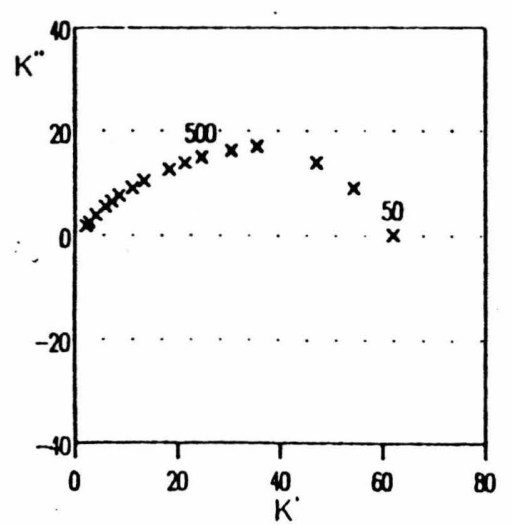

e. Cole plots, $0.8 \%$ water.

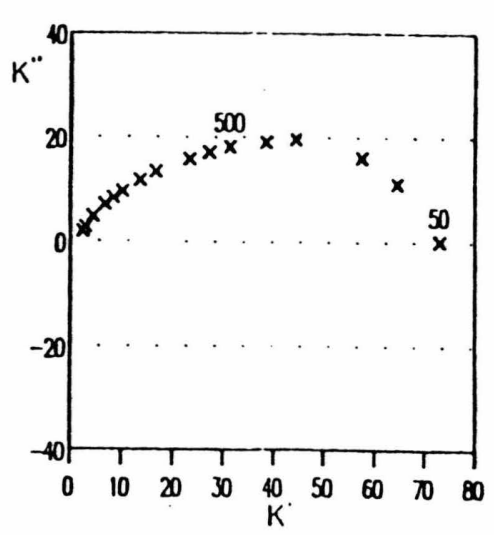

f. Cole plots, $3.6 \%$ water.

Figure 20. Dielectric spectra for sample 16 for indicated water contents (or temperatures). 


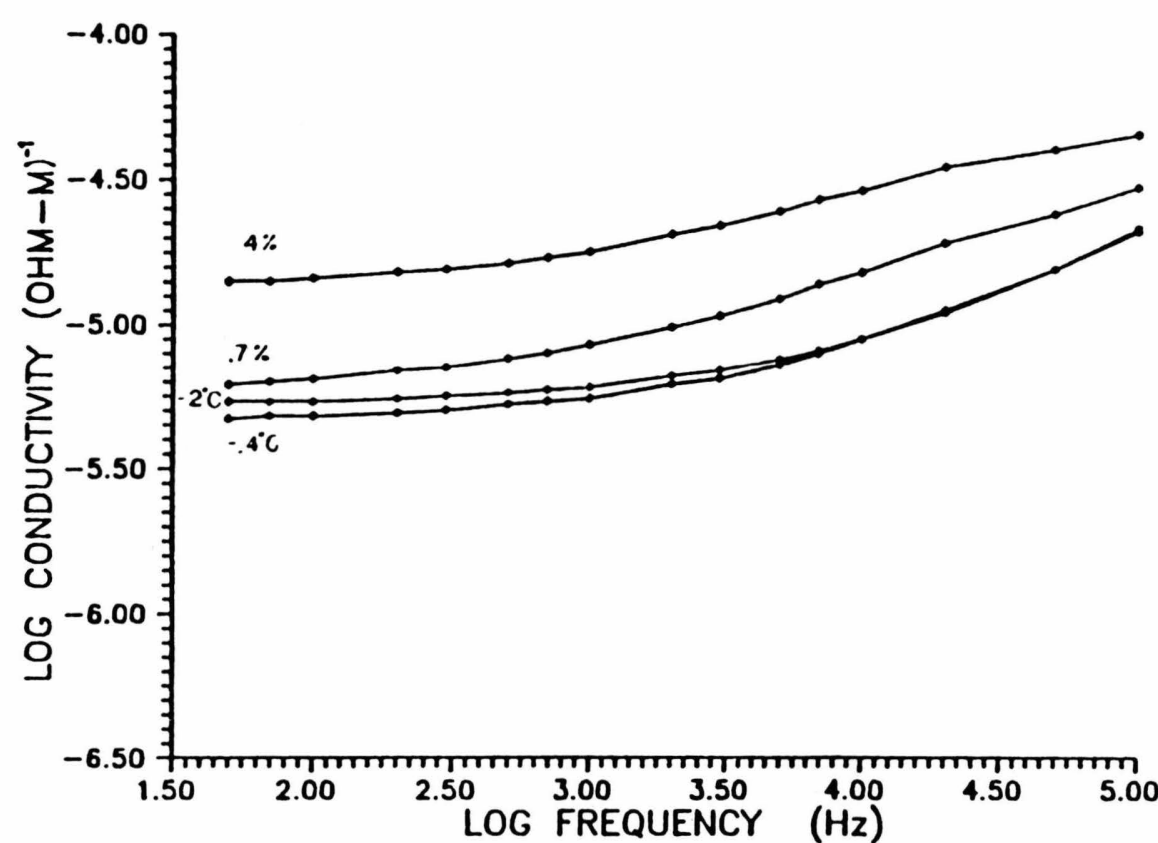

a. $\log _{10}$ conductivity vs $\log _{10}$ frequency.

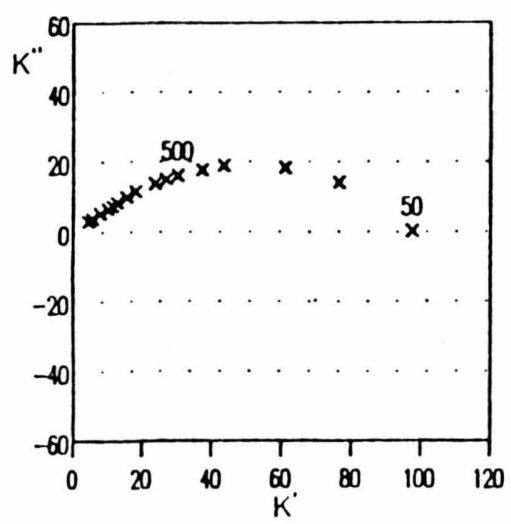

c. Cole plots, $-2^{\circ} \mathrm{C}$.

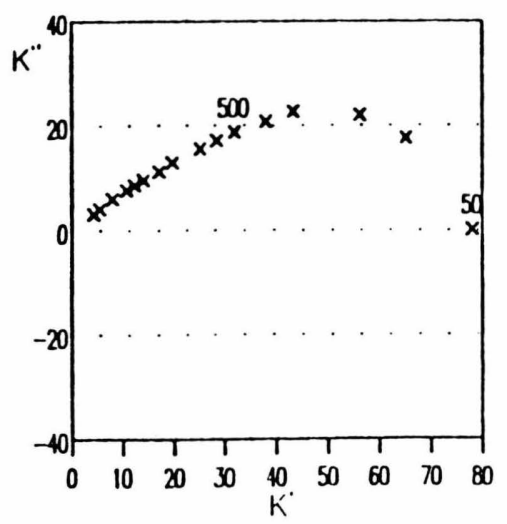

d. Cole plots, $-0.4^{\circ} \mathrm{C}$.

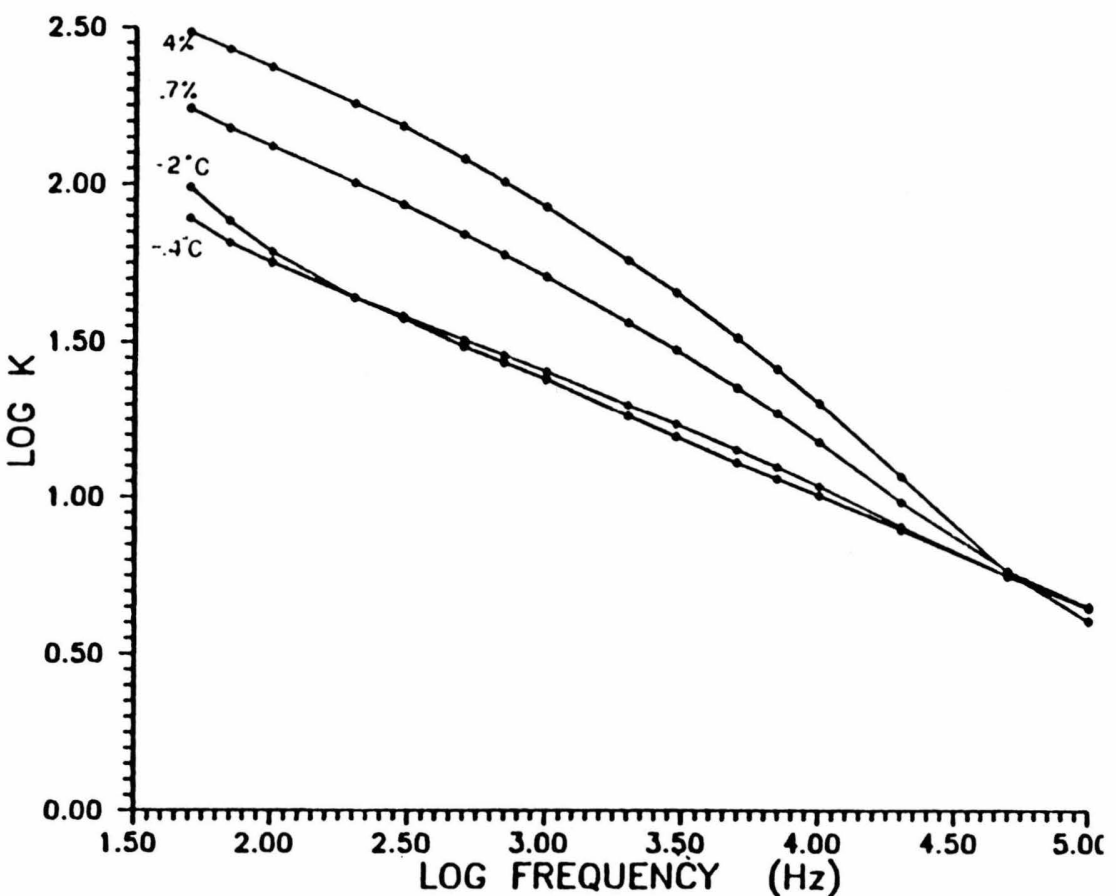

b. $\log _{10}$ dielectric constant vs $\log _{10}$ frequency.
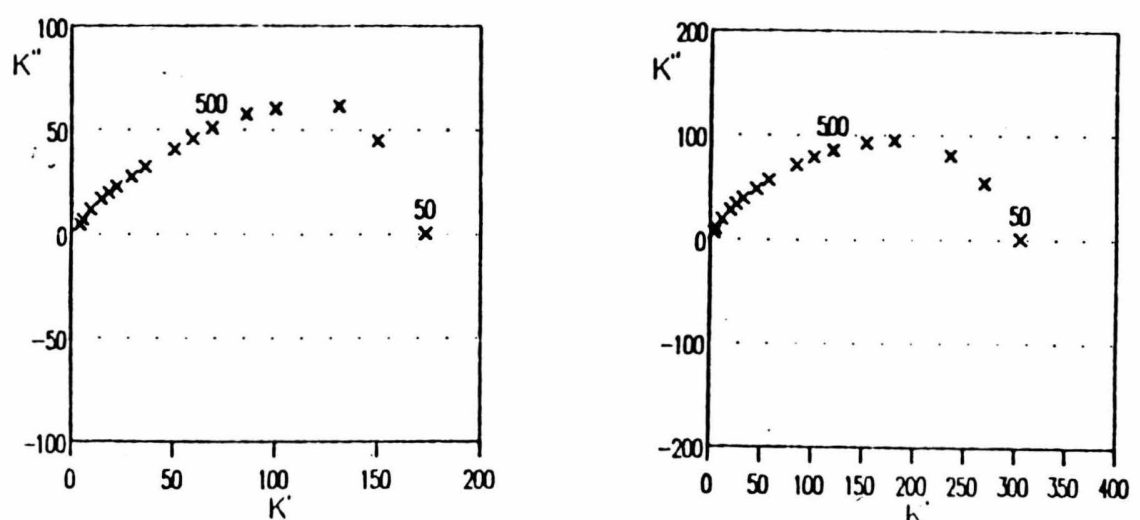

e. Cole plots, $0.7 \%$ water.

f. Cole plots, $4.0 \%$ water.

Figure 21. Dielectric spectra for sample 12 for indicated water contents (or temperatures). 

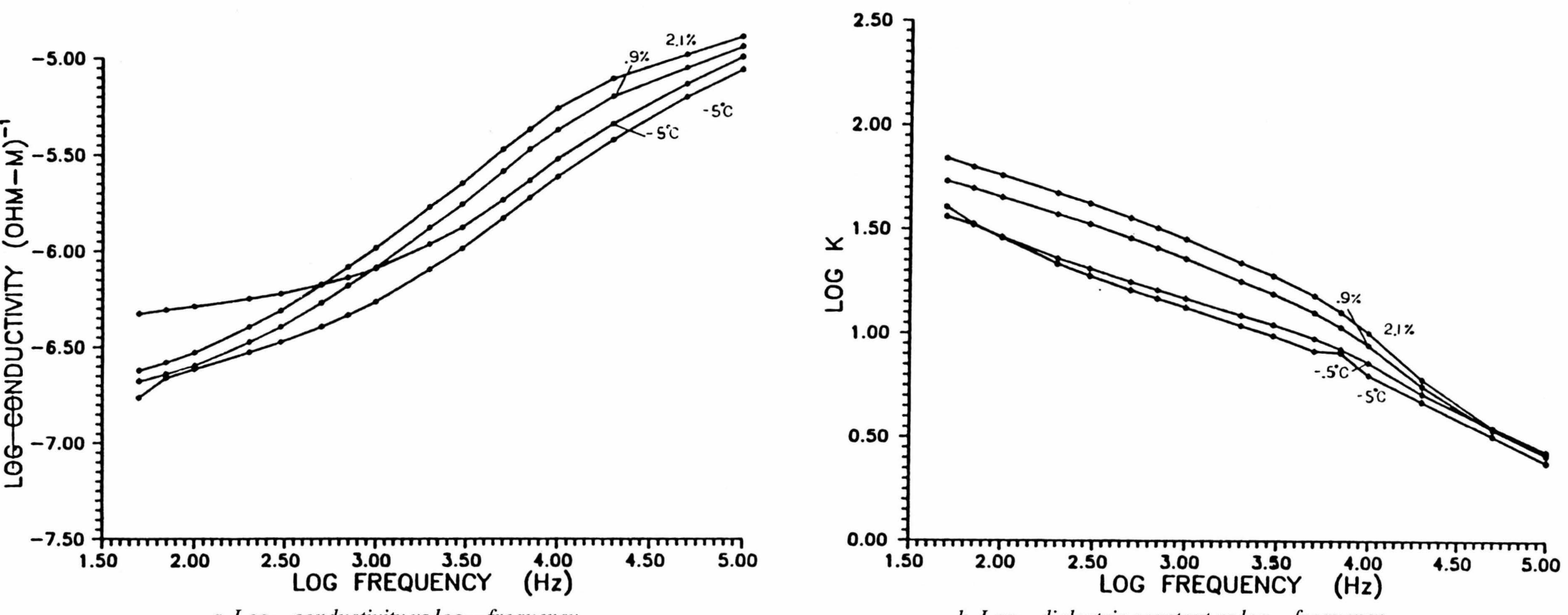

a. $\log _{10}$ conductivity vs $\log _{10}$ frequency.

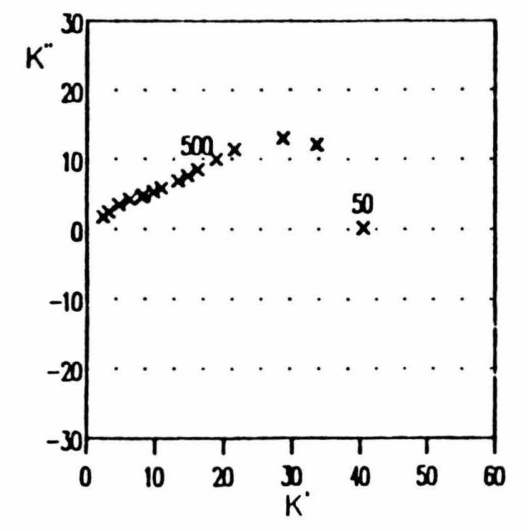

c. Cole plots, $-5^{\circ} \mathrm{C}$.

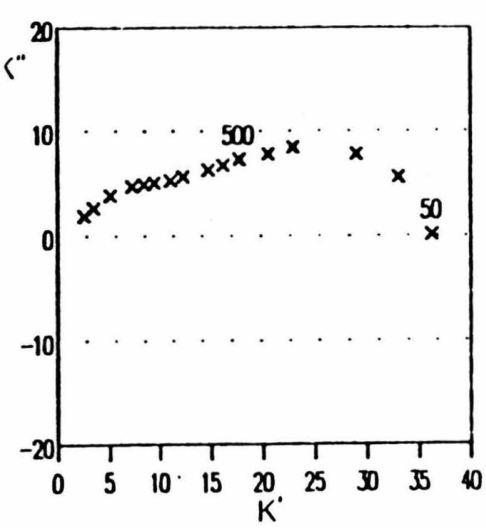

d. Cole plots, $-0.5^{\circ} \mathrm{C}$.

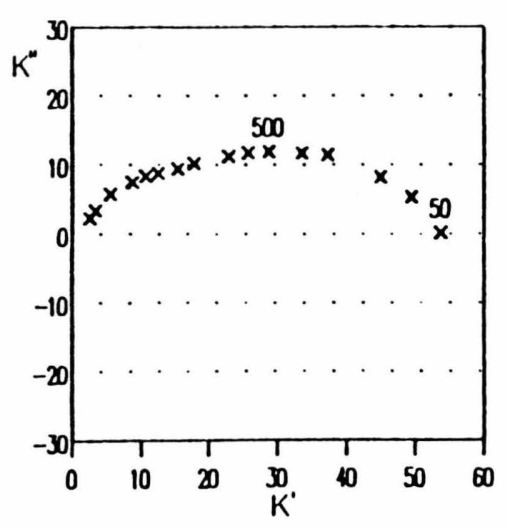

e. Cole plots, $0.9 \%$ water.

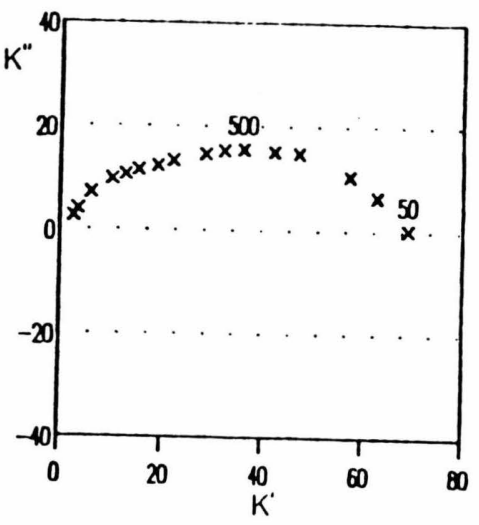

f. Cole plots, $2.1 \%$ water.

Figure 22. Dielectric spectra for sample 14 for indicated water contents (or temperatures). 


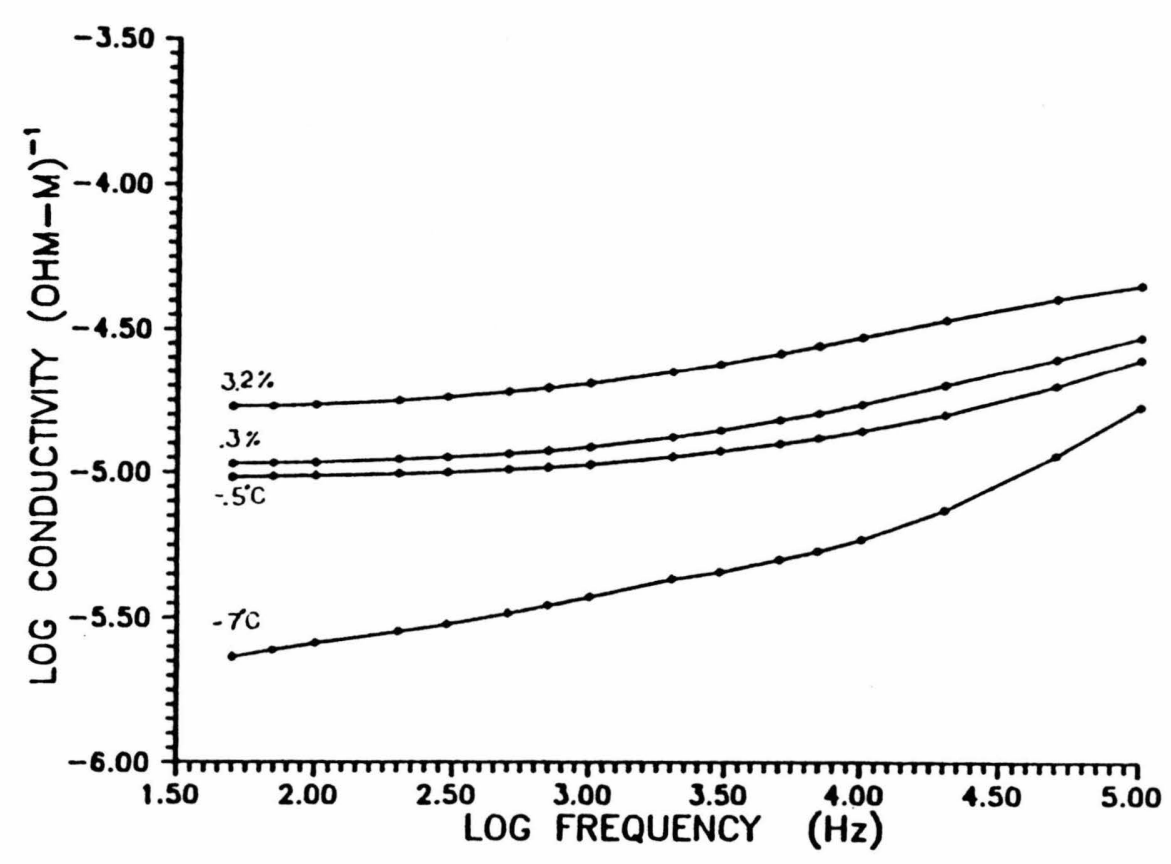

a. $\log _{10}$ conductivity vs $\log _{10}$ frequency.

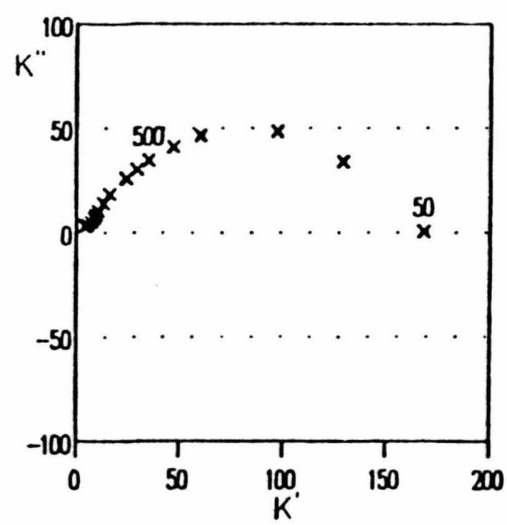

c. Cole plots, $-7^{\circ} \mathrm{C}$.

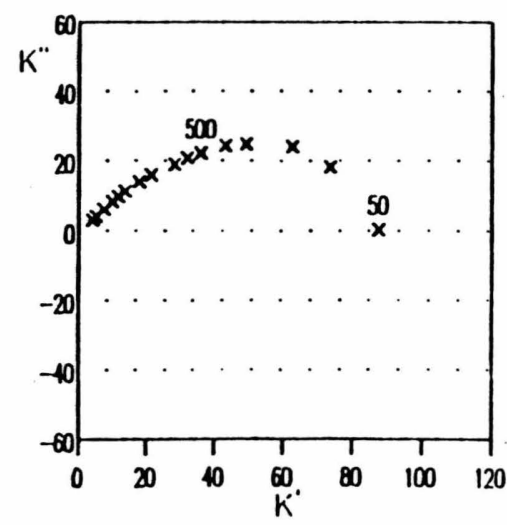

d. Cole plots, $-0.3^{\circ} \mathrm{C}$.

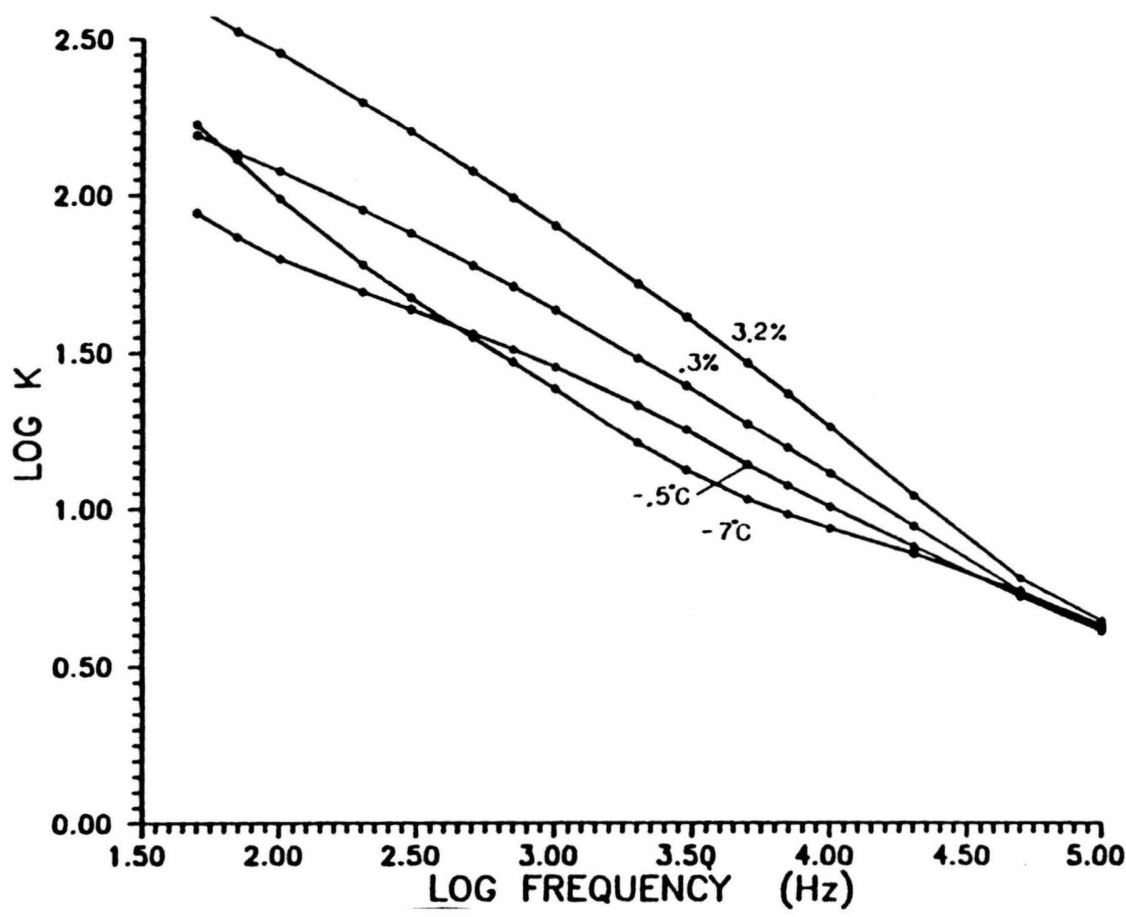

b. Log $_{10}$ dielectric constant vs $\log _{10}$ frequency.
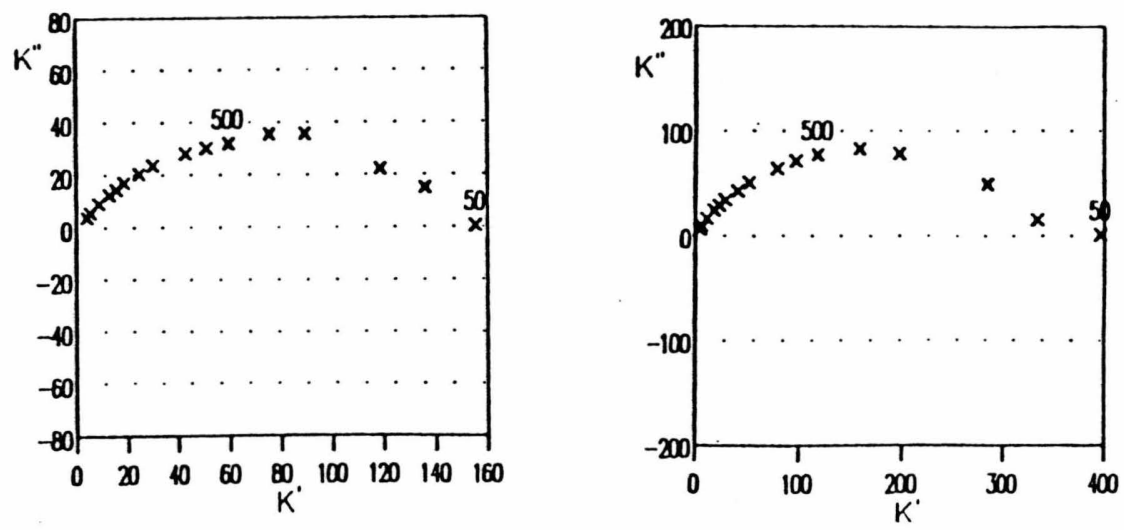

e. Cole plots, $0.3 \%$ water.

f. Cole plots, $3.2 \%$ water.

Figure 23. Dielectric spectra for sample 15 for indicated water contents (or temperatures). 


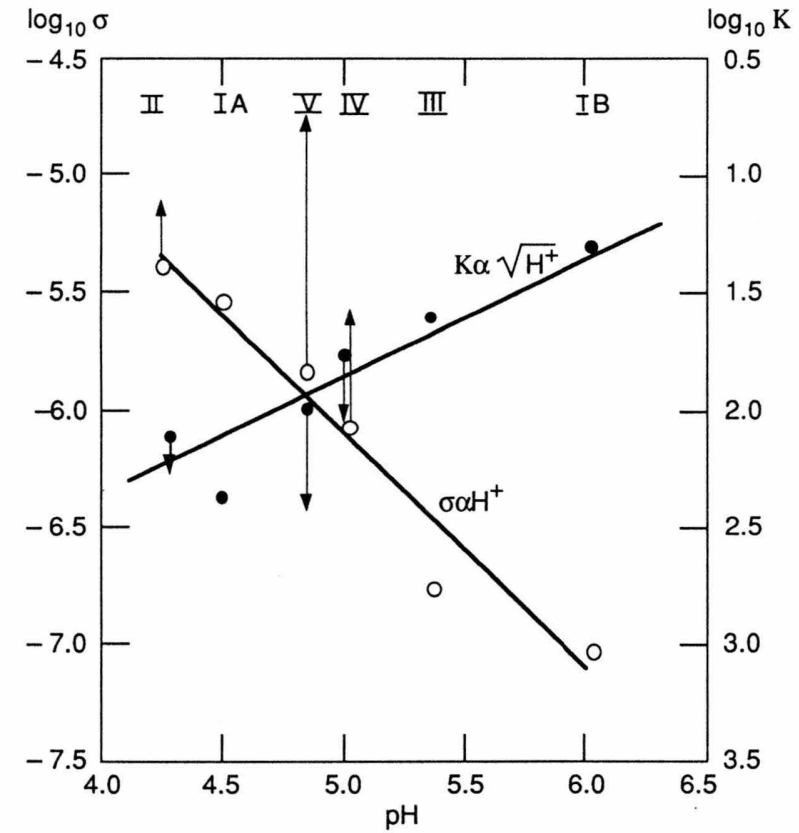

Figure 24. $\log _{10}$ low-frequency conductivity (left-hand scale) and $\log _{10}$ low-frequency dielectric constant (righthand scale) for various snows $v s \mathrm{pH}$ of the meltwater.

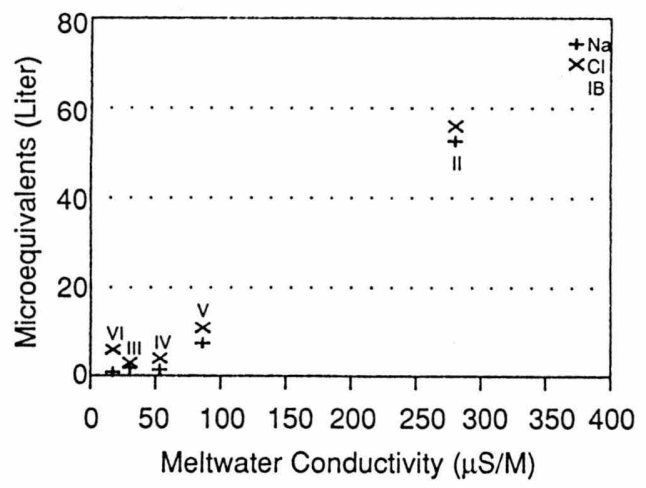

Figure 25. Concentrations of sodium and chloride ions vs conductivity $(1 \mathrm{kHz})$ of the meltwater for various snows.

These data have been corrected for temperature. To correct for density is more tenuous because, as will be seen, our density effect measurements gave rather ragged curves and were all made at $-9^{\circ} \mathrm{C}$. When we do attempt to correct for density, the points are moved as indicated by the arrows. Except for snow V, the general tendencies remain. But the effect on snow V is catastrophic. Possibly grain size plays a role here because samples IV and V, for which the correction is largest, are the samples with the finest grains. Exploring the questions raised by Figure 24 may be a fruitful area for future research.

The relationship between low-frequency conductance of the snow and the hydrogen ion concentration helps to explain the great difference between snow IA

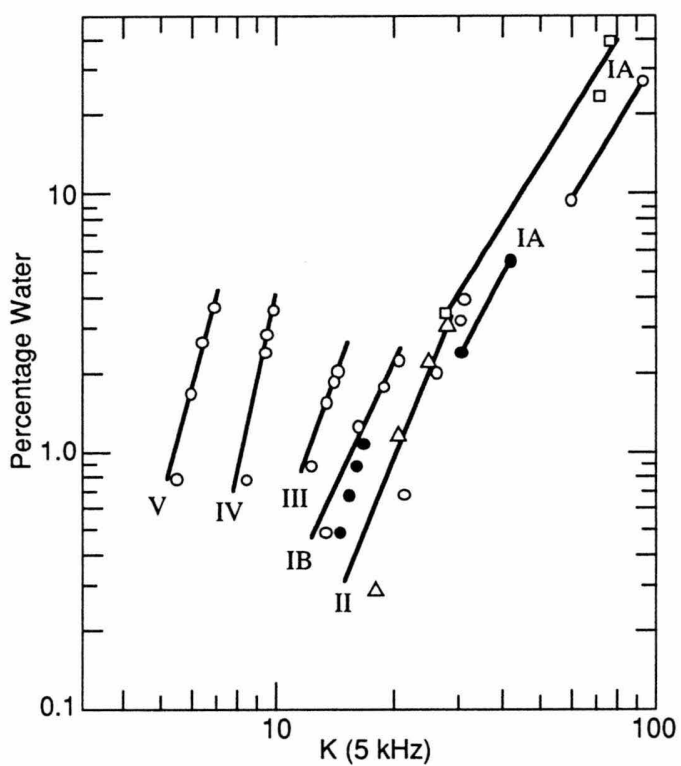

Figure 26. $\log _{10}$ percent water vs $\log _{10}$ dielectric constant at $5 \mathrm{kHz}$ for the snows indicated by Roman numerals.

(Fig. 14-16) and snow IB (Fig. 17, 18). The very low, low-frequency conduction of the latter exposes structure in the $\log \sigma$ vs $\log _{10}$ frequency curve, which is obscured by the high low-frequency conduction of sample IA. The conductivity of the melt is dominated by the ions of $\mathrm{NaCl}$ except at its lowest concentrations where the $\mathrm{H}^{+}$ion may play a role. This can be seen in Table 1 and Figure 25.

The water-content experiments all produced ordered sets of data. Even experiments on different samples of the same snow gave results that fit together rather well. In all, both the conductivity and dielectric constant increased as water content increased. Thus it is tempting to take vertical cuts of these data to see if, at a single frequency, a relation can be found between either parameter and the water content. Figure 26 is such a cut. It shows the variation with water content of the dielectric constant at $5 \mathrm{kHz}$ on a log-log plot. For a given snow, the data fall in a well-ordered sequence on a straight line. Where we report data on more than one sample of the same snow, different symbols are used for each sample but the points fall on nearly the same lines. This consistency builds confidence in our techniques. However, no two different snows lie on the same line. We have found no slice of this kind that appears to be useful for determining water content. Although there is an easily measurable variation of both the dielectric constant and conductivity spectra with water content, no relation has been found that works well with all snows. There appear to be too many variables to sort out.

We have tried several strategies to discover a way to 
Table 3. Polynomial fit to data for samples 10-16.

\begin{tabular}{|c|c|c|c|c|c|c|c|c|c|}
\hline \multirow{2}{*}{$\begin{array}{l}\text { Experiment } \\
\text { number }\end{array}$} & \multirow{2}{*}{$\begin{array}{l}\text { Snow } \\
\text { number }\end{array}$} & \multirow{2}{*}{$\begin{array}{c}\text { Meltwater } \\
(\sigma)\end{array}$} & \multirow{2}{*}{$\begin{array}{l}\text { Melt } \\
(p H)\end{array}$} & \multirow{2}{*}{$\begin{array}{r}\text { Density } \\
(\mathrm{g} / \mathrm{mL})\end{array}$} & \multirow{2}{*}{$\begin{array}{l}\text { Temp }(T) \\
\text { or \% } \mathrm{H}_{2} \mathrm{O}\end{array}$} & \multicolumn{3}{|c|}{$\begin{array}{c}\text { Polynomial fit } \\
A F^{-0.5}+B F^{0}+C F^{0.5}\end{array}$} & \multirow{2}{*}{$\begin{array}{c}\text { Average } \\
\text { percent } \\
\text { relative error }\end{array}$} \\
\hline & & & & & & $A$ & $B$ & $C$ & \\
\hline 10 & V & 68 & 4.8 & 0.182 & $T=-4.5$ & 674.07 & -7.585 & 0.0315 & 13.8 \\
\hline 10 & V & 68 & 4.8 & 0.182 & $T=-2$ & 532.39 & -3.651 & 0.0170 & 1.8 \\
\hline 10 & V & 68 & 4.8 & & 0.8 & 675.41 & -5.683 & 0.0234 & 4.2 \\
\hline 10 & V & 68 & 4.8 & & 1.7 & 609.69 & -3.725 & 0.0161 & 1.0 \\
\hline 10 & V & 68 & 4.8 & & 2.7 & 640.11 & -3.756 & 0.0157 & 0.7 \\
\hline 10 & V & 68 & 4.8 & & 3.7 & 718.70 & -4.366 & 0.0167 & 2.2 \\
\hline 11 & IV & 42 & 5 & 0.265 & $T=-5$ & 370.94 & 1.292 & -0.0005 & 5.2 \\
\hline 11 & IV & 42 & 5 & 0.265 & $T=-5$ & 234.33 & 4.388 & -0.0115 & 0.2 \\
\hline 11 & IV & 42 & 5 & & 0.8 & 443.06 & 3.377 & -0.0111 & 3.9 \\
\hline 11 & IV & 42 & 5 & & 2.5 & 512.71 & 3.279 & -0.0114 & 5.6 \\
\hline 11 & IV & 42 & 5 & & 2.9 & 511.56 & 3.849 & -0.0151 & 6.1 \\
\hline 11 & IV & 42 & 5 & & 3.6 & 542.40 & 3.970 & -0.0149 & 6.1 \\
\hline 12 & II & 220 & 4.27 & 0.36 & $T=-2$ & 634.04 & 4.019 & -0.0055 & 2.8 \\
\hline 12 & II & 220 & 4.27 & 0.36 & $T=-4$ & 508.96 & 8.705 & -0.0241 & 1.8 \\
\hline 12 & II & 220 & 4.27 & & 0.7 & 1263.95 & 7.472 & -0.0327 & 4.6 \\
\hline 12 & II & 220 & 4.27 & & 2.1 & 1743.51 & 6.002 & -0.0348 & 6.0 \\
\hline 12 & II & 220 & 4.27 & & 3.3 & 2269.86 & 2.865 & -0.0302 & 6.3 \\
\hline 12 & II & 220 & 4.27 & & 4.0 & 2331.67 & 3.313 & -0.0359 & 6.1 \\
\hline 13 & $\mathrm{Ib}$ & 294 & 6.05 & 0.423 & $T=-3.5$ & 83.21 & 10.048 & -0.0239 & 1.3 \\
\hline 13 & $\mathrm{Ib}$ & 294 & 6.05 & 0.423 & $T=-25$ & 93.32 & 11.561 & -0.0298 & 0.6 \\
\hline 13 & $\mathrm{Ib}$ & 294 & 6.05 & & 0.5 & 48.83 & 16.842 & -0.0505 & 2.1 \\
\hline 13 & $\mathrm{Ib}$ & 294 & 6.05 & & 1.3 & 39.39 & 21.434 & -0.0691 & 1.5 \\
\hline 13 & $\mathrm{Ib}$ & 294 & 6.05 & & 1.8 & 45.76 & 25.563 & -0.0856 & 1.3 \\
\hline 13 & $\mathrm{Ib}$ & 294 & 6.05 & & 2.3 & 40.62 & 28.591 & -0.0985 & 1.2 \\
\hline 14 & III & 24 & 5.36 & 0.391 & $T=-5$ & 240.13 & 6.089 & -0.0178 & 0.8 \\
\hline 14 & III & 24 & 5.36 & 0.391 & $T=-5$ & 207.33 & 8.457 & -0.0263 & 1.9 \\
\hline 14 & III & 24 & 5.36 & & 0.9 & 355.49 & 10.704 & -0.0397 & 6.6 \\
\hline 14 & III & 24 & 5.36 & & 1.6 & 423.59 & 11.452 & -0.0440 & 6.6 \\
\hline 14 & III & 24 & 5.36 & & 1.9 & 457.73 & 11.788 & -0.0461 & 6.7 \\
\hline 14 & III & 24 & 5.36 & & 2.1 & 464.52 & 12.482 & -0.0493 & 6.5 \\
\hline 15 & II & 220 & 4.27 & 0.372 & $T=-7$ & 1134.67 & -9.124 & 0.0424 & 9.5 \\
\hline 15 & II & 220 & 4.27 & 0.372 & $T=-5$ & 613.35 & 6.700 & -0.0188 & 3.8 \\
\hline 15 & II & 220 & 4.27 & & 0.3 & 1141.45 & 4.213 & -0.0172 & 4.2 \\
\hline 15 & II & 220 & 4.27 & & 1.2 & 1563.68 & -0.001 & -0.0059 & 3.2 \\
\hline 15 & II & 220 & 4.27 & & 2.3 & 2309.29 & -7.400 & 0.0134 & 2.7 \\
\hline 15 & II & 220 & 4.27 & & 3.2 & 2933.29 & -14.816 & 0.0344 & 0.4 \\
\hline 16 & Ib & 294 & 6.05 & 0.422 & $T=-8.5$ & 19.59 & 10.429 & -0.0239 & 3.1 \\
\hline 16 & $\mathrm{Ib}$ & 294 & 6.05 & 0.422 & $T=-5$ & 86.51 & 12.178 & -0.0309 & 0.9 \\
\hline 16 & $\mathrm{Ib}$ & 294 & 6.05 & & 0.5 & 32.84 & 18.490 & -0.0556 & 2.1 \\
\hline 16 & Ib & 294 & 6.05 & & 0.7 & 31.82 & 19.470 & -0.0592 & 2.2 \\
\hline 16 & Ib & 294 & 6.05 & & 0.9 & 29.27 & 20.694 & -0.0641 & 2.2 \\
\hline 16 & $\mathrm{Ib}$ & 294 & 6.05 & & 1.1 & 25.21 & 22.366 & -0.0708 & 2.6 \\
\hline
\end{tabular}

use our data to determine water content of snow. Despite clear trends of the dielectric data with water content, they are not free enough from variations due to other parameters to allow us to work backward from dielectric measurements to water content. One scheme was to fit our dielectric constant data with a polynomial of as low an order as we could in the hope that the coefficients would serve to catalog our samples. If there were orderly variations in these that could be related to water content, then we might have a useful tool. We found that we could fit all of our data for samples 10-16 using an equation, $A f^{-0.5}+B+C f^{0.5}$, where $f$ is the frequency in hertz and $A, B$ and $C$ are the parameters (see Table 3 ). We could fit the data for samples 1, 2 and 3 with an equation $A f^{-1}+B f^{-0.5}+C$. However, we were unable to find a three-parameter polynomial form which would fit all of our data. Note that the snow used in samples 1,2 and 3 was of type IA, having very large grains and large conductivity.

Another approach was to use the data describing the form of the various Cole plots, that is, the center frequencies of the major groups of dispersions, the strengths of these groups as indicated by the diameters of the Cole circles, and the distance below $K^{\prime \prime}=0$ of the centers of 
Table 4. Cole plot parameters for the various samples.

\begin{tabular}{|c|c|c|c|c|c|c|c|c|c|c|}
\hline \multirow[b]{2}{*}{$\begin{array}{c}\text { Sample } \\
\text { no. }\end{array}$} & \multirow[b]{2}{*}{$\begin{array}{l}\text { Snow } \\
\text { type }\end{array}$} & \multirow[b]{2}{*}{$\begin{array}{c}\text { Condition } \\
(\text { ohm-m) }\end{array}$} & \multirow[b]{2}{*}{$p H$} & \multirow[b]{2}{*}{$\begin{array}{l}\text { Temp. } \\
\text { or } \% W\end{array}$} & \multicolumn{3}{|c|}{ Low dispersion } & \multicolumn{3}{|c|}{ High dispersion } \\
\hline & & & & & $\begin{array}{c}f \\
H z\end{array}$ & $\begin{array}{c}S \\
p F\end{array}$ & $\begin{array}{c}H \\
p F\end{array}$ & $\begin{array}{c}f \\
H z\end{array}$ & $\begin{array}{c}S \\
p F\end{array}$ & $\begin{array}{c}H \\
p F \\
\end{array}$ \\
\hline 1 & Ia & $1.69 \mathrm{E}-03$ & 4.4 & $T=-6$ & 60 & 160 & 40 & 150 & 220 & 15 \\
\hline 1 & Ia & $1.69 \mathrm{E}-03$ & 4.4 & 3.5 & 100 & 1200 & 520 & 500 & 420 & 110 \\
\hline 1 & Ia & $1.69 \mathrm{E}-03$ & 4.4 & 24.0 & 70 & 3600 & 1000 & 200 & 3600 & 700 \\
\hline 1 & Ia & $1.69 \mathrm{E}-03$ & 4.4 & 38.0 & 110 & 4600 & 350 & & & \\
\hline 2 & Ia & $1.69 \mathrm{E}-03$ & 4.4 & $T=-4.5$ & 100 & 230 & 25 & & & \\
\hline 2 & Ia & $1.69 \mathrm{E}-03$ & 4.4 & 9.7 & 120 & 1600 & 400 & 1000 & 700 & 110 \\
\hline 2 & Ia & $1.69 \mathrm{E}-03$ & 4.4 & 28.6 & 200 & 4800 & 600 & & & \\
\hline 3 & Ia & $1.69 \mathrm{E}-03$ & 4.4 & $T=-4.5$ & 110 & 250 & 45 & & & \\
\hline 3 & Ia & $1.69 \mathrm{E}-03$ & 4.4 & $T=-0.2$ & 110 & 140 & 30 & & & \\
\hline 3 & Ia & $1.69 \mathrm{E}-03$ & 4.4 & 2.5 & 110 & 940 & 280 & & & \\
\hline 3 & Ia & $1.69 \mathrm{E}-03$ & 4.4 & 5.7 & 200 & 1120 & 310 & & & \\
\hline 10 & $\mathrm{~V}$ & $8.60 \mathrm{E}-04$ & 4.8 & $T=-4.5$ & 120 & 96 & 20 & & & \\
\hline 10 & $\mathrm{~V}$ & $8.60 \mathrm{E}-04$ & 4.8 & $T=-2$ & 160 & 70 & 8 & & & \\
\hline 10 & V & $8.60 \mathrm{E}-04$ & 4.8 & 0.8 & 170 & 96 & 22 & & & \\
\hline 10 & V & $8.6 \mathrm{OE}-04$ & 4.8 & 3.7 & 180 & 104 & 22 & & & \\
\hline 11 & IV & $5.30 \mathrm{E}-04$ & 5 & $T=-5$ & 150 & 780 & 14 & & & \\
\hline 11 & IV & $5.30 \mathrm{E}-04$ & 5 & $T=-0.6$ & 170 & 34 & 7 & & & \\
\hline 11 & IV & $5.30 \mathrm{E}-04$ & 5 & 0.8 & 200 & 56 & 12 & & & \\
\hline 11 & IV & $5.30 \mathrm{E}-04$ & 5 & 3.6 & 280 & 80 & 21 & & & \\
\hline 12 & II & $2.80 \mathrm{E}-03$ & 4.27 & $T=-2$ & 150 & 120 & 41 & & & \\
\hline 12 & II & $2.80 \mathrm{E}-03$ & 4.27 & $T=-4$ & 150 & 66 & 11 & & & \\
\hline 12 & II & $2.80 \mathrm{E}-03$ & 4.27 & 0.7 & 150 & 140 & 5 & & & \\
\hline 12 & II & $2.80 \mathrm{E}-03$ & 4.27 & 4.0 & 210 & 260 & 30 & & & \\
\hline 13 & Ib & $3.73 \mathrm{E}-03$ & 6.05 & $T=-3.5$ & 190 & 12 & 1 & 30000 & 8 & \\
\hline 13 & Ib & $3.73 \mathrm{E}-03$ & 6.05 & $T=-25$ & 200 & 16 & 3 & 30000 & 12 & 2 \\
\hline 13 & Ib & $3.73 \mathrm{E}-03$ & 6.05 & 0.5 & 250 & 12 & 2.5 & 20000 & 15 & 2 \\
\hline 13 & Ib & $3.73 E-03$ & 6.05 & 2.3 & 250 & 16 & 4 & 18000 & 26 & 3.5 \\
\hline 14 & III & $3.00 \mathrm{E}-04$ & 5.36 & $T=-5$ & 110 & 56 & 0 & 5000 & 22 & 6 \\
\hline 14 & III & $3.00 \mathrm{E}-04$ & 5.36 & $T=-0.5$ & 150 & 24 & 3 & 6000 & 15 & 2.5 \\
\hline 14 & III & $3.00 \mathrm{E}-04$ & 5.36 & 0.9 & 280 & 44 & 10 & 5000 & 24 & 4 \\
\hline 14 & III & $3.00 \mathrm{E}-04$ & 5.36 & 2.1 & 300 & 64 & 17 & 5000 & 28 & 4 \\
\hline 15 & II & $2.80 \mathrm{E}-03$ & 4.27 & $T=-7$ & 130 & 160 & 30 & & & \\
\hline 15 & II & $2.80 \mathrm{E}-03$ & 4.27 & $T=-0.5$ & 190 & 96 & 22 & & & \\
\hline 15 & II & $2.80 \mathrm{E}-03$ & 4.27 & 0.3 & 260 & 160 & 45 & & & \\
\hline 15 & II & $2.80 \mathrm{E}-03$ & 4.27 & 3.2 & 180 & 420 & 130 & & & \\
\hline 16 & Ib & $3.73 \mathrm{E}-03$ & 6.05 & $T=-8.5$ & 120 & 5 & 1 & 30000 & 8 & 1 \\
\hline 16 & Ib & $3.73 \mathrm{E}-03$ & 6.0 & $T=-0.5$ & 200 & 11 & 0 & 25000 & 12 & 2 \\
\hline 16 & Ib & $3.73 \mathrm{E}-03$ & 6.05 & 0.5 & 200 & 10 & 3 & 21000 & 16 & 3 \\
\hline 16 & $\mathrm{Ib}$ & $3.73 \mathrm{E}-03$ & 6.05 & 1.1 & 180 & 12 & 3 & 20000 & 16 & 2 \\
\hline
\end{tabular}

Notes:

$\mathrm{S}=$ Strength of the dispersion (diameter of Cole circle).

$\mathrm{H}=$ Displacement of the center of the circle below $K^{\prime \prime}=0$.

$\mathrm{f}=$ Frequency corresponding to center of circle.

these circles (which is an indication of the breadth of the distribution of the dispersions). In the case of two groups of dispersions, this would require a total of six parameters per sample. These data are given in Table 4. No strong dependence on water content is evident, although there does seem to be a clear tendency for the strength of the dispersions to increase with water content for those samples having no clear high-frequency dispersion. Again we find a profound difference between snow IA and all of the others.

\section{THE EFFECT OF DENSITY}

A series of experiments in which samples of dry snow at $-9^{\circ} \mathrm{C}$ were subjected to unconfined compression was undertaken to determine how sample density affected the dielectric properties. A guarded ring cell, one electrode of which was driven by a micrometer, was constructed of stainless steel (Fig. 27). The cell was placed on its side in an aluminum box which was loosely filled with snow. Bridge measurements were then made 


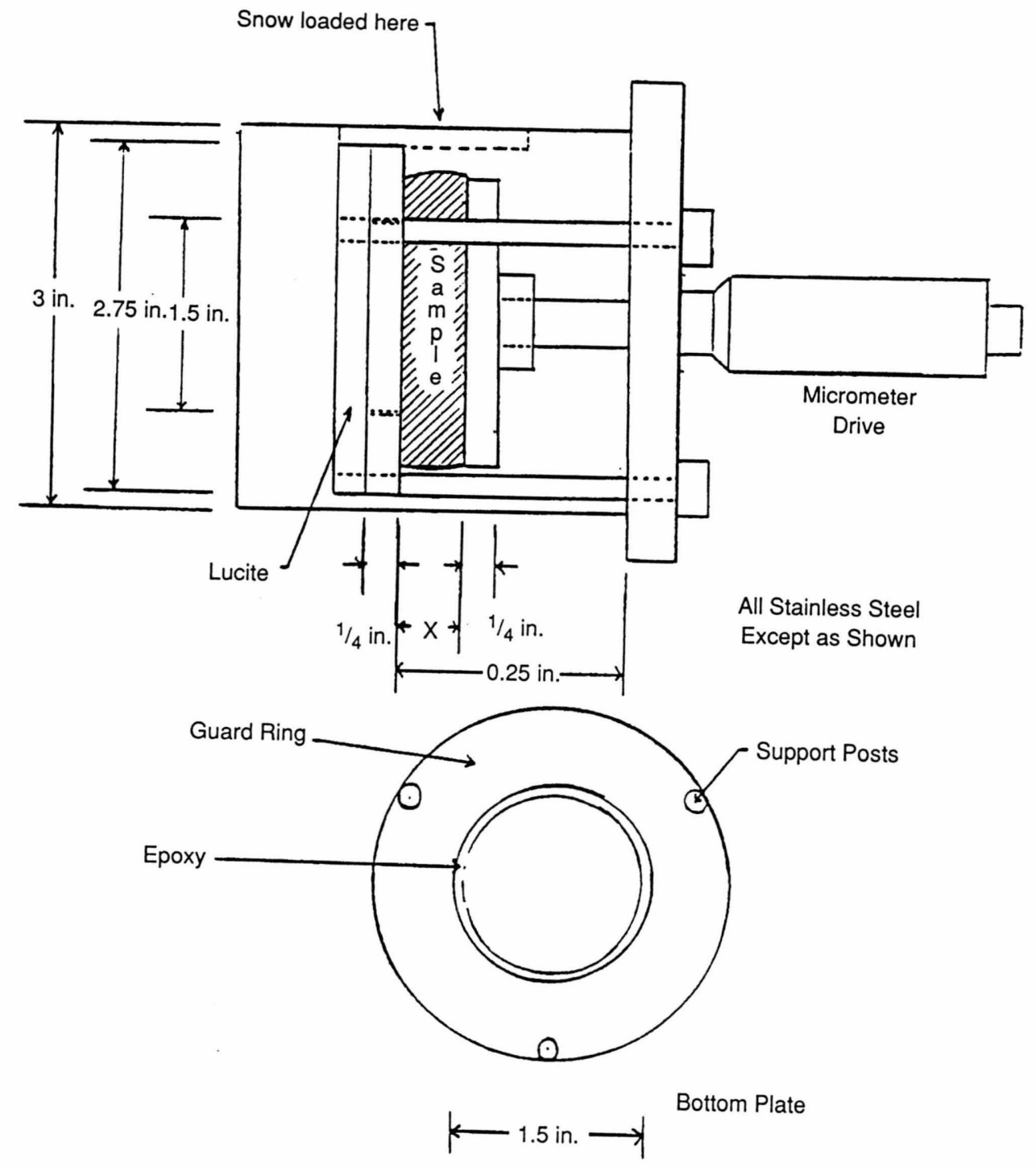

Figure 27. Micrometer cell used for variable density experiments.

Table 5. Cole plot parameters for the various samples, $-9^{\circ} \mathrm{C}$.

\begin{tabular}{cccccc} 
Sample & $\begin{array}{c}\text { Snow } \\
\text { type }\end{array}$ & $\begin{array}{c}\text { Freq } \\
(\mathrm{Hz})\end{array}$ & $\begin{array}{c}K \\
\text { ratio }\end{array}$ & $\begin{array}{c}\alpha \\
\text { ratio }\end{array}$ & $\begin{array}{c}\text { Density } \\
\text { ratio }\end{array}$ \\
\hline \multirow{2}{*}{9} & I & 50 & 2.8 & 5.0 & 1.4 \\
& & 500 & 2.6 & 4.6 & \\
& & $5 \mathrm{~K}$ & 2.3 & 4.6 & \\
& & $50 \mathrm{~K}$ & 1.2 & 2.6 & \\
8 & II & 50 & 1.4 & 13.5 & 1.8 \\
& & 500 & 1.6 & 11.2 & \\
& & $5 \mathrm{~K}$ & 1.4 & 8.5 & \\
& & $50 \mathrm{~K}$ & 1.02 & 4.9 & \\
5 & III & 50 & 7.9 & 27 & 2.4 \\
& & 500 & 6.4 & 17 & \\
& & $5 \mathrm{~K}$ & 3.0 & 10.8 & \\
& & $50 \mathrm{~K}$ & 1.4 & 4.8 & \\
& & & & &
\end{tabular}

\begin{tabular}{|c|c|c|c|c|c|}
\hline Sample & $\begin{array}{c}\text { Snow } \\
\text { type }\end{array}$ & $\begin{array}{l}\text { Freq } \\
(\mathrm{Hz})\end{array}$ & $\begin{array}{c}K \\
\text { ratio } \\
\end{array}$ & $\begin{array}{c}\alpha \\
\text { ratio }\end{array}$ & $\begin{array}{c}\text { Density } \\
\text { ratio } \\
\end{array}$ \\
\hline 6 & III & $\begin{array}{r}50 \\
500 \\
5 \mathrm{~K} \\
50 \mathrm{~K}\end{array}$ & $\begin{array}{l}4.5 \\
4.3 \\
2.6 \\
1.4\end{array}$ & $\begin{array}{r}22.4 \\
14.2 \\
8.5 \\
3.2\end{array}$ & 2.1 \\
\hline 7 & IV & $\begin{array}{r}50 \\
500 \\
5 \mathrm{~K} \\
50 \mathrm{~K}\end{array}$ & $\begin{array}{c}22 . \\
6 \\
9 \\
7\end{array}$ & $\begin{array}{c}157 \\
48 \\
24 \\
8.1\end{array}$ & 6.0 \\
\hline Average & for sam & $\begin{array}{c}\text { oles } 5 \text { th } \\
50 \\
500 \\
5 \mathrm{~K} \\
50 \mathrm{~K}\end{array}$ & $\begin{array}{l}\text { ugh } 9 \text { c } \\
4.2 \\
3.7 \\
2.3 \\
1.26 \\
\end{array}$ & $\begin{array}{c}\text { nitting } 7 \\
17 . \\
12 . \\
8.1 \\
3.9 \\
\end{array}$ & 1.93 \\
\hline
\end{tabular}


at $50 \mathrm{~Hz}, 500 \mathrm{~Hz}, 5 \mathrm{kHz}$ and $50 \mathrm{kHz}$. The micrometer was turned to somewhat compress the sample and a new frequency spectrum was run. This process was repeated several times to produce data over a range of densities. In all, samples of four different snows were run in this manner with two different samples of one snow. The

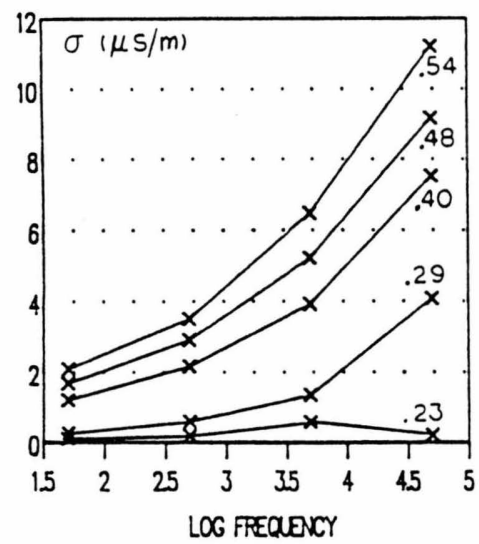

results are shown in Figures 28-36. Figures 28-32 show frequency spectra for conductivity and dielectric constant with density as a parameter. Both increase somewhat regularly with density in a manner roughly proportional to the initial magnitude. The scatter in the data from sample to sample is emphasized when the conduc-

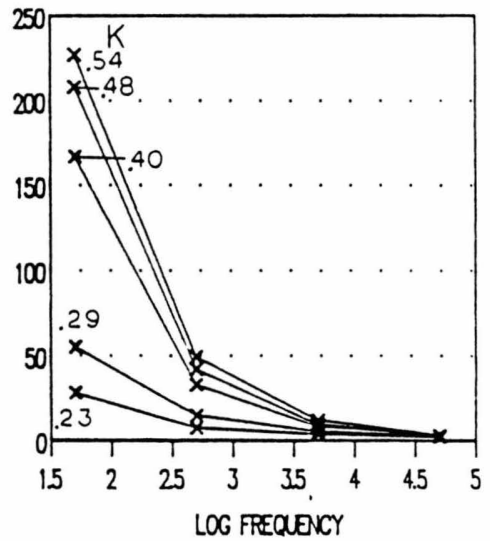

Figure 28. Conductivity, $\sigma$, and dielectric constant, $\mathrm{K}$, as functions of frequency for sample 5. Density in $\mathrm{g} / \mathrm{cm}^{3}$ is shown as a parameter.
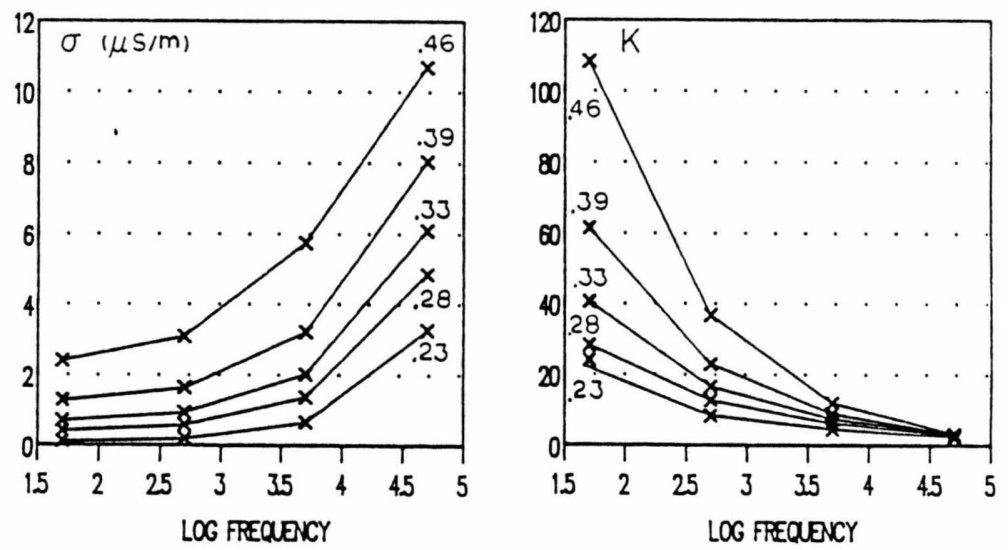

Figure 29. Conductivity and dielectric constant as functions of frequency for sample 6. Density in $\mathrm{g} / \mathrm{cm}^{3}$ is shown as a parameter.
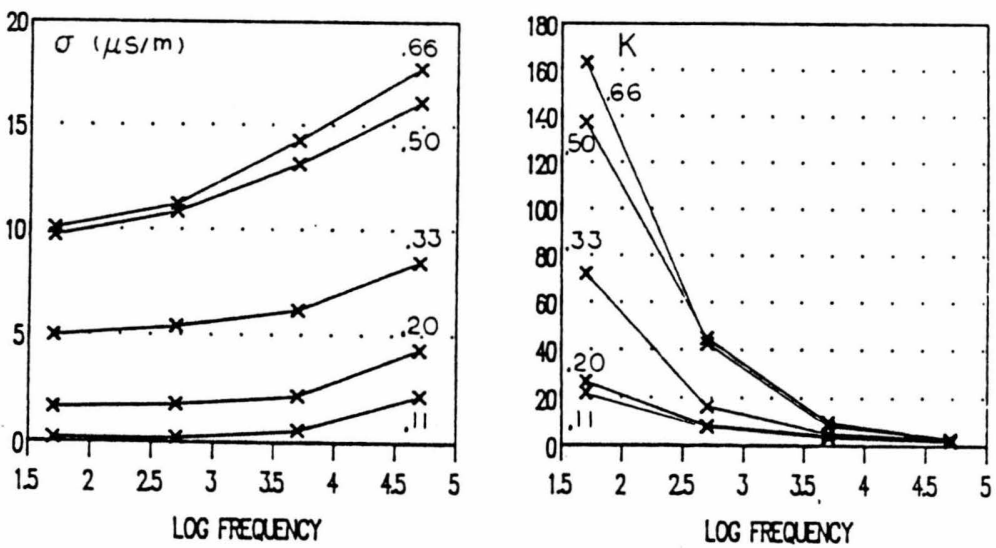

Figure 30. Conductivity and dielectric constant as functions of frequency for sample 7. Density in $\mathrm{g} / \mathrm{cm}^{3}$ is shown as a parameter. 

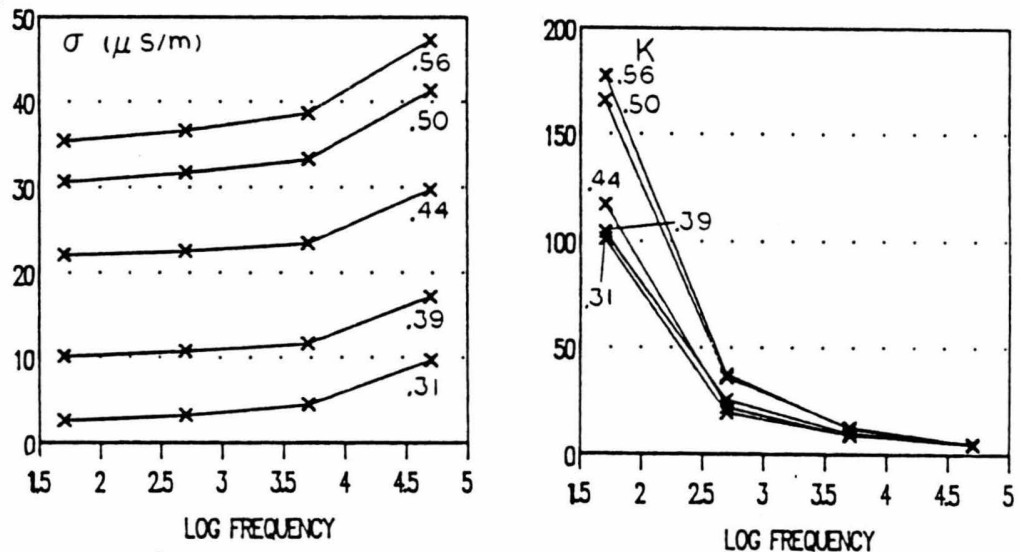

Figure 31. Conductivity and dielectric constant as functions of frequency for sample 8. Density in $\mathrm{g} / \mathrm{cm}^{3}$ is shown as a parameter.
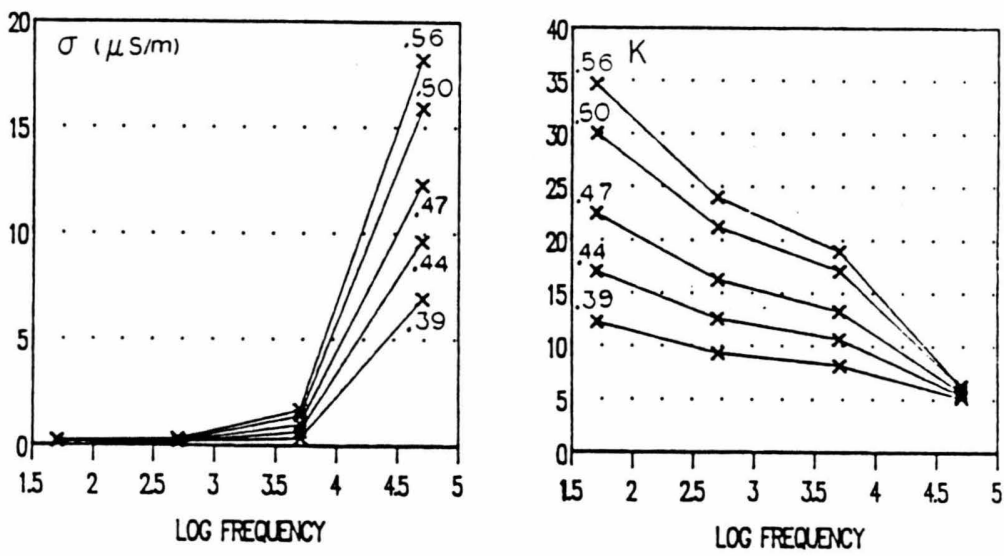

Figure 32. Conductivity and dielectric constant as functions of frequency for sample 9. Density in $\mathrm{g} / \mathrm{cm}^{3}$ is shown as a parameter.

tivity and dielectric constant are plotted against density for three given frequencies with the sample as a parameter (Figures 33-36). Sample 8 (snow IB) is clearly anomalous as is sample 9 (snow II) to a lesser extent. Each snow behaves in a fairly orderly way but each is somewhat unique. To illustrate this more fully, Table 5 gives the ratio of $K$ for maximum density to $K$ for minimum density and the same for conductivity. This shows

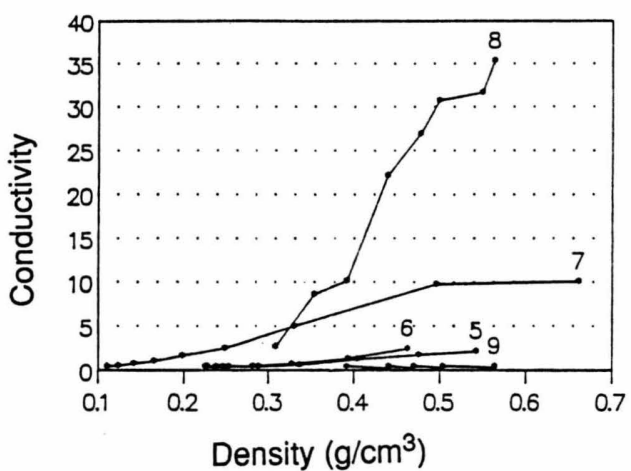

the trends and the variability. At the bottom of Table 5 is given the average for the first four samples, which have approximately the same density range. This gives an overall idea of how density differences among samples may affect their dielectric response.

Figure 37 is a plot of the difference between the conductivity at $50 \mathrm{kHz}$ and that at $50 \mathrm{~Hz}$ vs density for dry snow. This difference in conductivity is roughly pro-

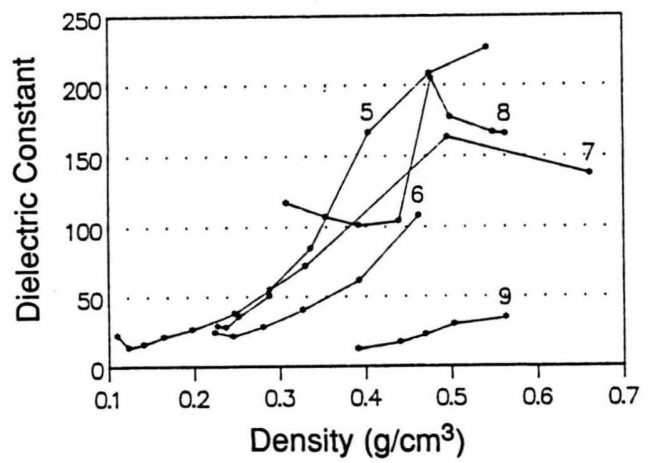

Figure 33. Conductivity and dielectric constant at $50 \mathrm{~Hz}$ vs density for the samples indicated by the number. 

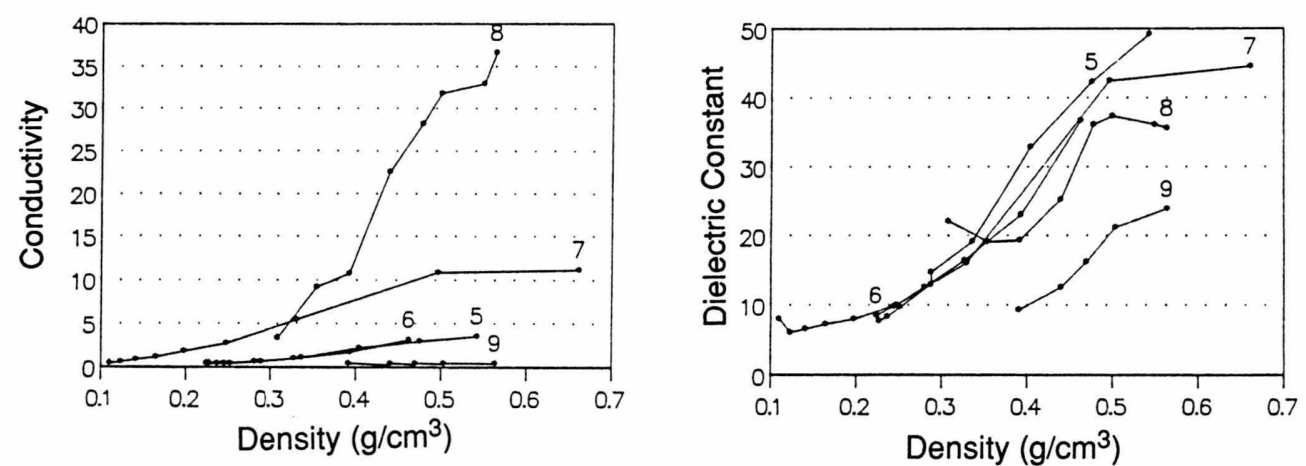

Figure 34. Conductivity, $\sigma(\mu \mathrm{S} / \mathrm{m})$ and dielectric constant, $\mathrm{K}$, at $500 \mathrm{~Hz}$ vs density for the samples indicated by the number.
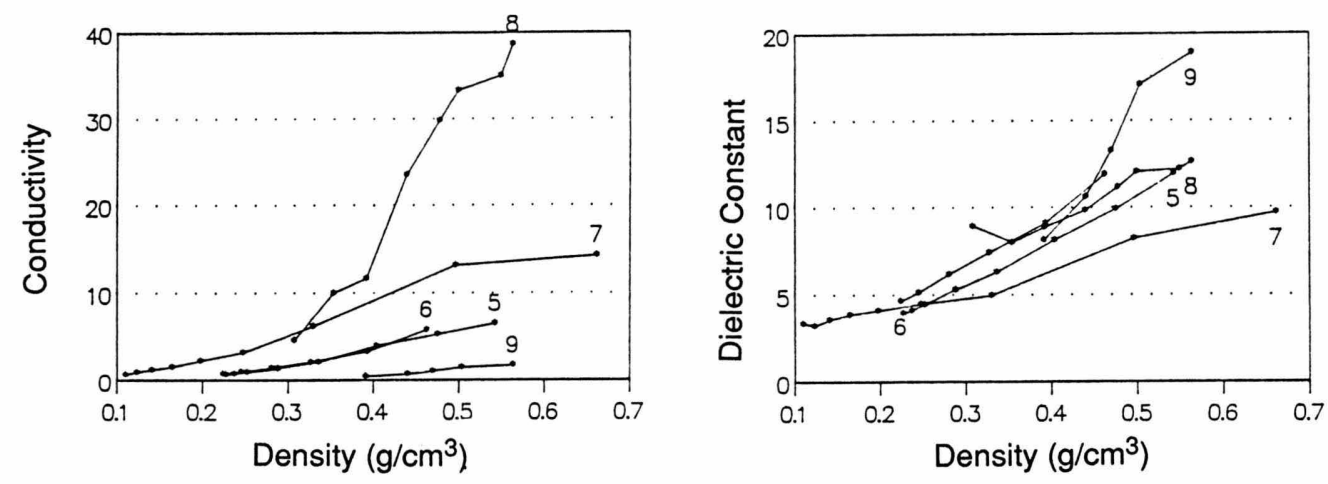

Figure 35. Conductivity and dielectric constant at $5 \mathrm{~Hz}$ vs density for the samples indicated by the number.
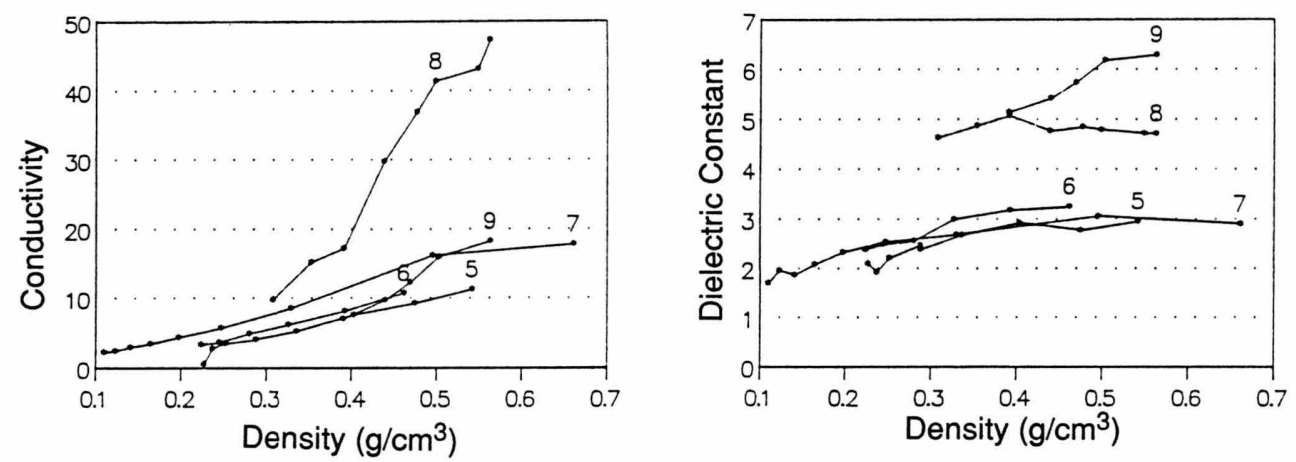

Figure 36. Conductivity and dielectric constant at $50 \mathrm{kHz}$ vs densityfor the samples indicated by the number.

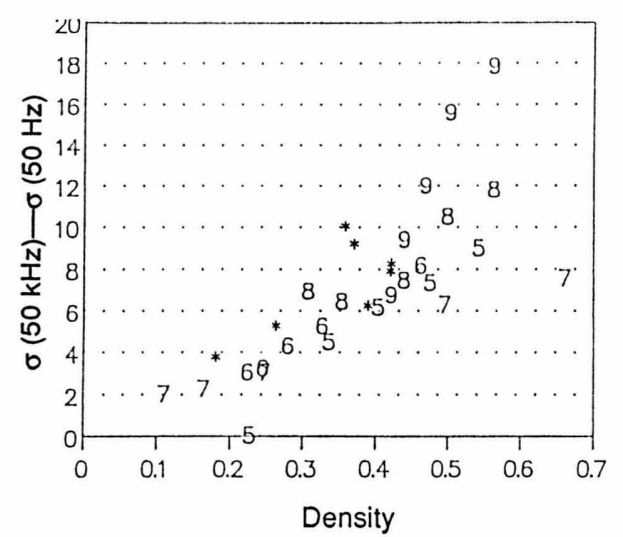

Figure 37. Conductivity difference, $\sigma(\mu S /$ m) at $50 \mathrm{kHz}$ minus that at $50 \mathrm{~Hz}$ vs density $\left(\mathrm{g} / \mathrm{cm}^{3}\right)$ for dry snow. The numbers refer to density experiments at $-9^{\circ} \mathrm{C}$. The $*$ are from samples $10-16$ in the temperature range from $-2{ }^{\circ} \mathrm{C}$ to $-5^{\circ} \mathrm{C}$. 

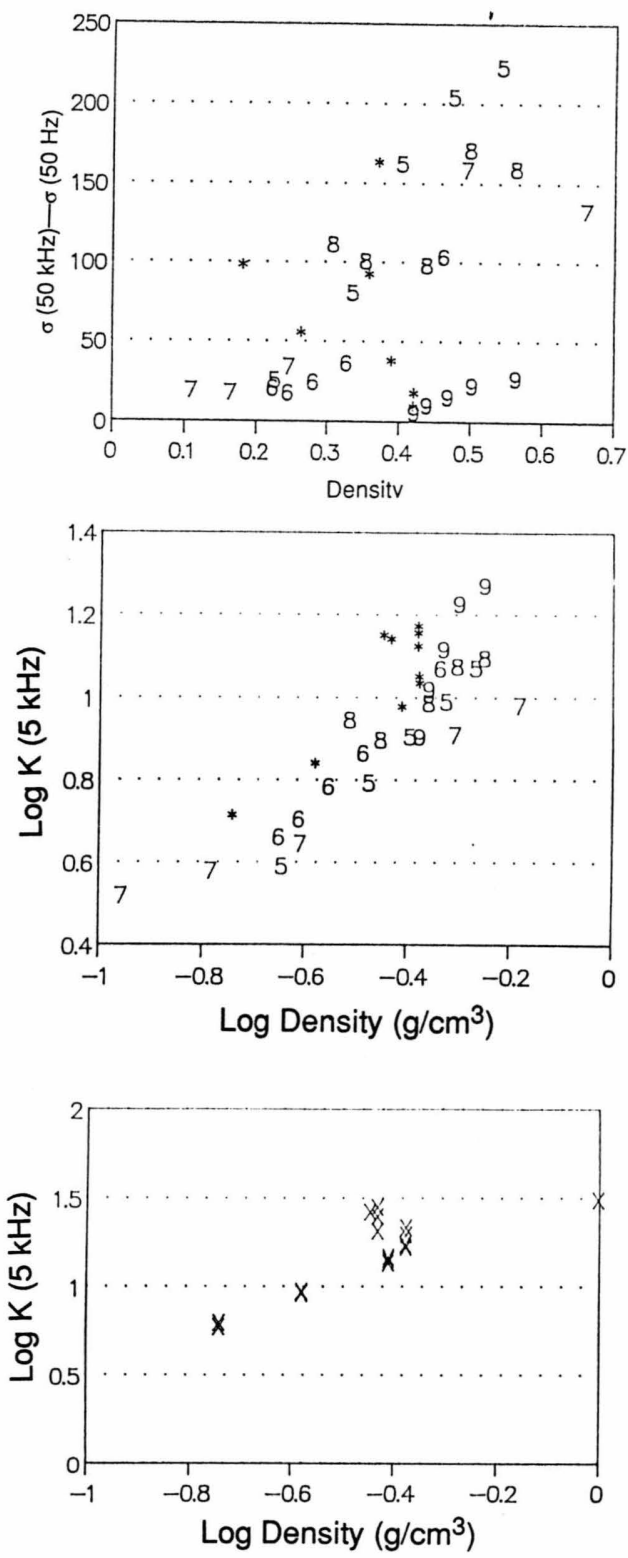

portional to density, not surprising when one considers that it represents the parallel sum of the conductances which appear in all of the Debye dispersions making up the sample. Because each sample has a different distribution of dispersions, we would expect each to behave differently in detail. Note that the data converge toward the origin as they should. We were surprised that a similar plot of the dielectric constant difference vs density (Fig. 38) showed a very broad scatter and only a very general tendency to increase with density.

However for dry snow close to the melting point, we see in Figure 39 that the $\log _{10}$ of dielectric constant at 5 $\mathrm{kHz}$ increases nearly proportionally to the $\log _{10}$ of density. Thus the dielectric constant at $5 \mathrm{kHz}$ is roughly proportional to the density. Unfortunately, the band of values in both Figures 37 and 39 is too broad to make
Figure 38. Dielectric constant at $50 \mathrm{kHz}$ minus that at $50 \mathrm{~Hz}$ vs density for dry snow. Points * are for samples 10-16. The numbers indicate samples used in the density experiments.

Figure 39. $\log _{10} \mathrm{~K}($ at $5 \mathrm{kHz})$ vs $\log _{10}$ density for dry snow samples numbered as shown $\left(-9^{\circ} \mathrm{C}\right)$.

Figure 40. $\log _{10} \mathrm{~K}$ (at $5 \mathrm{kHz}$ ) vs $\log _{10}$ density for samples 10-16 having water contents between 1 and 3\%. Where more than one $\mathrm{X}$ appears for a given density, the higher the mark, the higher the water content.

possible more than a rough estimate of density from measurements of $\sigma$ or $K$. Similar data for samples having a small water content, from $1 \%$ to $3 \%$, are shown in Figure 40 . The same tendency is present; but the values of $K$ are shifted upward by roughly $50 \%$ from those for dry snow.

\section{CONCLUSIONS AND RECOMMENDATIONS}

Detailed discussion will be found in each appropriate section. Here we summarize our major observations and comment on possibly useful further studies.

\section{Technique}

The electrical heating procedure developed for incrementally melting the snow in order to vary the water 
content works very well. By improving the power measurement, particularly by improving the measurement of phase, control of water content can be made more sensitive. While the accuracy of the present system was adequate to our needs, greater precision might make possible very useful experiments. For example, at temperatures close to the melting point, the surface properties of ice are believed to change markedly. The mobility of protons near the surface is greatly enhanced and the material is often said to become "liquid like." One would like to study this phenomenon in a system like snow in which the surface-to-volume ratio is high. Well-controlled electrical heating of the kind we have used should make it possible to change the temperature of the whole sample uniformly at temperatures close to $0^{\circ} \mathrm{C}$. Dielectric measurements should then be responsive to changes in the surface properties.

Our technique of monitoring the electrode separation also makes it possible to study the dimensional changes of a system under constant load as the water content changes. We suggest that interesting mechanical information about snow, and possibly other systems, may be obtained by exploring dimensional changes in this way, particularly at temperatures close to the melting point. We believe that this technique could be made more sensitive with more sophisticated apparatus and that an effort at such improvement would be worthwhile.

The consistency of the data gives some confidence in the reliability of the technique. For example, the data for samples 1,2 and 3, all from snow IA, form a consistent set for 10 different water contents. Their spectra at zero water content and approximately the same temperature are very nearly the same (see Fig. 14-16).

\section{Meltwater}

Room temperature analysis of the meltwater of the various snows shows a wide range of impurities, $\mathrm{C}_{\mathrm{a}}^{+}$and $\mathrm{SO}_{4}^{-}$being the most abundant ions. The details are given in Table 1. Figure 25 shows that the conductivity is dominated by $\mathrm{NaCl}$ except at the lowest values. It may also be of interest that the total anions minus the total cations is the most positive for the lowest $\mathrm{pH}$ and most negative for the two highest values of $\mathrm{pH}$. We believe that a continuing program of routine collection and analysis of fresh snow might be useful. Much analysis of this kind is done in connection with acid rain studies, but in the work with which we are familiar, rain and snow are sometimes collected together and periodically analyzed.

\section{Dry snow}

For dry snow (at about $-9^{\circ} \mathrm{C}$ ), the low-frequency conductivity is proportional to the hydrogen-ion con- centration and seems quite insensitive to other ions (see Fig. 24). Thus proton hopping seems to be the dominant process. If this were a surface conductivity, we would expect a large effect of grain size, of which we find a hint in the discussion of Figure 24 . At $-9^{\circ} \mathrm{C}$, we would not expect large surface conductivity for ice, but it might be important as the melting point was approached. As noted above, our mechanism for heating would seem well suited to such studies.

It was shown in Figure 37 that the difference between the high-frequency conductivity and the low-frequency conductivity was roughly proportional to density but that the proportionality was different for different samples. No such relation seemed to hold for the differences in dielectric constant. But there was a proportionality for the dielectric constant measured at $5 \mathrm{kHz}$.

Pressure of itself seems to have little or no effect on the dielectric properties of dry snow. This would indicate that the contact pressure between grains plays only a small role in determining the electrical properties of dry snow. (This tentative result should be followed up by more extensive experiments.) However, the change in density resulting from pressure is very important.

Although based on only five different snows, our measurements suggest that the low-frequency conductivity of dry snow is proportional to the hydrogen ion concentration and that the low-frequency dielectric constant is proportional to the square root of the hydrogen ion concentration. To explore this further would seem to be a fairly simple and useful project. If proton hopping is the dominant process for low-frequency conduction in dry snow, activation energy measurements in this region might provide some confirmation and useful information relating to bulk and surface processes. This too should be a straightforward experiment.

\section{Wet snow}

\section{Mechanical}

Because of the sensitivity of our apparatus for measuring the thickness of the sample, we were able to monitor the dimensional change as the water content increased. There was a steep change at the start and then a rather uniform change as the water content increased. The steep change at the start we attribute to capillarity and possibly to liquid-like surface states as the temperature approaches very close to zero. Our technique seems well suited to studying this process in more detail.

\section{Electrical}

We have developed a body of data for five different snows which is as detailed and complete as time and facilities permitted. It is presented in a form making it 
available for further analysis. The dominant properties affecting the dielectric spectra are water content, density and $\mathrm{pH}$ of the melt water. Grain size seems to be important, but we do not have enough detailed information to be sure. Ionic impurities do not appear to play a strong role in dry snow but they seem to make a major contribution to the meltwater conduction when their abundance is high.

Experiments on dry snow indicated that the intergranular pressure was not important in determining the dielectric properties. It would be useful to explore this for wet snow.

The dielectric properties vary strongly with water content. Both conductivity and dielectric constant increase but not in the same manner from sample to sample. This is not surprising considering the complexity of the system. We have explored two different approaches to searching for useful regularities in it. In one, we attempted to fit all of our data with a three-parameter power law polynomial, each sample to be characterized by different coefficients. (Our thought was that if there were three important properties, they might be separable in this way.) We were able to fit much, but not all, of our data with one equation. In the other approach we analyzed our data in terms of Cole plot parameters (Table 4). In neither did we establish a method by which these data might be used to evaluate the water content of an unknown sample. However, we think it might be interesting to try to deconvolute these spectra by assuming that water content, density, grain size and possibly hydrogen ion concentration each affect the spectra in its own characteristic way and that they combine in a linear way to produce the measured spectra.

\section{ANNOTATED BIBLIOGRAPHY}

Ambach, W. and A. Denoth (1975) On the dielectric constant of wet snow. In Proceedings, Snow Mechanics Symposium, April 1974. IAHS-AISH Publication No. 114.

Measurements in the frequency range: 1 to $20 \mathrm{MHz}$. At $f \geq 20 \mathrm{MHz}$ the authors suggest $W=\alpha\left[\left(\varepsilon \infty^{\prime}-1\right)-2.22\right]$ where $W=$ free water content, $\alpha=$ density.

Ambach, W. and A. Denoth (1972) Studies on the dielectric properties of snow. Zeitschrift für Gletscherkunde and Glazialgeologie, VIII, Hett 1-2: 113-123.

Use Wiener's formula for describing dielectric constant of snow as a mixture. Depends on a linear relation between $\varepsilon \infty^{\prime}$ and density.

Boyne, H. and D. Fisk (1987) Comparison of snow cover liquid water measurement techniques. Water Resources Research, 23(10): 1833-1836.
Freezing calorimetry, alcohol calorimetry, dilution and capacitance are compared and believed to be accurate to 2-3\% water content.

Brun, E. (1989) Investigation of wet-snow metamorphism in respect of water content. Annals of Glaciology, 13: $22-26$.

A study of the grain growth in snow as a function of time at different water contents. The water content was controlled by melting a portion of the sample by dielectric heating at $20 \mathrm{kHz}$. Little detail is given.

Camp, P., W. Kiszenick and D.A. Arnold (1967) Electrical conduction in ice. USA Cold Regions Research and Engineering Laboratory, Research Report 198. Bulk and surface dielectric properties of single crystal ice from $-60^{\circ}$ to melting in the frequency range DC to $100 \mathrm{kHz}$.

Colbeck, S. (1978) Difficulties of measuring the water saturation and porosity of snow. Journal of Glaciology, 20(82): 189-201.

Analyzes the errors inherent in many types of measurement. The factors affecting errors in liquid water content, water saturation and porosity are discussed.

Colbeck, S. (1973) Theory of metamorphism of wet snow. USA Cold Regions Research and Engineering Laboratory, Research Report 313.

A fundamental treatment using thermodynamics to predict the rate of grain growth in snow.

Denoth, A., A. Fogler, P. Wieland, C. Mätzler, H. Aebischer, M. Tiuri and A.Sihvola (1984) The comparative study of instruments for measuring the liquid water content of snow. Journal of Applied Physics, 56(7): 2154-2160.

A review of measurement methods at high frequencies.

Denoth, A. (1982) Effect of grain geometry on electrical properties of snow at frequencies up to $100 \mathrm{MHz}$. Journal of Applied Physics, 53(11): 7496.

Measurements in the range $1 \mathrm{MHz}$ to $100 \mathrm{MHz}$ show that grain size and distribution are important.

Denoth, A. and A. Foglar (1986) Recent developments of snow moisture dielectric devices. Presented at International Snow Science Workshop, Lake Tahoe, California, October 1986.

Reviews measurement techniques at high frequencies and comments on their applicability. Good recent references.

Evans, S. (1965) Dielectric properties of ice and snowA review. Journal of Glaciology, 5(42): 773-792.

Provides an excellent guide to the literature before 1965. His data on wet snow are mostly at microwave frequencies. Uses Weiner's formula for mixtures and 
considers complex permittivities. Reviews the general subject of ice, snow and water. Little on wet snow.

Fisk, D. (1986) Method of measuring liquid water mass fraction of snow by alcohol solution. Journal of Glaciology, 32(112): 529-530.

Describes the technique in sufficient detail for others to use. Claims accuracy of $0.3 \%$ volume liquid water.

Kuroiwa, D. (1962) Electrical properties of snow. In Physics and Mechanics of Snow as a Material. USA Cold Regions Research and Engineering Laboratory, Cold Regions Science and Engineering Monograph IIB, Chapter J, p. 63-79.

An excellent review of the work on electrical properties of snow up to 1962. Considers the real and imaginary parts of the dielectric constant in both the audio and microwave regions. Treats both dry and wet snow.

Meredith, R. (1959) Studies on the conductivities of dispersions. University of California, Berkeley.

A basic theoretical and experimental study of twophase systems.

Olhoeft, G. (1979) Electrical properties (of rocks). In Initial Report of the Petrophysics Laboratory (G.R. Hunt et al., Ed.). Geological Survey Circular 789, p. 126.

Gives a very useful summary of the theory of dielectric processes in rocks and similar materials and describes the apparatus used. Effects of water content included.

Perla, R. (1990) Real permittivity of snow at $1 \mathrm{MHz}$ and $0^{\circ} \mathrm{C}$. Submitted to Journal of Glaciology.

Measured 200 samples of natural and artificial snow. Finds data fit and empirical function $\varepsilon=\Sigma v_{\mathrm{j}} \varepsilon j-0.43 v_{\mathrm{A}} v_{\mathrm{I}}$ $-50 v_{\mathrm{I}} v_{\mathrm{W}}-100 v_{\mathrm{A}} v_{\mathrm{W}}$, where $\varepsilon$ is real permittivity, $i j=$ $A, I$, or $W$ (air, ice or water); $v_{\mathrm{j}}$ is the volume proportion of each phase and $\varepsilon_{\mathrm{j}}$, is the dielectric constant of each phase. Other polynomials are discussed.

Perla, R. and J. Banner (1988) Calibration of capacitance cells for measuring water in snow. Cold Regions Science and Technology, 15: 225-231.

Uses acid dilution to calibrate water content. Natural snow measured at $1 \mathrm{MHz}$.

Pradhan, B.P. and R.C. Gupta (1964) Dielectric constants of mixtures. Dielectrics, I(4): 195-200.

Theory of complex dielectric constants for different shapes, data for mixtures of $\mathrm{ZnO}$, silicon, and magnesia.

Sadiku, M. (1985) Refractive index of snow at microwave frequencies. Applied Optics, 24(4): February 15. Uses Weiner's formula with a form factor which increases with water content.

Sihvola, A.H. and J.A. Kong (1988) Effective permittivity of dielectric mixtures. IEEE Transactions on Geoscience and Remote Sensing, 26(4): 420-429.

Calculation at $1 \mathrm{GHz}$ for different shaped particles as a function of water content.

Von Hippel, A. (1972) Dielectric and mechanical response of ice $\mathrm{I}_{\mathrm{h}}$ single crystals and its interpretation. Journal of Chemical Physics, 57(6): 25602571.

Summarizes vigorous research over a period of many years. Accepts the Bjerrun defect model for normal volume polarization of ice but suggests mechanical losses result from Frenkel defects. For much more extensive coverage of his experiments and the underlying physics, refer to the author's Technical Reports 8 and 9, Massachusetts Institute of Technology, 1970 and 1971.

Watt, A.D. and E.L. Maxwell (1960) Measured electrical properties of snow and glacial ice. Journal of Research of the National Bureau of Standards, 64d(4).

Gives experimental data on natural snow, $200 \mathrm{~Hz}$ to 100 $\mathrm{kHz}$, at snow temperatures of $0^{\circ} \mathrm{C}$ but no water content (or density) measurements. Considers glacial ice. Uses four electrode techniques to measure conductivity. 
APPENDIX A. DATA TABLE

\begin{tabular}{|c|c|c|c|c|c|c|c|c|c|c|c|}
\hline & $\begin{array}{c}\text { Sample } \\
\text { no. }\end{array}$ & $\begin{array}{l}\text { Density } \\
\left(\mathrm{g} / \mathrm{cm}^{3}\right)\end{array}$ & $\begin{array}{l}\operatorname{Temp}\left({ }^{\circ} \mathrm{C}\right) \\
\text { or } \% \mathrm{H}_{2} \mathrm{O}\end{array}$ & $\begin{array}{l}\operatorname{LogK} \\
50 \mathrm{~Hz}\end{array}$ & $\begin{array}{l}\operatorname{LogK} \\
500 \mathrm{~Hz}\end{array}$ & $\begin{array}{l}\operatorname{LogK} \\
5 \mathrm{kHz}\end{array}$ & $\begin{array}{c}\operatorname{LogK} \\
50 \mathrm{kHz}\end{array}$ & $\begin{array}{l}\log \sigma \\
50 \mathrm{~Hz}\end{array}$ & $\begin{array}{c}\log \sigma \\
500 \mathrm{~Hz}\end{array}$ & $\begin{array}{l}\log \sigma \\
5 \mathrm{kHz}\end{array}$ & $\begin{array}{c}\log \sigma \\
50 \mathrm{kHz}\end{array}$ \\
\hline \multirow{4}{*}{$1 \mathrm{~A}$} & 1 & 0.42 & $T=-6$ & 2.473 & 1.620 & 1.122 & 0.802 & -5.539 & -5.344 & -5.161 & -4.824 \\
\hline & 1 & 0.42 & $3.5 \%$ & 2.835 & 2.223 & 1.476 & 0.455 & -4.695 & -4.636 & -4.481 & -4.343 \\
\hline & 1 & & $24.0 \%$ & 3.698 & 2.837 & 1.866 & 1.062 & -3.965 & -3.884 & -3.784 & -3.736 \\
\hline & 1 & & $38.0 \%$ & 3.821 & 2.932 & 1.893 & 1.238 & -3.837 & -3.711 & -3.617 & -3.568 \\
\hline \multirow{3}{*}{$1 \mathrm{~A}$} & 2 & 0.42 & $T=-4.5$ & 2.380 & 1.538 & 1.154 & 0.807 & -5.547 & -5.377 & -5.191 & -4.801 \\
\hline & 2 & & $9.7 \%$ & 3.332 & 2.623 & 1.796 & 0.785 & -4.348 & -4.272 & -4.127 & -4.002 \\
\hline & 2 & & $28.6 \%$ & 3.811 & 2.987 & 1.982 & 1.118 & -3.814 & -3.725 & -3.637 & -3.598 \\
\hline \multirow{4}{*}{$1 \mathrm{~A}$} & 3 & 0.42 & $T=-4.5$ & 2.378 & 1.678 & 1.171 & 0.821 & -5.588 & -5.393 & -5.158 & -4.806 \\
\hline & 3 & & $T=-0.2$ & 2.240 & 1.641 & 1.234 & 0.831 & -5.414 & -5.317 & -5.123 & -4.753 \\
\hline & 3 & & $2.5 \%$ & 2.881 & 2.203 & 1.503 & 0.777 & -4.690 & -4.614 & -4.472 & -4.310 \\
\hline & 3 & & $5.7 \%$ & 3.068 & 2.409 & 1.634 & 0.840 & -4.531 & -4.454 & -4.299 & -4.172 \\
\hline \multirow{5}{*}{ II } & 4 & 0.264 & $T=-9$ & 2.029 & 1.364 & 0.954 & 0.689 & -5.585 & -5.520 & -5.397 & -5.032 \\
\hline & 4 & 0.317 & $T=-9$ & 2.460 & 1.742 & 1.LO0 & 0.737 & -5.078 & -4.990 & -4.909 & -4.699 \\
\hline & 4 & 0.366 & $T=-9$ & 2.635 & 1.996 & 1.279 & 0.823 & -4.806 & -4.730 & -4.645 & -4.465 \\
\hline & 4 & 0.396 & $T=-9$ & 2.808 & 2.063 & 1.325 & 0.867 & -4.739 & -4.643 & -4.568 & -4.395 \\
\hline & 4 & 0.432 & $T=-9$ & 2.887 & 2.134 & 1.385 & 0.900 & -4.637 & -4.548 & -4.414 & -4.310 \\
\hline \multirow{5}{*}{ III } & 5 & 0.228 & $T=-9$ & 1.457 & 0.885 & 0.595 & 0.320 & -7.106 & -6.685 & -6.222 & -6.632 \\
\hline & 5 & 0.337 & $T=-9$ & 1.927 & 1.282 & 0.798 & 0.427 & -6.260 & -5.987 & -5.692 & -5.286 \\
\hline & 5 & 0.405 & $T=-9$ & 2.222 & 1.517 & 0.911 & 0.465 & -5.917 & -5.666 & -5.407 & -5.124 \\
\hline & 5 & 0.476 & $T=-9$ & 2.319 & 1.626 & 0.996 & 0.442 & -5.770 & -5.535 & -5.282 & -5.037 \\
\hline & 5 & 0.543 & $T=-9$ & 2.356 & 1.692 & 1.077 & 0.469 & -5.681 & -5.456 & -5.189 & -4.951 \\
\hline \multirow{5}{*}{ III } & 6 & 0.225 & $T=-9$ & 1.383 & 0.929 & 0.667 & 0.376 & -6.972 & -6.664 & -6.169 & -5.483 \\
\hline & 6 & 0.246 & $T=-9$ & 1.330 & 0.990 & 0.710 & 0.394 & -6.630 & -6.452 & -6.032 & -5.443 \\
\hline & 6 & 0.281 & $T=-9$ & 1.450 & 1.099 & 0.790 & 0.407 & -6.380 & -6.230 & -5.864 & -5.314 \\
\hline & 6 & 0.328 & $T=-9$ & 1.607 & 1.216 & 0.870 & 0.476 & -6.156 & -6.027 & -5.696 & -5.215 \\
\hline & 6 & 0.463 & $T=-9$ & 2.034 & 1.565 & 1.075 & 0.511 & -5.621 & -5.510 & -5.241 & -4.971 \\
\hline \multirow{5}{*}{ IV } & 7 & 0.111 & $T=-9$ & 1.343 & 0.901 & 0.524 & 0.228 & -7.195 & -6.632 & -6.231 & -5.657 \\
\hline & 7 & 0.166 & $T=-9$ & 1.325 & 0.859 & 0.585 & 0.317 & -6.004 & -5.959 & -5.833 & -5.471 \\
\hline & 7 & 0.248 & $T=-9$ & 1.580 & 1.001 & 0.651 & 0.404 & -5.611 & -5.573 & -5.501 & -5.249 \\
\hline & 7 & 0.497 & $T=-9$ & 2.213 & 1.628 & 0.915 & 0.485 & -5.013 & -4.965 & -4.881 & -4.792 \\
\hline & 7 & 0.662 & $T=-9$ & 2.137 & 1.649 & 0.987 & 0.462 & -4.999 & -4.952 & -4.846 & -4.751 \\
\hline \multirow{5}{*}{ II } & 8 & 0.309 & $T=-9$ & 2.068 & 1.344 & 0.951 & 0.665 & -5.581 & -5.485 & -5.344 & -5.014 \\
\hline & 8 & 0.355 & $T=-9$ & 2.029 & 1.280 & 0.903 & 0.687 & -5.068 & -5.039 & -5.001 & -4.820 \\
\hline & 8 & 0.440 & $T=-9$ & 2.018 & 1.403 & 0.992 & 0.678 & -4.656 & -4.647 & -4.630 & -4.527 \\
\hline & 8 & 0.500 & $T=-9$ & 2.249 & 1.572 & 1.081 & 0.680 & -4.513 & -4.498 & -4.478 & -4.384 \\
\hline & 8 & 0.564 & $T=-9$ & 2.219 & 1.551 & 1.101 & 0.673 & -4.452 & -4.437 & -4.413 & -4.326 \\
\hline \multirow{5}{*}{ IB } & 9 & 0.423 & $T=-9$ & 1.087 & 0.967 & 0.910 & 0.711 & -7.410 & -7.128 & -6.436 & -5.159 \\
\hline & 9 & 0.441 & $T=-9$ & 1.230 & 1.098 & 1.026 & 0.733 & -7.091 & -6.884 & -6.181 & -5.017 \\
\hline & 9 & 0.470 & $T=-9$ & 1.351 & 1.209 & 1.122 & 0.758 & -6.938 & -6.734 & -6.006 & -4.912 \\
\hline & 9 & 0.504 & $T=-9$ & 1.477 & 1.326 & 1.232 & 0.791 & -6.799 & -6.589 & -5.850 & -4.799 \\
\hline & 9 & 0.564 & $T=-9$ & 1.539 & 1.379 & 1.276 & 0.798 & -6.708 & -6.494 & -5.778 & -4.740 \\
\hline \multirow{6}{*}{ V } & 10 & 0.182 & $T=-4.5$ & 2.001 & 1.250 & 0.674 & 0.391 & -5.852 & -5.704 & -5.564 & -5.289 \\
\hline & 10 & 0.182 & $T=-0.2$ & 1.865 & 1.297 & 0.712 & 0.402 & -5.697 & -5.590 & -5.454 & -5.221 \\
\hline & 10 & & $0.8 \%$ & 1.975 & 1.363 & 0.757 & 0.408 & -5.789 & -5.649 & -5.483 & -5.226 \\
\hline & 10 & & $1.7 \%$ & 1.922 & 1.370 & 0.784 & 0.415 & -5.794 & -5.656 & -5.474 & -5.208 \\
\hline & 10 & & $2.7 \%$ & 1.943 & 1.396 & 0.809 & 0.417 & -5.788 & -5.649 & -5.453 & -5.191 \\
\hline & 10 & & $3.7 \%$ & 2.000 & 1.431 & 0.851 & 0.410 & -5.758 & -5.615 & -5.410 & -5.166 \\
\hline \multirow{6}{*}{ IV } & 11 & 0.265 & $T=-5$ & 1.761 & 1.206 & 0.825 & 0.452 & -6.074 & -5.932 & -5.666 & -5.215 \\
\hline & 11 & 0.265 & $T=-5$ & 1.572 & 1.166 & 0.838 & 0.457 & -5.731 & -5.682 & -5.522 & -5.151 \\
\hline & 11 & & $0 \sim 8 \%$ & 1.793 & 1.392 & 0.939 & 0.459 & -5.915 & -5.789 & -5.483 & -5.113 \\
\hline & 11 & & $2.5 \%$ & 1.841 & 1.460 & 0.975 & 0.480 & -5.901 & -5.769 & -5.443 & -5.084 \\
\hline & 11 & & $2.9 \%$ & 1.839 & 1.471 & 0.987 & 0.441 & -5.896 & -5.762 & -5.425 & -5.084 \\
\hline & 11 & & $3.6 \%$ & 1.864 & 1.495 & 1.011 & 0.488 & -5.872 & -5.734 & -5.403 & -5.075 \\
\hline
\end{tabular}




\begin{tabular}{|c|c|c|c|c|c|c|c|c|c|c|c|}
\hline & $\begin{array}{c}\text { Sample } \\
\text { no. }\end{array}$ & $\begin{array}{l}\text { Density } \\
\left(\mathrm{g} / \mathrm{cm}^{3}\right)\end{array}$ & $\begin{array}{l}\operatorname{Temp}\left({ }^{\circ} \mathrm{C}\right) \\
\text { or } \% \mathrm{H}_{2} \mathrm{O}\end{array}$ & $\begin{array}{l}\operatorname{LogK} \\
50 \mathrm{~Hz}\end{array}$ & $\begin{array}{c}\operatorname{LogK} \\
500 \mathrm{~Hz}\end{array}$ & $\begin{array}{l}\operatorname{LogK} \\
5 \mathrm{kHz}\end{array}$ & $\begin{array}{c}\log \mathrm{K} \\
50 \mathrm{kHz}\end{array}$ & $\begin{array}{l}\log \sigma \\
50 \mathrm{~Hz}\end{array}$ & $\begin{array}{c}\log \sigma \\
500 \mathrm{~Hz}\end{array}$ & $\begin{array}{l}\log \sigma \\
5 \mathrm{kHz}\end{array}$ & $\begin{array}{c}\log \sigma \\
50 \mathrm{kHz}\end{array}$ \\
\hline \multirow{6}{*}{ II } & 12 & 0.36 & $T=-2$ & 1.990 & 1.484 & 1.106 & 0.749 & -5.273 & -5.239 & -5.120 & -4.814 \\
\hline & 12 & 0.36 & $T=-4$ & 1.893 & 1.505 & 1.149 & 0.747 & -5.329 & -5.284 & -5.137 & -4.807 \\
\hline & 12 & & $0.7 \%$ & 2.239 & 1.839 & 1.351 & 0.765 & -5.209 & -5.120 & -4.907 & -4.618 \\
\hline & 12 & & $2.1 \%$ & 2.363 & 1.968 & 1.435 & 0.781 & -5.041 & -4.968 & -4.764 & -4.513 \\
\hline & 12 & & $3.3 \%$ & 2.470 & 2.066 & 1.499 & 0.799 & -4.916 & -4.843 & -4.651 & -4.428 \\
\hline & 12 & & $4.0 \%$ & 2.483 & 2.078 & 1.512 & 0.759 & -4.854 & -4.786 & -4.608 & -4.401 \\
\hline \multirow{5}{*}{ IB } & 13 & 0.423 & $T=-3.5$ & 1.348 & 1.112 & 0.981 & 0.706 & -6.950 & -6.646 & -6.109 & -5.080 \\
\hline & 13 & 0.423 & $T=-25$ & 1.395 & 1.174 & 1.033 & 0.725 & -6.947 & -6.635 & -6.052 & -5.023 \\
\hline & 13 & & $0.5 \%$ & 1.391 & 1.239 & 1.147 & 0.760 & -7.192 & -6.865 & -5.996 & -4.909 \\
\hline & 13 & & $1.3 \%$ & 1.439 & 1.327 & 1.234 & 0.790 & -7.198 & -6.848 & -5.876 & -4.822 \\
\hline & 13 & & $1.8 \%$ & 1.511 & 1.402 & 1.305 & 0.822 & -7.159 & -6.800 & -5.776 & -4.747 \\
\hline \multirow{7}{*}{ III } & 13 & & $2.3 \%$ & 1.540 & 1.443 & 1.347 & 0.830 & -7.164 & -6.787 & -5.723 & -4.708 \\
\hline & 14 & 0.391 & $T=-5$ & 1.607 & 1.209 & 0.917 & 0.503 & -6.764 & -6.395 & -5.829 & -5.195 \\
\hline & 14 & 0.391 & $T=-5$ & 1.560 & 1.249 & 0.976 & 0.545 & -6.327 & -6.174 & -5.734 & -5.128 \\
\hline & 14 & & $0.9 \%$ & 1.730 & 1.460 & 1.101 & 0.536 & -6.679 & -6.270 & -5.586 & -5.044 \\
\hline & 14 & & $1.6 \%$ & 1.800 & 1.518 & 1.145 & 0.546 & -6.639 & -6.211 & -5.517 & -5.002 \\
\hline & 14 & & $1.9 \%$ & 1.829 & 1.546 & 1.165 & 0.549 & -6.632 & -6.183 & -5.489 & -4.983 \\
\hline & 14 & & $2.1 \%$ & 1.840 & 1.557 & 1.181 & 0.549 & -6.621 & -6.176 & -5.471 & -4.975 \\
\hline \multirow{6}{*}{ II } & 15 & 0.372 & $T=-7$ & 2.226 & 1.546 & 1.028 & 0.734 & -5.636 & -5.487 & -5.301 & -4.941 \\
\hline & 15 & 0.372 & $T=-0.5$ & 1.943 & 1.559 & 1.140 & 0.720 & -5.020 & -4.993 & -4.900 & -4.696 \\
\hline & 15 & & $0.3 \%$ & $2.1 \mathrm{gl}$ & 1.774 & 1.271 & 0.739 & -4.973 & -4.938 & -4.816 & -4.602 \\
\hline & 15 & & $1.2 \%$ & 2.325 & 1.870 & 1.328 & 0.755 & -4.951 & -4.906 & -4.773 & -4.553 \\
\hline & 15 & & $2.3 \%$ & 2.488 & 2.006 & 1.410 & 0.774 & -4.845 & -4.791 & -4.651 & -4.456 \\
\hline & 15 & & $3.2 \%$ & 2.600 & 2.072 & 1.463 & 0.779 & -4.774 & -4.722 & -4.584 & -4.392 \\
\hline \multirow{6}{*}{ IB } & 16 & 0.422 & $T=-8.5$ & 1.149 & 1.013 & 0.957 & 0.714 & -1.399 & -7.107 & -6.351 & -5.102 \\
\hline & 16 & 0.422 & $T=-5$ & 1.375 & 1.192 & 1.049 & 0.752 & -6.638 & -6.447 & -5.988 & -4.998 \\
\hline & 16 & & $0.5 \%$ & 1.379 & 1.259 & 1.178 & 0.792 & -7.175 & -6.873 & -5.985 & -4.878 \\
\hline & 16 & & $0.7 \%$ & 1.395 & 1.278 & 1.198 & 0.804 & -7.194 & -6.885 & -5.962 & -4.855 \\
\hline & 16 & & $0.9 \%$ & 1.411 & 1.300 & 1.221 & 0.812 & -7.222 & -6.896 & -5.934 & -4.832 \\
\hline & 16 & & $1.1 \%$ & 1.433 & 1.325 & 1.250 & 0.823 & -7.222 & -6.901 & -5.895 & -4.802 \\
\hline
\end{tabular}


Public reporting burden for this collection of information is estimated to average 1 hour per response, including the time for reviewing instructions, searching existing data sources, gathering and maintaining the data needed, and completing and reviewing the collection of information. Send comments regarding this burden estimate or any other aspect of this collection of information, including suggestion for reducing this burden, to Washington Headquarters Services, Directorate for Information Operations and Reports, 1215 Jefferson Davis Highway, Suite 1204, Arlington, VA 22202-4302, and to the Office of Management and Budget, Paperwork Reduction Project (0704-0188), Washington, DC 20503.

\begin{tabular}{|l|l|l}
\hline 1. AGENCY USE ONLY (Leave blank) & 2. REPORT DATE & 3. REPORT TYPE AND DATES COVERED
\end{tabular}

4. TITLE AND SUBTITLE

July 1992

Determination of the Water Content of Snow

by Dielectric Measurements

6. AUTHORS

Paul R. Camp and David R. LaBrecque

7. PERFORMING ORGANIZATION NAME(S) AND ADDRESS(ES)

Department of Physics, University of Maine, Orono, Maine

MicroPhysics, Old Town, Maine

8. PERFORMING ORGANIZATION

REPORT NUMBER

PE: $6.27 .84 \mathrm{~A}$

PR: 4A762784AT42

TA: FS

WU: 032

\begin{tabular}{|c|c|c|}
\hline \multicolumn{2}{|c|}{ 9. SPONSORING/MONITORING AGENCY NAME(S) AND ADDRESS(ES) } & 10. SPONSORING/MONITORING \\
\hline $\begin{array}{l}\text { Office of the Chief of Engineers } \\
\text { Washington, D.C. 20314-1000 }\end{array}$ & $\begin{array}{l}\text { U.S. Army Cold Regions Research } \\
\text { and Engineering Laboratory } \\
\text { Hanover, N.H. } 03755-1290\end{array}$ & Special Report 92-18 \\
\hline
\end{tabular}

11. SUPPLEMENTARY NOTES

12a. DISTRIBUTION/AVAILABILITY STATEMENT

12b. DISTRIBUTION CODE

Approved for public release; distribution is unlimited.

Available from NTIS, Springfield, Virginia 22161.

13. ABSTRACT (Maximum 200 words)

The dielectric properties of wet and dry natural snow were studied in the frequency range of $50 \mathrm{~Hz}$ to $100 \mathrm{kHz}$ to determine whether measurements made in this frequency range might prove useful in evaluating the water content of snow. Dielectric heating at $20 \mathrm{kHz}$ proved a very useful means of modifying the water content from 0 to $30 \%$ by weight. Six different natural snows were used in these experiments. Meltwater was analyzed for conductivity, $\mathrm{pH}$, and impurity content. In addition to developing information on the dielectric properties of wet and dry snow, we measured the changes produced in dry snow by altering its density over the range of 0.11 to $0.66 \mathrm{~g} / \mathrm{cm}^{3}$. Details of the experimental technique and the data obtained are fully reported. Our results do not lead to optimism about the usefulness of measurements in this frequency range alone for the determination of water content.

\section{SUBJECT TERMS}

Dielectric measurement

Liquid water content Snow

15. NUMBER OF PAGES 43

16. PRICE CODE

17. SECURITY CLASSIFICATION OF REPORT

UNCLASSIFIED

19. SECURITY CLASSIFICATION
OF ABSTRACT
UNCLASSIFIED

UNCLASSIFIED
20. LIMITATION OF ABSTRACT

UL 